Universidade de São Paulo

Instituto de Astronomia, Geofísica e Ciências Atmosféricas

Departamento de Geofísica

Caio Morelli Vicentini

\title{
CARACTERIZAÇÃO GEOQUÍMICA E ISOTÓPICA (Sr-Nd-Pb) DOS LITOTIPOS SUBALCALINOS DIFERENCIADOS DO ENXAME DA SERRA DO MAR
}

São Paulo 


\section{Caio Morellil Vicentini}

\section{CARACTERIZAÇÃO GEOQUÍMICA E ISOTÓPICA (Sr-Nd-Pb) DOS LITOTIPOS SUBALCALINOS DIFERENCIADOS DO ENXAME DA SERRA DO MAR}

Dissertação apresentada ao Departamento de Geofísica do Instituto de Astronomia, Geofísica e Ciências Atmosféricas da Universidade de São Paulo como requisito parcial para obtenção do título de Mestre em Ciências.

Área de Concentração: Geofísica Orientador(a): Prof(a). Dr(a). Leila Soares Marques

Versão Corrigida. $O$ original encontra-se disponível na Unidade.

São Paulo 
“Até aqui nos ajudou o Senhor.” I Sm 7.12b 


\section{RESUMO}

Este trabalho apresenta a caracterização geoquímica e isotópica ( $\mathrm{Sr}-\mathrm{Nd}-\mathrm{Pb}$ ) das rochas subalcalinas diferenciadas dos diques do Enxame da Serra do Mar (ESM), localizado na costa dos estados de São Paulo e Rio de Janeiro, sendo constituído principalmente por diques básicos com altos teores de $\mathrm{TiO}_{2}(>3 \%)$. Os diques intermediários e ácidos, encontrados apenas na Ilha de São Sebastião e costa adjacente, foram submetidos à análise de elementos traços por ativação com nêutrons (AAN), que possibilitou a determinação de elementos terras raras (La, Ce, Nd, Sm, Eu, $\mathrm{Tb}, \mathrm{Yb}$ e Lu) e outros traços incompatíveis (U, Th, Hf, Ta, Ba e Rb), além de Co e Sc. As amostras foram também analisadas por espectrometria de massa com plasma indutivamente acoplado (ICP-MS), que permitiu efetuar uma comparação entre os resultados obtidos pelos dois métodos. Foram ainda determinadas as razões isotópicas de $\mathrm{Sr}$, $\mathrm{Nd}$ e $\mathrm{Pb}$ em cinco amostras representativas. Os dados obtidos por AAN indicam precisão de até 14\% (maioria abaixo de $10 \%$ ) e exatidão de até 4\%. A comparação estatística dos dados de AAN com ICP-MS mostrou que as técnicas fornecem resultados estatisticamente concordantes para a grande maioria dos elementos analisados. Os diques diferenciados são quimicamente representados por latiandesitos (LTA), dacitos (DAC) e riodacitos (RC). Dentre os LTA observa-se um conjunto de 4 amostras (Grupo 1) com características geoquímicas semelhantes às rochas basálticas Pitanga da Província Magmática do Paraná (PMP), embora apresentem razões isotópicas iniciais de Sr e $\mathrm{Pb}$ mais radiogênicas. Os demais LTA (Grupo 2) apresentam enriquecimento significativo de elementos fortemente incompatíveis. Entre as rochas mais diferenciadas dos LTA (Grupo 2) e aquelas dos DAC e RC há lacunas composicionais, sugerindo que a evolução não ocorreu por cristalização fracionada. À semelhança da gênese das rochas vulcânicas ácidas do tipo ChapecóOurinhos da PMP, é possível que os diques DAC e RC tenham sido originados por refusão de material de composição basáltica aprisionado na descontinuidade crosta-manto. As razões isotópicas dos diques do ESM sugerem que a gênese desse material basáltico envolveu fusão de manto litosférico subcontinental metassomatizado, conforme proposto para os diques mesozoicos do Espinhaço Meridional (Craton do São Francisco), que possuem composições isotópicas similares. Os magmas diferenciados gerados nesse processo podem ter sofrido contaminação crustal, conforme indicado também pelas composições isotópicas de $\mathrm{Sr}, \mathrm{Nd}$ e $\mathrm{Pb}$, requerendo, no entanto, um contaminante com características muito específicas.

Palavras-chave: Província Magmática do Paraná, Enxame de diques da Serra do Mar, diques subalcalinos diferenciados, análise por ativação com nêutrons, diques intermediários da Ilha de São Sebastião. 


\section{ABSTRACT}

The geochemical and isotopic ( $\mathrm{Sr}-\mathrm{Nd}-\mathrm{Pb}$ ) characterization of the subalkaline differentiated dykes from the Serra do Mar Swarm (ESM) is presented. These rocks are located at the coast of São Paulo and Rio de Janeiro states and are mainly composed by basic dikes with high contents of $\mathrm{TiO}_{2}(>3 \%)$. Intermediate and acid dykes, which are found only in the São Sebastião Island and adjacent coast area were investigated by using neutron activation analysis (AAN), allowing determination of the concentrations of rare earth elements ( $\mathrm{La}, \mathrm{Ce}, \mathrm{Nd}, \mathrm{Sm}, \mathrm{Eu}, \mathrm{Tb}, \mathrm{Yb}$ and $\mathrm{Lu}$ ) and other compatible (Co and Sc) and incompatible trace elements (U, Th, Hf, Ta, Ba and Rb). The samples were also analyzed by mass spectrometry with inductively coupled plasma (ICPMS), permitting the comparison between the results obtained by the two methods. The isotope compositions of $\mathrm{Sr}, \mathrm{Nd}$ and $\mathrm{Pb}$ were also determined in five representative samples. The data obtained by AAN indicate precision of up to $14 \%$ (most below 10\%) and accuracy of up to $4 \%$. The statistical comparison of AAN and ICP-MS data showed that the techniques provide statistically identical results for the vast majority of the analyzed elements. The differentiated dykes are chemically represented by lati-andesites (LTA), dacites (DAC) and riodacites (RC). Four LTA samples (Group 1) have geochemical similarities with Pitanga basaltic flows from Paraná Magmatic Province (PMP), although presenting $\mathrm{Sr}$ and $\mathrm{Pb}$ initial ratios slightly more radiogenic. The remaining LTA (Group 2) rocks are enriched in highly incompatible trace elements. The compositional gap between the most evolved LTA (Group 2) and the DAC and RC suggests that the evolution of this rocks is not compatible with fractional crystallization processes. Likewise the genesis of Chapecó-Ourinhos acid volcanic rocks from PMP, it is possible that the DAC and RC have been generated by melting of basalt material, which was trapped in crust-mantle discontinuity. The isotope ratios of the ESM dykes suggest that this basaltic material was generated by melting of a metasomatized subcontinental lithospheric mantle source, due to ancient subduction processes, as proposed for the Mesozoic dykes from the Espinhaço Meridional (São Francisco Craton), whose isotope ratios are very similar. The differentiated magmas generated in this process would be affected by crustal contamination during their ascension, as also indicated by the $\mathrm{Sr}, \mathrm{Nd}$ and $\mathrm{Pb}$ isotope compositions, requiring however, very specific characteristics for the contaminant.

Key-words: Paraná Magmatic Province, Serra do Mar dyke swarm, subalkaline differentiated dykes, neutron activation analysis, intermediate dykes from São Sebastião Island. 


\section{AGRADECIMENTOS}

Ao Senhor Deus, em primeiro lugar, por me conduzir em mais uma etapa de minha vida e por permitir sua conclusão.

À Prof ${ }^{a}$ Dr ${ }^{\mathrm{a}}$ Leila Soares Marques, pela orientação, apoio, dedicação ao ensino e às discussões, pelo empenho em buscar respostas, pela calma e paciência ao lidar comigo (que muitas vezes eu não teria...), e ao mesmo por toda a cobrança (que é muito necessária...). A todo o “cuidado de mãe" para que o trabalho fosse desenvolvido da melhor forma, apesar de todos os contratempos e infortúnios; sem a senhora a conclusão do trabalho não seria possível.

À Prof ${ }^{a}$ Dr - Ana Maria Graciano Figueiredo, pela orientação, apoio e supervisão no trabalho referente à irradiação, realizada no IPEN, e pela prontidão em ajudar e sugestões ao longo desses anos.

À CAPES, pelos primeiros meses de bolsa concedidos, e ao CNPq, pela bolsa concedida e todo apoio financeiro referente à divulgação do trabalho em congressos e simpósios.

À FAPESP, pelo financiamento do projeto.

Aos meus queridos amigos, com quem divido grande parte dos momentos fora da universidade. Sem vocês a vida teria bem menos graça... E muito mais números!!

A todos os meus familiares, que estão sempre torcendo por mim e, cada um a seu modo, me incentivando a continuar na caminhada.

A todos os meus colegas e professores do Instituto de Astronomia, Geofísica e Ciências Atmosféricas, que ajudaram direta ou indiretamente na conclusão deste trabalho.

Em especial aos meus pais, Carlos e Tereza, e ao meu irmão, Pedro, que sempre me apoiaram de todas as formas nesses anos de estudos. São os primeiros a sonhar, os primeiros a sacrificar e que sejam os primeiros a receber os frutos de todo esse esforço!

Deus abençoe a todos e que venham os próximos desafios! 


\section{SUMÁRIO}

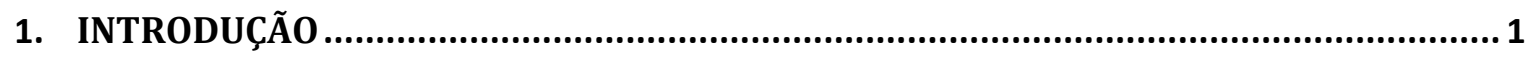

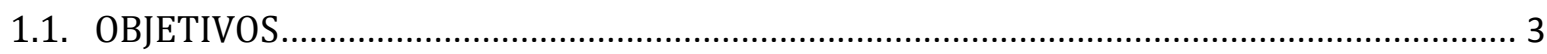

1.2. MÉTODOS UTILIZADOS NO ESTUDO …....................................................................... 3

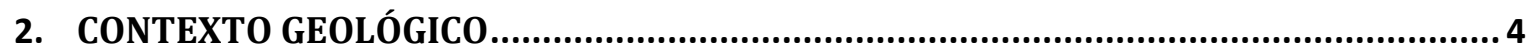

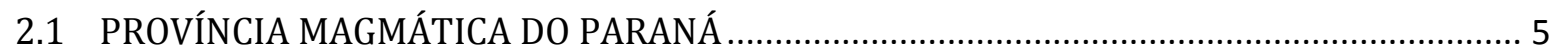

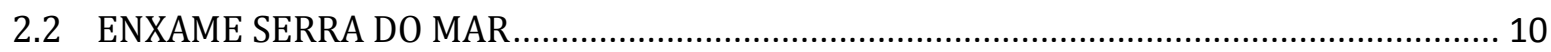

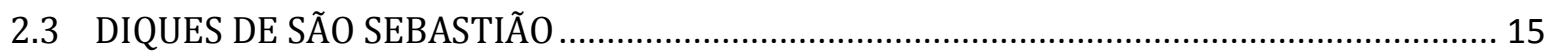

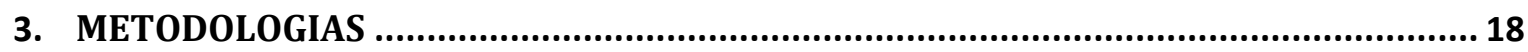

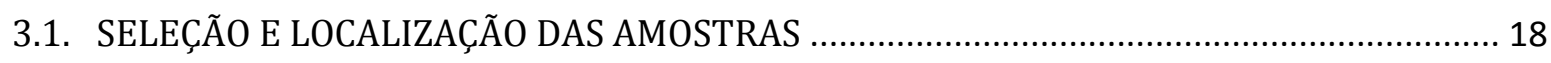

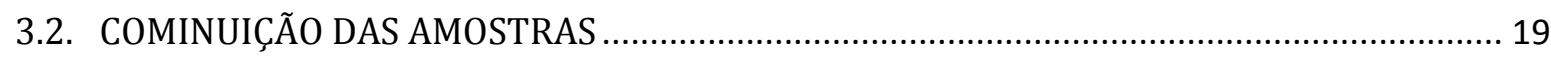

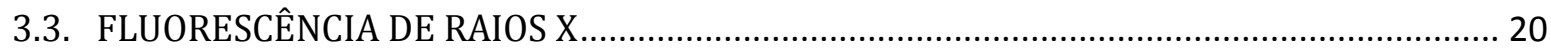

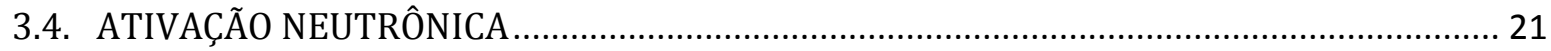

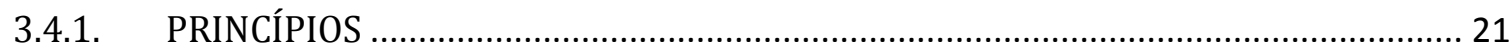

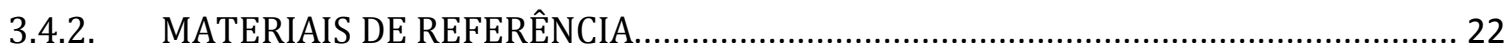

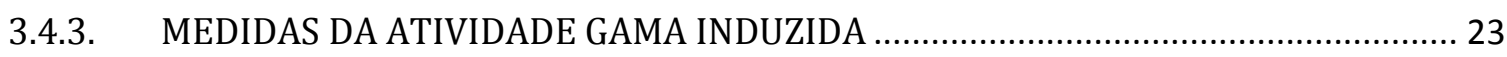

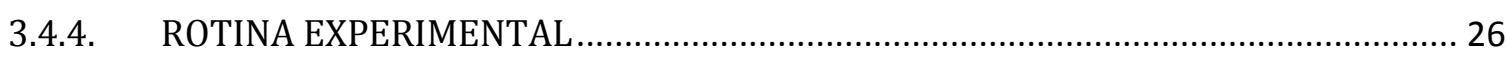

3.5. ESPECTROMETRIA DE MASSA COM FONTE DE PLASMA INDUZIDO (ICP-MS) ................ 28

3.6. ESPECTROMETRIA DE MASSA DE TERMOIONIZAÇÃO (TIMS) …..................................... 29

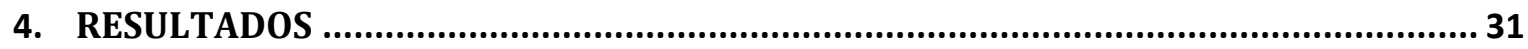

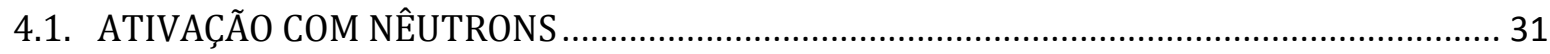

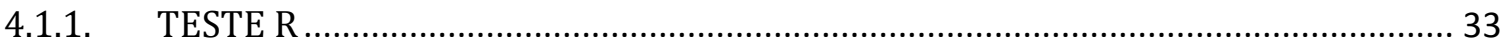

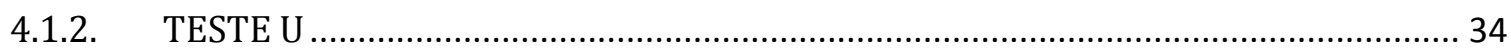

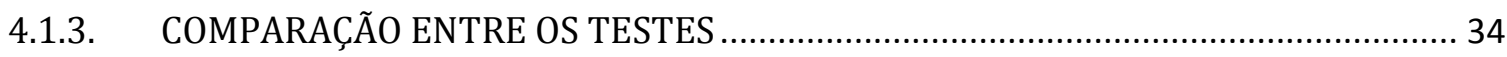

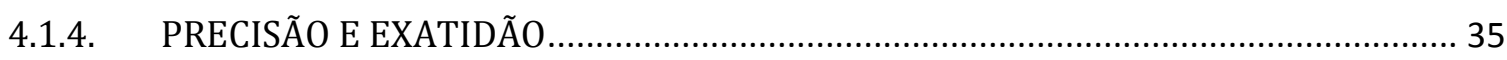

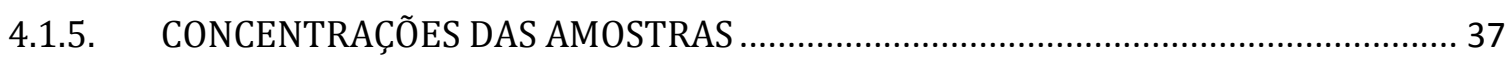

4.2. ESPECTROMETRIA DE MASSA COM FONTE DE PLASMA INDUZIDO …............................ 42

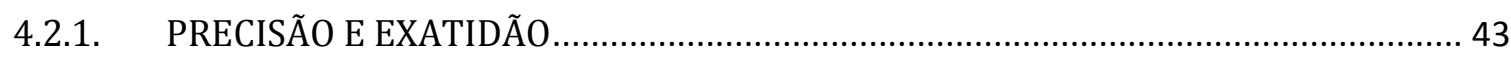


4.3. COMPARAÇÃO ENTRE RESULTADOS OBTIDOS POR AAN E ICP-MS …............................. 46

4.3.1. MÉTODO DAS DIFERENÇAS ENTRE OS RESULTADOS ................................................. 46

4.3.3. DADOS DE FLUORESCÊNCIA DE RAIOS X................................................................ 51

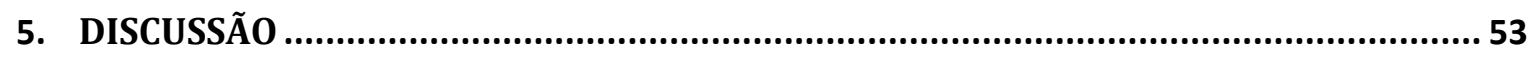

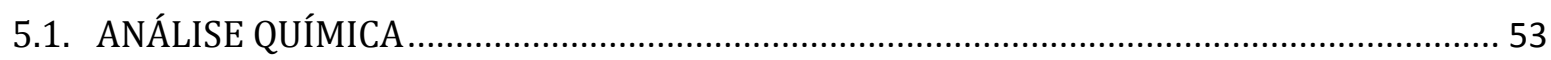

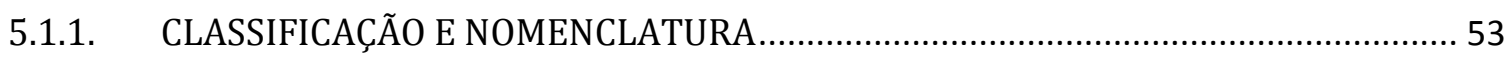

5.1.2. DEFINIÇÃO DOS MAGMAS-TIPO PARA OS DIQUES BÁSICOS .................................... 56

5.1.3. DIAGRAMAS DE VARIAÇÃO DE ÓXIDOS MAIORES E MENORES ................................ 57

5.1.4. DIAGRAMAS DE VARIAÇÃO DE ELEMENTOS TRAÇO ………………...................... 59

5.1.5. PADRÕES DE ABUNDÂNCIA DE ELEMENTOS TERRAS RARAS ………..................... 62

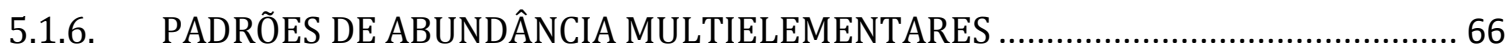

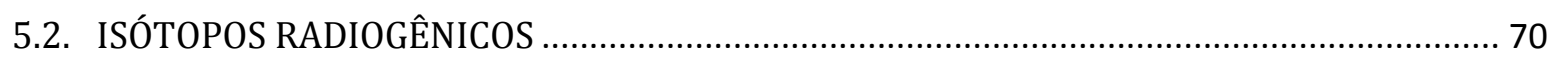

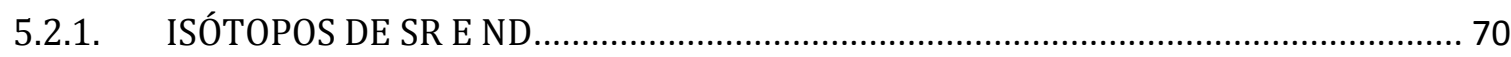

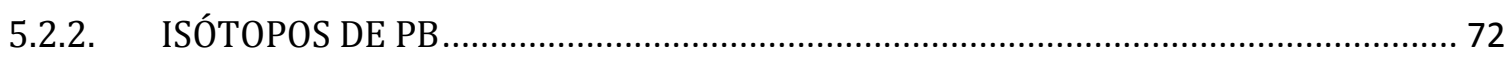

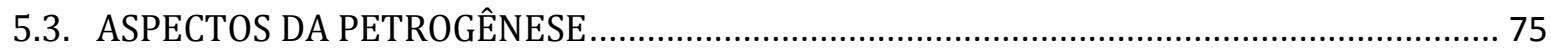

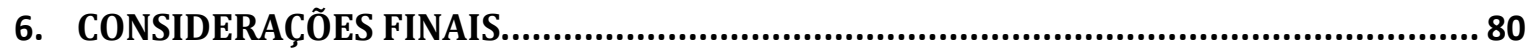

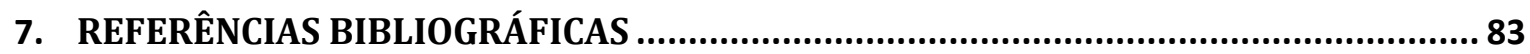

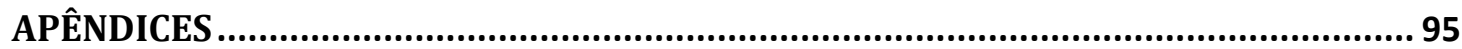




\section{IV. ÍNDICE DE FIGURAS}

FIGURA 2.1.: MAPA GEOLÓGICO SIMPLIFICADO DA BACIA DO PARANÁ (BELLIENI ET AL., 1986; NARDY ET $A L$., 2001): (1) EMBASAMENTO CRISTALINO; (2) SEDIMENTOS PRÉ-VULCÂNICOS (PRINCIPALMENTE PALEOZOICOS); (3) ROCHAS VULCÂNICAS BÁSICAS A INTERMEDIÁRIAS DA PROVÍNCIA MAGMÁTICA DO PARANÁ; (4) ROCHAS ÁCIDAS DO TIPO PALMAS DA PROVÍNCIA MAGMÁTICA DO PARANÁ; (5) ROCHAS ÁCIDAS DO TIPO CHAPECÓ DA PROVÍNCIA MAGMÁTICA DO PARANÁ; (6) ENXAMES DE DIQUES DA PROVÍNCIA MAGMÁTICA DO PARANÁ; (7) SEDIMENTOS PÓS-VULCÂNICOS (PRINCIPALMENTE DO CRETÁCEO SUPERIOR); (8) ALINHAMENTOS TECTÔNICOS E/OU MAGNÉTICOS. EXTRAÍDO DE MARQUES (2001).

FIGURA 2.2.: (A) MAPA DE LOCALIZAÇÃO DOS DIQUES DO ENXAME DA SERRA DO MAR (SIMPLIFICADO DE ALMEIDA, 1986), MOSTRANDO A LOCALIZAÇÃO DOS DIQUES INTERMEDIÁRIOS ESTUDADOS. LEGENDA: CÍRCULO = LATI-ANDESITOS; CRUZ = DACITOS E RIODACITOS. EXTRAIIDO DE MARQUES (2001). (B) MAPA GEOLÓGICO SIMPLIFICADO DA BACIA DO PARANÁ (SIMPLIFICADO DE NARDY ET AL., 2008). LEGENDA: 1 - EMBASAMENTO ADJACENTE; 2 - SEDIMENTOS PRÉ-VULCÂNICOS; 3 - DERRAMES BASÁLTICOS DA FORMAÇÃO SERRA GERAL; 4 - ROCHAS ÁCIDAS DA FORMAÇÃO SERRA GERAL (A: MEMBRO CHAPECÓ; B: MEMBRO PALMAS); 5 - SEDIMENTOS PÓS-VULCÂNICOS; 6 - ESTRUTURAS ANTICLINAIS; 7 ESTRUTURAS SINCLINAIS; 8 - LINEAMENTOS OCEÂNICOS; 9 - LINEAMENTO TECTÔNICO E/OU MAGNÉTICO; 10 - ENXAME DA SERRA DO MAR. EXTRAÍDO DE LUCHETTI ET AL. (2014).

FIGURA 4.1.: AJUSTE LINEAR APLICADO NOS DADOS DA AAN EM FUNÇÃO DOS DADOS DE ICPMS PARA ELEMENTOS TRAÇO.

FIGURA 4.2.: AJUSTE LINEAR APLICADO NOS DADOS DA AAN EM FUNÇÃO DOS DADOS DE ICPMS PARA ELEMENTOS TERRAS RARAS.

FIGURA 4.3.: COMPARAÇÃO ENTRE OS DADOS DE FRX E OS DADOS DE ICP-MS. A CURVA TRACEJADA INDICA A RETA $Y(X)=X$. 51

FIGURA 5.1.: NOMENCLATURA DOS DIQUES SEGUNDO CLASSIFICAÇÃO PROPOSTA POR LE BAS ET AL. (1986). LEGENDA: CÍRCULOS E CRUZES CHEIAS = PRESENTE ESTUDO. CORES: VERMELHO = TIPO URUBICI; VERDE = TIPO PITANGA; AMARELO = TIPO MISTO (QUE NÃO POSSUI EQUIVALENTE EXTRUSIVO NA PMP; MARQUES, 2001); ROXO E AZUL = ROCHAS MAIS DIFERENCIADAS. LINHA ROXA: LINHA DIVISÓRIA ENTRE OS CAMPOS ALCALINO E SUBALCALINO PROPOSTA POR IRVINE \& BARAGAR (1971).

FIGURA 5.2.: NOMENCLATURA DOS DIQUES SEGUNDO CLASSIFICAÇÃO PROPOSTA POR DE LA ROCHE ET AL. (1980). LEGENDA: CÍRCULOS E CRUZES CHEIAS = PRESENTE ESTUDO. CORES: VERMELHO = TIPO URUBICI; VERDE = TIPO PITANGA; AMARELO = TIPO MISTO (QUE NÃO POSSUI EQUIVALENTE EXTRUSIVO NA PMP; MARQUES, 2001); ROXO E AZUL = ROCHAS MAIS DIFERENCIADAS.

FIGURA 5.3.: NOMENCLATURA DAS ROCHAS BÁSICAS ESTUDADAS (PEATE ET AL., 1992). LEGENDA: CÍRCULOS CHEIOS = PRESENTE ESTUDO; CORES: VERMELHO = TIPO URUBICI; VERDE = TIPO PITANGA; AMARELO = TIPO MISTO (QUE NÃO POSSUI EQUIVALENTE EXTRUSIVO NA PMP; MARQUES, 2001). 
FIGURA 5.4.: DIAGRAMAS DE VARIAÇÃO DOS ÓXIDOS MAIORES EM FUNÇÃO DE MGO. LEGENDA: CÍRCULOS E CRUZES CHEIAS = PRESENTE ESTUDO; CÍRCULOS MEIO CHEIOS E CRUZES VAZIAS = MARQUES (2001); QUADRADOS = CHAPECÓ-OURINHOS. CORES: VERMELHO = TIPO URUBICI; VERDE = TIPO PITANGA; AMARELO = TIPO MISTO; ROXO CLARO = LTA-1; ROXO = LTA-2A; ROXO ESCURO = LTA-2B; AZUL = DAC; AZUL ESCURO = RC. 58

FIGURA 5.5.: DIAGRAMAS DE VARIAÇÃO DE ETR EM FUNÇÃO DO ZR (FORTEMENTE INCOMPATÍVEL). LEGENDA: CÍRCULOS E CRUZES CHEIAS = PRESENTE ESTUDO; CÍRCULOS MEIO CHEIOS E CRUZES VAZIAS = MARQUES (2001); QUADRADOS = CHAPECÓ-OURINHOS. CORES: VERMELHO = TIPO URUBICI; VERDE = TIPO PITANGA; AMARELO = TIPO MISTO; ROXO CLARO = LTA-1; ROXO = LTA-2A; ROXO ESCURO = LTA-2B; AZUL = DAC; AZUL ESCURO = RC. LINHAS PRETAS: REPRESENTAM AS POSSÍVEIS TRAJETÓRIAS DE DIFERENCIAÇÃO MAGMÁTICA DOS GRUPOS 1 E 2.

FIGURA 5.6.: DIAGRAMAS DE VARIAÇÃO DE ELEMENTOS TRAÇO EM FUNÇÃO DO ZR. LEGENDA: CÍRCULOS E CRUZES CHEIAS = PRESENTE ESTUDO; CÍRCULOS MEIO CHEIOS E CRUZES VAZIAS = MARQUES (2001); QUADRADOS = CHAPECÓ-OURINHOS. CORES: VERMELHO = TIPO URUBICI; VERDE = TIPO PITANGA; AMARELO = TIPO MISTO (MARQUES, 2001); ROXO CLARO = LTA-1; ROXO = LTA-2A; ROXO ESCURO = LTA-2B; AZUL = DAC; AZUL ESCURO = RC. LINHAS PRETAS: REPRESENTAM AS POSSÍVEIS TRAJETÓRIAS DE DIFERENCIAÇÃO MAGMÁTICA DOS GRUPOS 1 E 2.

FIGURA 5.7.: DIAGRAMAS DAS CONCENTRAÇÕES DE ELEMENTOS TERRAS RARAS NORMALIZADAS EM RELAÇÃO AOS CONDRITOS (MCDONOUGH \& SUN, 1995) PARA OS LITOTIPOS BÁSICOS. LEGENDA: CÍRCULOS CHEIOS = PRESENTE ESTUDO; CÍRCULOS MEIO CHEIOS = MÉDIA ESM (MARQUES, 2001); TRIÂNGULOS VAZIOS = MÉDIA DOS DERRAMES PITANGA E URUBICI DA PMP (MANTOVANI ET AL., 1985A; MARQUES ET AL., 1989; PEATE ET $A L ., 1999)$. CORES: VERMELHO = TIPO URUBICI; VERDE = TIPO PITANGA; AMARELO = TIPO MISTO; PRETO = DERRAMES DA PMP. 64

FIGURA 5.8.: DIAGRAMAS DAS CONCENTRAÇÕES DE ELEMENTOS TERRAS RARAS NORMALIZADAS EM RELAÇÃO AOS CONDRITOS (MCDONOUGH \& SUN, 1995) PARA OS LITOTIPOS DIFERENCIADOS. LEGENDA: CÍRCULOS E CRUZES CHEIAS = PRESENTE ESTUDO; CÍRCULOS MEIO CHEIOS = MÉDIA ESM (MARQUES, 2001); TRIÂNGULOS VAZIOS = MÉDIA DOS DERRAMES PITANGA DA PMP (MANTOVANI ET AL., 1985A; MARQUES ET AL., 1989). CORES: VERDE = TIPO PITANGA; ROXO CLARO = LTA-1; ROXO = LTA-2A; ROXO ESCURO = LTA-2B; AZUL = DAC; AZUL ESCURO = RC; LINHA PRETA = MÉDIA DAS VULCÂNICAS ÁCIDAS TIPO CHAPECÓ-OURINHOS. 65

FIGURA 5.9.: DIAGRAMAS MULTIELEMENTARES NORMALIZADOS EM RELAÇÃO AO MANTO PRIMITIVO (MCDONOUGH \& SUN, 1995) PARA OS LITOTIPOS BÁSICOS. LEGENDA: CÍRCULOS MEIO CHEIOS = MÉDIA ESM (MARQUES, 2001). CORES: VERMELHO = TIPO URUBICI; VERDE = TIPO PITANGA; AMARELO = TIPO MISTO; PRETO = DERRAMES DA PMP (MANTOVANI ET AL., 1985A; MARQUES ET AL., 1989; PEATE ET AL., 1999).

FIGURA 5.10.: DIAGRAMAS MULTIELEMENTARES NORMALIZADOS EM RELAÇÃO AO MANTO PRIMITIVO (MCDONOUGH \& SUN, 1995) PARA OS LITOTIPOS DIFERENCIADOS. LEGENDA: CÍRCULOS MEIO CHEIOS = MÉDIA ESM (TIPO PITANGA - MARQUES, 2001). CORES: VERDE = TIPO PITANGA; ROXO CLARO = LTA-1; ROXO = LTA-2A; ROXO ESCURO = LTA-2B; AZUL = DAC; AZUL ESCURO $=$ RC; PRETO $=$ DERRAMES DA PMP (MANTOVANI ET AL., 1985A; MARQUES ET $A L ., 1989$ ).

FIGURA 5.11.: DIAGRAMAS DE ELEMENTOS TERRAS RARAS NORMALIZADOS EM RELAÇÃO AOS CONDRITOS E DIAGRAMAS MULTIELEMENTARES NORMALIZADOS EM RELAÇÃO AO 
MANTO PRIMITIVO (MCDONOUGH \& SUN, 1995), COMPARANDO TODOS OS LITOTIPOS ESTUDADOS. LEGENDA INDICADA NA FIGURA.

FIGURA 5.12.: DIAGRAMA DAS RAZÕES ISOTÓPICAS INICIAIS DE SR E ND PARA AS ROCHAS INTERMEDIÁRIAS DO ESM. LEGENDA: CÍRCULOS E CRUZES CHEIAS = PRESENTE ESTUDO; QUADRADO = CHAPECÓ-OURINHOS; ESTRELAS = DIQUES MESOZOICOS DO ESPINHAÇO MERIDIONAL (MARQUES ET AL., 2015). CORES: ROXO CLARO = LTA-1; ROXO ESCURO = LTA-2B; AZUL = DAC; AZUL ESCURO = RC. CAMPOS: VERMELHO = DERRAMES URUBICI (PMP); VERDE = DERRAMES PITANGA; AMARELO = DIQUES ESM (BELLIENI ET AL. (1990); MARQUES, $2001 \mathrm{E}$ DADOS INÉDITOS; CARVAS, 2014); AZUL = DERRAMES ESMERALDA E GRAMADO. LINHA TRACEJADA VERDE = LINHA DE MISTURA DE BASALTOS DO TIPO PITANGA COM CROSTA CONTINENTAL SUPERIOR (CCS; RUDINICK \& GAO, 2003). 71

FIGURA 5.13.: DIAGRAMAS DE ${ }^{207} \mathrm{~PB} /{ }^{204} \mathrm{~PB}$ VS. ${ }^{206} \mathrm{~PB} /{ }^{204} \mathrm{~PB}$ E DE ${ }^{208} \mathrm{~PB} / 204 \mathrm{~PB}$ VS. ${ }^{206 \mathrm{~PB} / 204 \mathrm{~PB}}$ PARA AS ROCHAS INTERMEDIÁRIAS DO ESM. LEGENDA: CÍRCULOS E CRUZES CHEIAS = PRESENTE ESTUDO; QUADRADO = CHAPECÓ-OURINHOS; ESTRELAS = DIQUES MESOZOICOS DO ESPINHAÇO MERIDIONAL (MARQUES ET AL., 2015). CORES: ROXO CLARO = LTA-1; ROXO ESCURO = LTA-2B; AZUL = DAC; AZUL ESCURO = RC. CAMPOS: VERMELHO = DERRAMES URUBICI; VERDE = DERRAMES PITANGA; AMARELO = DIQUES ESM (BELLIENI ET AL. (1990); MARQUES, 2001 E DADOS INÉDITOS; CARVAS, 2014); AZUL = DERRAMES ESMERALDA E GRAMADO. LINHA TRACEJADA VERDE = LINHA DE MISTURA DE BASALTOS DO TIPO PITANGA COM CROSTA CONTINENTAL SUPERIOR (CCS; RUDINICK \& GAO, 2003).

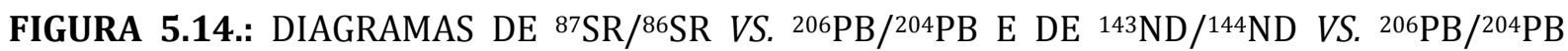
PARA AS ROCHAS INTERMEDIÁRIAS DO ESM. LEGENDA: CÍRCULOS E CRUZES CHEIAS = PRESENTE ESTUDO; QUADRADO = CHAPECÓ-OURINHOS; ESTRELAS = DIQUES MESOZOICOS DO ESPINHAÇO MERIDIONAL (MARQUES ET AL., 2015). CORES: ROXO CLARO = LTA-1; ROXO ESCURO = LTA-2B; AZUL = DAC; AZUL ESCURO = RC. CAMPOS: VERMELHO = DERRAMES URUBICI; VERDE = DERRAMES PITANGA; AMARELO = DIQUES ESM (BELLIENI ET AL. (1990); MARQUES, 2001 E DADOS INÉDITOS; CARVAS, 2014); AZUL = DERRAMES ESMERALDA E GRAMADO. LINHA TRACEJADA VERDE = LINHA DE MISTURA DE BASALTOS DO TIPO PITANGA COM CROSTA CONTINENTAL SUPERIOR (CCS; RUDINICK \& GAO, 2003). 74

FIGURA 5.15.: DIAGRAMAS DE RAZÕES ENTRE ELEMENTOS FORTEMENTE INCOMPATÍVEIS EM FUNÇÃO DO ELEMENTO DE MAIOR INCOMPATIBILIDADE. LEGENDA: CÍRCULOS E CRUZES CHEIAS = PRESENTE ESTUDO; CÍRCULOS MEIO CHEIOS E CRUZES VAZIAS = MARQUES (2001); QUADRADOS = CHAPECÓ-OURINHOS. CORES: VERMELHO = TIPO URUBICI; VERDE $=$ TIPO PITANGA; AMARELO = TIPO MISTO (MARQUES, 2001); ROXO CLARO = LTA-1; ROXO = LTA-2A; ROXO ESCURO = LTA-2B; AZUL = DAC; AZUL ESCURO = RC. 76

FIGURA 5.16.: DIAGRAMAS DE VARIAÇÃO DE ELEMENTOS TRAÇO EM FUNÇÃO DA RAZÃO

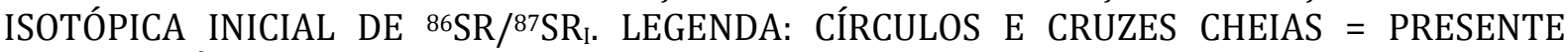
ESTUDO; CÍRCULOS MEIO CHEIOS E CRUZES VAZIAS = MARQUES (2001); QUADRADOS = CHAPECÓ-OURINHOS. CORES: VERMELHO = TIPO URUBICI; VERDE = TIPO PITANGA; AMARELO = TIPO MISTO (MARQUES, 2001); ROXO CLARO = LTA-1; ROXO = LTA-2A; ROXO ESCURO = LTA2B; AZUL = DAC; AZUL ESCURO = RC.. 


\section{V. ÍNDICE DE TABELAS}

TABELA 3.1.: VALORES CERTIFICADOS DOS MATERIAIS DE REFERÊNCIA USADOS NAS IRRADIAÇÕES ( $\mu \mathrm{G} / \mathrm{G})$. RETIRADOS DE GOVINDARAJU (1994) - BE-N E GS-N; E COTTA ET AL. (2008) - BRP-1.

TABELA 3.2.: ELEMENTOS ANALISADOS E CARACTERÍSTICAS PRINCIPAIS DE SEUS RADIOISÓTOPOS

TABELA 4. 1.: RESULTADOS DOS TESTES ESTATÍSTICOS REALIZADOS PARA AVALIAÇÃO DA QUALIDADE E CONFIABILIDADE DOS RESULTADOS DAS ANÁLISES DO MATERIAL DE REFERÊNCIA BRP-1. OBSERVA-SE QUE, NO CASO DO TESTE R, OS CASOS COM N > 25 SEGUEM $O$

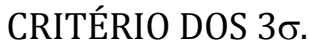

TABELA 4.2.: VALORES DE PRECISÃO (\%) E EXATIDÃO (\%) INFERIDOS PARA AS DETERMINAÇÕES CALCULADOS ATRAVÉS DAS ANÁLISES DO MATERIAL DE REFERÊNCIA BRP1.

TABELA 4.3.: RESULTADO DAS ANÁLISES POR ATIVAÇÃO COM NÊUTRONS OBTIDAS NO CENTRO DO REATOR DE PESQUISAS (CRPQ) DO INSTITUTO DE PESQUISAS ENERGÉTICAS NUCLEARES (IPEN-CNEN/SP). O DESVIO PADRÃO APRESENTADO “ $\sigma$ " SE REFERE AO DESVIO PADRÃO DA ANÁLISE ELEMENTAR DE CADA AMOSTRA E “N” É O NÚMERO DE DETERMINAÇÕES QUE COMPÕE A MÉDIA “ $x$ ”.

TABELA 4.4.:RESULTADO DAS ANÁLISES POR ICP-MS OBTIDAS NO LABORATÓRIO DE QUÍMICA E ICP DO INSTITUTO DE GEOCIÊNCIAS DA USP.

TABELA 4.5.: VALORES DE PRECISÃO (\%) E EXATIDÃO (\%) INFERIDOS PARA OS DADOS DE ICP-MS CALCULADOS ATRAVÉS DAS ANÁLISES DO BASALTO BR (CRPG).

TABELA 4.6.: PARÂMETROS CALCULADOS PARA DETERMINAÇÃO DO T EXP PARA CADA ELEMENTO INVESTIGADO NESSE ESTUDO, PARA $\mathrm{N}=16$

TABELA 4.7.: COEFICIENTES ANGULAR (B) E LINEAR (A) E OS RESPECTIVOS ERROS ASSOCIADOS AO AJUSTE REALIZADO PELO SOFTWARE ORIGIN PRO 7.0, SEGUNDO A EQUAÇÃO $(\mathrm{X}): \mathrm{Y}(\mathrm{X})=\mathrm{A}+\mathrm{B}^{*} \mathrm{X}$

TABELA 5.1.: VALOR MÉDIO E DESVIO PADRÃO DAS RAZÕES ENTRE ELEMENTOS MENORES E TRAÇO CALCULADAS PARA AS ROCHAS ESTUDADAS. 63

TABELA 5.2.: VALORES MEDIDOS DAS RAZÕES ISOTÓPICAS DE SR, ND E PB PARA CINCO AMOSTRAS REPRESENTATIVAS DOS DIQUES DIFERENCIADOS DO ESM. 


\section{Introdução}

Grandes províncias ígneas (Large Igneous Provinces - LIP’s) são objeto de muito estudo por estarem fortemente associadas a processos de ruptura da litosfera, tanto oceânica como continental e, consequentemente, por atingirem proporções globais. Dentre as características que definem uma LIP estão o volume de magma, sua extensão, duração dos pulsos magmáticos e duração do magmatismo em si (Coffin \& Eldholm, 1994; Bryan \& Ernst, 2008). Enfatizando essas quatro características, esses últimos autores definiram as LIP's como províncias magmáticas que cobrem uma área maior do que $100.000 \mathrm{~km}^{2}$, apresentando um volume de rochas maior do que $100.000 \mathrm{~km}^{3}$, caracterizada por pulsos de curta duração (1 - $5 \mathrm{Ma}$ ) durante o qual grande parte do material (> 75\%), principalmente máfico, tenha sido colocado, e com duração máxima de 50 Ma.

Apesar de muito esforço ter sido empregado nas últimas décadas a fim de se propor modelos para a geração desse expressivo magmatismo ainda não existe um consenso sobre os processos geodinâmicos associados às LIP's. Como exemplos podem ser citados o modelo proposto por Richards et al. (1989), em que o magma é gerado antes do processo de ruptura continental e está associado a grandes anomalias térmicas (plumas mantélicas), e o modelo antagônico de White \& McKenzie, (1989), no qual o magma é gerado após processos de "rift" (com ou sem evolução para abertura de oceanos) e está associado à subida do manto anomalamente quente em processos de descompressão adiabática.

0 estudo das LIP's pode fornecer informações precisas acerca dos processos tectônicos envolvidos em sua geração e desenvolvimento e também a respeito das fontes mantélicas responsáveis pelo magmatismo, pois elas preservam esses registros. Em especial, aquelas com idades do Mesozoico e Cenozoico são as mais bem preservadas (Ernst et al., 2004), e entre os diversos elementos tectônicos que as compõem podem ser destacados os enxames de diques (Ernst \& Bleeker, 2010).

Neste contexto, o estudo específico dos enxames de diques pode fornecer ferramentas para um melhor entendimento das LIP's, uma vez que estes corpos, 
cuja extensão é muito maior do que a sua largura, carregam informações de caráter estrutural, como direção preferencial, variações regionais de atitude padrões radiais (Halls, 1982), como também de caráter composicional.

Tratando-se de grandes províncias ígneas, a região sul e sudeste do Brasil é particularmente interessante para a obtenção de informações sobre esses processos tectônicos e magmáticos, pois nela encontra-se registrado um dos maiores episódios de atividade ígnea de caráter continental conhecida no planeta, representado pela Província Magmática do Paraná (PMP). A atividade ígnea que deu origem à PMP precedeu a ruptura continental América do Sul - África e ocorreu principalmente na forma de intenso vulcanismo de natureza toleítica, atingindo cerca de $780.000 \mathrm{~km}^{3}$ de material efusivo (Piccirillo \& Melfi, 1988).

A PMP é predominantemente composta por derrames básicos que cobriram a maior parte da área da Bacia do Paraná, e apresenta caráter bimodal,

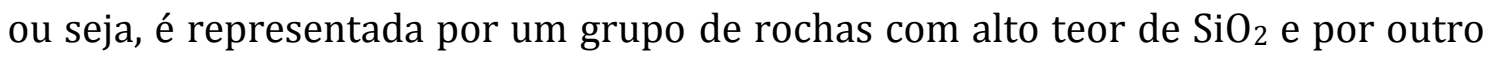
com baixo teor de $\mathrm{SiO}_{2}$. Associada ao vulcanismo ocorreu significativa atividade intrusiva na forma de soleiras e de três importantes enxames de diques (e.g.: Almeida, 1986; Piccirillo \& Melfi, 1988; Peate et al., 1997; Ernesto et al., 1999; Marques \& Ernesto, 2004), dois dos quais localizados em áreas costeiras e denominados de enxames da Serra do Mar (litoral de São Paulo e Rio de Janeiro) e de Florianópolis (Ilha de Santa Catarina e continente adjacente), enquanto o outro, Enxame de Ponta Grossa, adentra pelo continente, paralelamente ao arco homônimo.

Almeida et al. (2013) apresentam uma discussão sobre a colocação desses diques costeiros do sudeste do Brasil, associados à ruptura do Gondwana. Os autores chamam a atenção de que o então continente teria sido formado a partir de múltiplos processos de colisão, apresentando blocos constituídos por litologias diferentes e separados por descontinuidades. Eles identificam ainda outros dois enxames de diques, além dos três já citados, a saber, enxame de Vitória-Colatina e enxame de Resende, os quais aproveitaram as zonas de sutura e se arranjaram ao longo de uma junção tripla (SE do Brasil, Uruguai e Argentina, e SW da África e Antártica). 


\subsection{Objetivos}

Sob este prisma, o objetivo deste trabalho é estudar o enxame de diques subalcalinos da Serra do Mar (ESM). Especificamente, os que afloram na Ilha de São Sebastião, localizada no litoral norte do Estado de São Paulo, e na área continental adjacente, onde ocorrem diques mais diferenciados, com conteúdos de $\mathrm{SiO}_{2}$ acima de $55 \%$ e $\mathrm{MgO}<3 \%$, que se distinguem fortemente dos demais do ESM (Bellieni et al., 1990; Garda, 1995). De acordo com esses autores, nessa região, além de litotipos básicos, com $\mathrm{TiO}_{2}>3 \%$ (quimicamente representados por andesi-basaltos toleíticos, lati-basaltos e lati-andesitos), ocorrem de modo subordinado, diques com composição de quartzo-latitos, dacitos e riodacitos.

Pretende-se investigar de modo detalhado essas ocorrências, sendo que há uma carência de informações acerca desse magmatismo mais diferenciado. Buscase enfatizar as suas relações genéticas com as rochas intrusivas e extrusivas da PMP, particularmente os diques básicos do ESM, os basaltos do tipo Pitanga (Piccirillo et al., 1987; Marques, 2001) e as vulcânicas ácidas do tipo Chapecó (Marques, 1988; Garland et al., 1995), que ocorrem no norte da província.

\subsection{Métodos utilizados no estudo}

Para atingir os objetivos propostos, foram determinados os teores de elementos traço, tais como, terras raras ( $\mathrm{La}, \mathrm{Ce}, \mathrm{Sm}, \mathrm{Nd}, \mathrm{Tb}, \mathrm{Eu}, \mathrm{Yb}$ e $\mathrm{Lu}$ ), $\mathrm{Rb}, \mathrm{Ba}, \mathrm{U}$, Th, Ta e Hf, em um conjunto de 16 amostras do ESM. Assim, realizou-se um estudo do comportamento desses elementos que, por serem excelentes traçadores dos processos petrogenéticos e indicadores das fontes envolvidas no magmatismo, puderam fornecer informações fundamentais sobre a origem e evolução das rochas investigadas. Além disso, foram também efetuadas determinações das razões isotópicas de $\mathrm{Sr}, \mathrm{Nd}$ e $\mathrm{Pb}$, por meio de espectrometria de massa termoiônica, com o objetivo de investigar melhor a natureza das fontes envolvidas no magmatismo e averiguar possíveis processos de contaminação crustal, que podem ter afetado significativamente a composição das rochas investigadas, mascarando as características geoquímicas dos magmas originais. 


\section{Contexto Geológico}

As rochas aqui estudadas fazem parte da Província Magmática do Paraná (PMP - Figura 2.1), uma das maiores manifestações vulcânicas do mundo, desenvolvida na Bacia do Paraná, a qual se apresenta majoritariamente em território brasileiro, estendendo-se também no Uruguai, Argentina e numa pequena área do Paraguai. A bacia possui formato próximo a um "J", com a maior extensão de aproximadamente 1700 km na direção NNE-SSW e largura média de $900 \mathrm{~km}$, alcançando até $8 \mathrm{~km}$ de material depositado nas regiões mais centrais (Almeida, 1986).

A Bacia do Paraná se estabeleceu em áreas afetadas pelo Ciclo Brasiliano, o qual uniu diversas áreas cratônicas por meio de deformação, metamorfismo e granitogênese, devido a múltiplos e fortes processos colisionais intercalados com orogênese, subsidência e sedimentação (Cordani et al., 1984; Zálan et al., 1986; Quintas et al., 1999; Almeida et al., 2013). São reconhecidos seis ciclos sedimentares que ocorreram entre o Ordoviciano e o Cretáceo Superior, sendo basicamente: três ciclos transgressivo-regressivos compreendidos entre o Ordoviciano e o Permiano; sedimentos fluvio-lacustres do Triássico; arenitos eólicos e sequências de lavas compreendidas entre o Jurássico e o Cretáceo Inferior; sedimentos continentais do Cretáceo Superior (Milani, 1992; Milani et al., 2007). O embasamento na borda da bacia apresenta, em geral, rochas metassedimentares do Proterozoico Superior e estruturas arqueadas como Arco de São Vicente, ao norte, o Arco de Assunção, a oeste, e o Arco do Rio Grande, ao sul, que a limitam.

O magmatismo observado na Bacia apresenta caráter predominantemente toleítico, representado por estruturas como diques e soleiras de diabásio, além dos derrames basálticos, presentes em grande parte de sua extensão (Almeida, 1986). Também é observado um magmatismo alcalino em regiões soerguidas nas margens ou transversais às bordas da Bacia, o qual apresenta duas fases principais, uma a $\sim 130 \mathrm{Ma}$, próxima aos basaltos, e outra mais jovem, $\sim 80 \mathrm{Ma}$ (e.g.: Gomes et al., 2011). Entre os corpos alcalinos podem ser destacados por sua magnitude Poços de Caldas, Itatiaia-Passa Quatro e os da Ilha de São Sebastião, localizados na região costeira leste e sudeste, onde ocorrem stocks, plugs, possíveis chaminés, 
diques e alguns poucos derrames e piroclastos, sendo rochas peralcalinas predominantemente félsicas (Almeida, 1986).

\subsection{Província Magmática do Paraná}

A Província Magmática do Paraná (PMP) é representada pelos derrames basálticos que compõem a Formação Serra Geral da Bacia do Paraná, ocorrendo principalmente sobre os arenitos da Formação Botucatu e são recobertos pelo Grupo Bauru. A PMP apresenta a maior área de rochas vulcânicas continuamente expostas de todo o Brasil (Almeida, 1986), e corresponde a uma das maiores províncias magmáticas do mundo em termos de área de exposição $\left(\sim 1,0 \times 10^{6} \mathrm{~km}^{2}\right)$, contando com um volume estimado de magma extravasado de $6,0 \times 10^{5} \mathrm{~km}^{3}$ (Frank et al., 2009). As maiores espessuras de lavas são encontradas no centro da bacia e nas regiões de borda ocorrem enxames de diques.

As rochas da PMP são majoritariamente basaltos toleíticos e seus equivalentes intrusivos, representando $90 \%$ do volume de material extrusivo. Além das rochas básicas, principalmente nas porções centro-meridionais da província, ocorrem litotipos intermediários a ácidos, representados por andesitos (7\% do volume total), e riolitos e riodacitos (3\% do volume total) respectivamente (Piccirillo et al., 1988; Piccirillo et al., 1989; Marques \& Ernesto, 2004). Por estarem mais próximas às margens da bacia e por estarem no topo da sequência, essas rochas mais diferenciadas representam os estágios finais do magmatismo toleítico (Piccirillo \& Melfi, 1988).

De maneira geral, os derrames da PMP são compostos por rochas básicas com textura afírica a subafírica, enquanto que as intermediárias são afíricas a porfiríticas e as ácidas são fracamente porfiríticas a porfiríticas. Essas rochas são constituídas principalmente por plagioclásio, dois piroxênios (augita e pigeonita) e rara Mg-olivina (feno a microfenocristais nos termos mais básicos), imersos em matriz composta essencialmente pelos mesmos minerais, além de titanomagnetita e ilmenita, apresentando, por vezes, cristais, mais comumente de plagioclásio e augita, variando de micro a macrofenocristais numa relação diretamente proporcional ao grau de evolução. Também são reportados microfenocristais de apatita e quartzo (matriz) nos termos mais diferenciados (e.g.: Bellieni et al., 1984; 


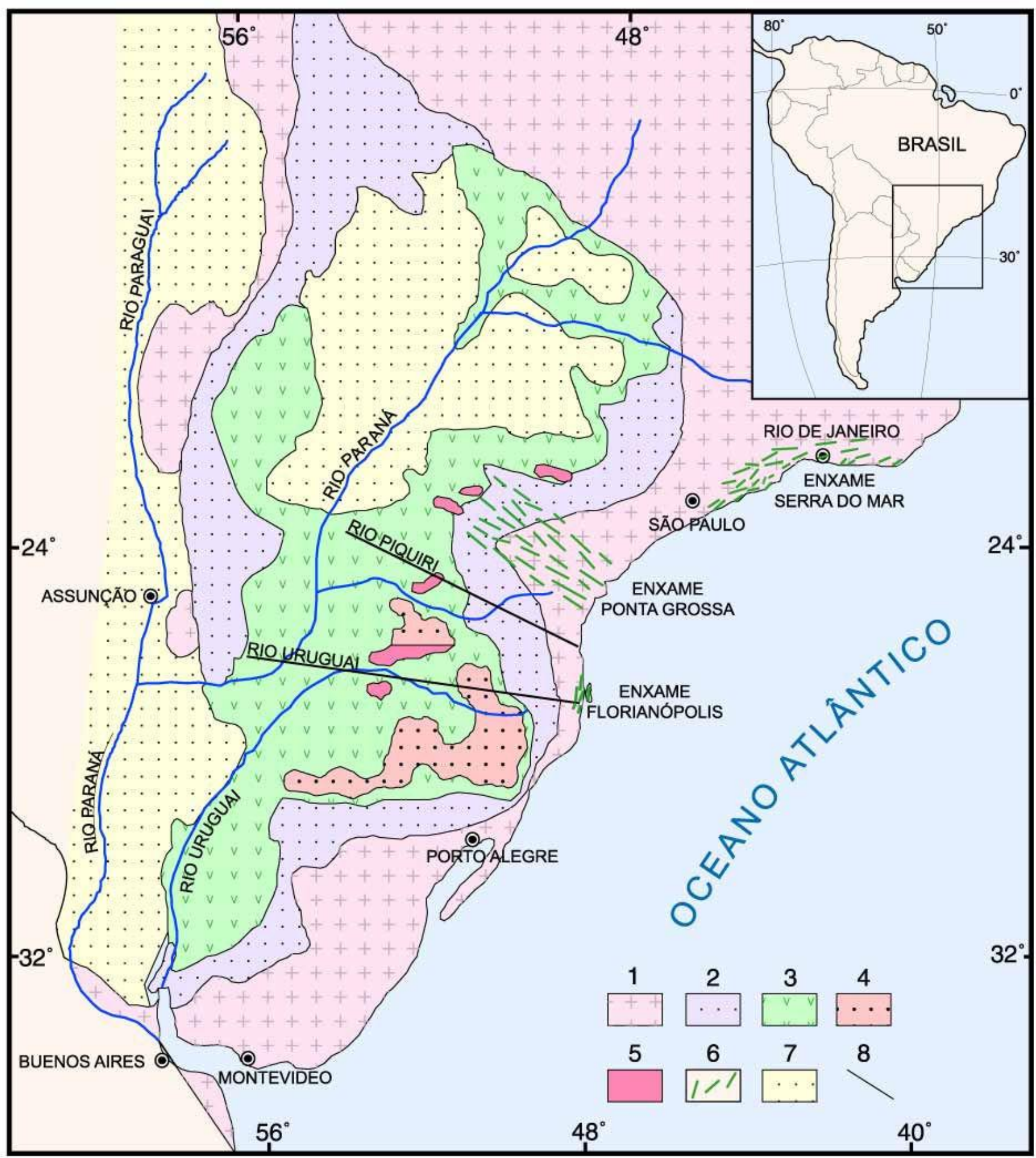

Figura 2.1.: Mapa geológico simplificado da Bacia do Paraná (Bellieni et al., 1986; Nardy et al., 2001): (1) embasamento cristalino; (2) sedimentos pré-vulcânicos (principalmente paleozoicos); (3) rochas vulcânicas básicas a intermediárias da Província Magmática do Paraná; (4) rochas ácidas do tipo Palmas da Província Magmática do Paraná; (5) rochas ácidas do tipo Chapecó da Província Magmática do Paraná; (6) enxames de diques da Província Magmática do Paraná; (7) sedimentos pós-vulcânicos (principalmente do Cretáceo Superior); (8) alinhamentos tectônicos e/ou magnéticos. Extraído de Marques (2001). 
Bellieni et al., 1986; Comin-Chiaramonti et al., 1988; Piccirillo et al., 1988; Nardy, 1996; Nardy et al., 2008; Machado et al., 2015).

As primeiras datações realizadas pelo método potássio-argônio em basaltos da PMP forneceram idades entre 100 e 160Ma, com maior ocorrência de eventos entre 130 e 135Ma (e.g.: Amaral et al., 1966; Melfi, 1967). No final da década de 80, utilizando a mesma metodologia, foram obtidas idades entre 133 135Ma para riolitos dos estados do sul do Brasil (Mantovani et al., 1985b; Piccirillo et al., 1987; Raposo, 1987), sendo, porém, criticado o método devido a possível perda de Ar, principalmente devido a intemperismo e outros processos pósmagmáticos. As análises das idades, especialmente as obtidas a partir de amostras de poços, permitiram concluir que o magmatismo ocorreu em múltiplos eventos, devido a variações regionais nas idades, e em intervalos de poucos milhões de anos (Rocha-Campos et al., 1988). Mais tarde, dados paleomagnéticos vieram a ressaltar a colocação dos derrames num curto período de tempo (análise da polaridade dos derrames) e a destacar a migração do magmatismo de sul para norte (Ernesto et al., 1999; Marques \& Ernesto, 2004).

Datações realizadas pelo método ${ }^{40} \mathrm{Ar} /{ }^{39} \mathrm{Ar}$ sugeriram também que a fase principal do magmatismo ocorreu em curtos intervalos de tempo (2-3Ma) centrada em 133-134Ma (e.g.: Renne et al., 1992), corroborada mais tarde por Thiede \& Vasconcelos (2010). Utilizando o método U-Pb em frações de zircão e badeleíta, Freitas (2009) encontrou idades de 134,4 \pm 0,9 Ma em rochas ácidas da região de Ourinhos/SP. Idades semelhantes foram também apresentadas por Janasi et al. (2011) e Florisbal et al. (2014) utilizando este mesmo método.

Do ponto de vista geoquímico os basaltos toleíticos e andesi-basaltos da Província Magmática do Paraná são divididos em dois principais grupos em função do conteúdo de $\mathrm{TiO}_{2}$ (Bellieni et al., 1984; Mantovani et al., 1985a; Piccirillo \& Melfi, 1988; Marques et al., 1989): um grupo caracterizado por altas concentrações do óxido de titânio $\left(\mathrm{TiO}_{2} \geq 2 \%\right.$; média $=3,1 \pm 0,2 \%$ ), denominado alto- $\mathrm{TiO}_{2}$ ou A-Ti; e outro caracterizado pelas baixas concentrações $\left(\mathrm{TiO}_{2}<2 \%\right.$; média $\left.=1,5 \pm 0,2 \%\right)$, baixo- $\mathrm{TiO}_{2}$ ou B-Ti. Observa-se também um empobrecimento no grupo B-Ti em elementos como $\mathrm{P}_{2} \mathrm{O}_{5}, \mathrm{Sr}, \mathrm{Zr}$, Ba e elementos terras raras em geral, em relação ao grupo A-Ti. 
Peate et al. (1992) separam os basaltos toleíticos e andesi-basaltos em seis subgrupos baseados nos conteúdos de Ti, Y, Sr e Zr. Três grupos associados aos derrames A-Ti são denominados como Urubici $\left(\mathrm{TiO}_{2}>3 \%\right.$; $\mathrm{Sr}>550 \mu \mathrm{g} / \mathrm{g}$; $\mathrm{Ti} / \mathrm{Y}>$ 500), Pitanga $\left(\mathrm{TiO}_{2}>3 \%\right.$; $\left.\mathrm{Sr}>350 \mu \mathrm{g} / \mathrm{g} ; \mathrm{Ti} / \mathrm{Y}>350\right)$ e Paranapanema $\left(2 \%<\mathrm{TiO}_{2}<\right.$ 3\%; $200<\mathrm{Sr}<450 \mu \mathrm{g} / \mathrm{g} ; \mathrm{Ti} / \mathrm{Y}>330$ ), e três grupos são associados aos B-Ti, sendo eles Gramado $\left(\mathrm{TiO}_{2} \leq 2 \% ; 140<\mathrm{Sr}<400 \mu \mathrm{g} / \mathrm{g}\right.$; $\left.\mathrm{Ti} / \mathrm{Y}<300\right)$, Esmeralda $\left(\mathrm{TiO}_{2} \leq 2 \%\right.$; $120<\mathrm{Sr}<250 \mu \mathrm{g} / \mathrm{g} ; \mathrm{Ti} / \mathrm{Y}>500)$ e Ribeira $\left(\mathrm{TiO}_{2} \leq 2 \% ; 200<\mathrm{Sr}<375 \mu \mathrm{g} / \mathrm{g} ; \mathrm{Ti} / \mathrm{Y}>\right.$ 300). Cabe destacar que os basaltos Urubici só ocorrem na região sul da PMP, enquanto os Ribeira só ocorrem na parte norte da província.

As rochas vulcânicas ácidas (riodacitos e riolitos) também são divididas em dois grupos principais, um grupo denominado Chapecó, caracterizado por ser mais enriquecido em óxidos como $\mathrm{TiO}_{2}, \mathrm{P}_{2} \mathrm{O}_{5}$ e $\mathrm{K}_{2} \mathrm{O}$, em elementos traço como $\mathrm{Ba}$, $\mathrm{Nb}, \mathrm{Zr}, \mathrm{Y}, \mathrm{La}, \mathrm{Ce}, \mathrm{Nd}$, Lu e Yb e empobrecido em Rb, Th e U em comparação com as do outro grupo, chamado Palmas (Piccirillo \& Melfi, 1988). Outra diferença marcante entre os dois grupos de ácidas é a textura das rochas: aquelas do grupo Chapecó são fortemente a fracamente porfiríticas, com fenocristais de plagioclásio que chegam a $20 \mathrm{~mm}$, enquanto as do grupo Palmas são fracamente porfiríticas a afíricas, ocorrendo por vezes obsidiana (Nardy et al., 2008). Nos trabalhos de mapeamento desses litotipos ácidos nota-se que as rochas tipo Chapecó localizamse na porção centro-norte da província, correspondendo a cerca de 0,5\% do volume de magma, enquanto as do tipo Palmas estão na área centro-sul e correspondem a cerca de $2 \%$ do volume total de rochas extrusivas (Nardy, 1996; Nardy et al., 2002, 2008). Na região delimitada pelos alinhamentos Rio Piquiri e Rio Uruguai situa-se uma área de transição, encontrando-se rochas do tipo Chapecó sobrepostas às Palmas, e intercalações de litotipos básicos e intermediários com as vulcânicas do tipo Palmas.

Do ponto de vista geoquímico, os riodacitos e riolitos da PMP também são subdivididos de acordo com os teores de $\mathrm{TiO}_{2}, \mathrm{P}_{2} \mathrm{O}_{5}$ e elementos incompatíveis $(\mathrm{Rb}$, Sr, Ba, La, Nb) (Piccirillo \& Melfi, 1988; Marques, 1988; Garland et al., 1995; Nardy, 1996; Nardy et al., 2008). Para o tipo Chapecó são distinguidos três subtipos chamados Ourinhos $\left(\mathrm{SiO}_{2}>65 \% ; \mathrm{TiO}_{2}<1,3 \% ; \mathrm{P}_{2} \mathrm{O}_{4}<0,37 \% ; \mathrm{Rb}>120 \mu \mathrm{g} / \mathrm{g}\right.$; U >

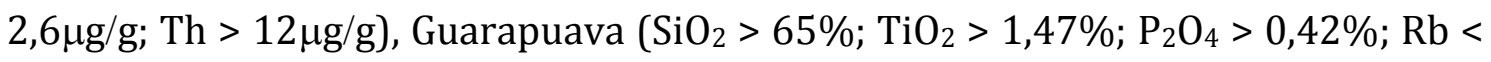
$120 \mu \mathrm{g} / \mathrm{g} ; \mathrm{U}<9 \mu \mathrm{g} / \mathrm{g} ; \mathrm{Th}<2 \mu \mathrm{g} / \mathrm{g}$ ) e Tamarana (intermediário aos outros dois: 1,38\% 
$\left.<\mathrm{TiO}_{2}<1,51 \% ; 0,40 \%<\mathrm{P}_{2} \mathrm{O}_{4}<0,48 \% ; 2 \mu \mathrm{g} / \mathrm{g}<\mathrm{U}<2,6 \mu \mathrm{g} / \mathrm{g} ; 9,4 \mu \mathrm{g} / \mathrm{g}<\mathrm{Th}<11 \mu \mathrm{g} / \mathrm{g}\right)$. Já o tipo Palmas são divididos em cinco subtipos nomeados como Santa Maria $\left(\mathrm{TiO}_{2}<0,87 \% ; \mathrm{P}_{2} \mathrm{O}_{4} \leq 0,21 \%\right)$, Clevelândia $\left(\mathrm{TiO}_{2}<0,87 \% ; 0,21 \%<\mathrm{P}_{2} \mathrm{O}_{5} \leq 0,23 \%\right)$, Anita Garibaldi $\left(1,06 \%<\mathrm{TiO}_{2}<1,25 \% ; 0,32 \%<\mathrm{P}_{2} \mathrm{O}_{5}<0,36 \%\right)$, Caxias do Sul $\left(0,91 \%<\mathrm{TiO}_{2}<1,03 \% ; 0,25 \%<\mathrm{P}_{2} \mathrm{O}_{5}<0,28 \%\right)$, e Jacuí $\left(1,05 \%<\mathrm{TiO}_{2}<1,16 \%\right.$; $0,28 \%<\mathrm{P}_{2} \mathrm{O}_{4}<0,31 \%$ ).

Do ponto de vista isotópico, os basaltos A-Ti do norte (Pitanga e Paranapanema), assim como aqueles B-Ti da mesma região (Ribeira) apresentam valores bastante uniformes (razões iniciais corrigidas para $133 \mathrm{Ma}$ ): ${ }^{87} \mathrm{Sr} /{ }^{86} \mathrm{Sr}_{\mathrm{i}}$ entre 0,70506 e 0,70689 (média $=0,70580 \pm 0,00028 ; \mathrm{N}=74$ ) com maioria entre 0,70540 e 0,$70600 ;{ }^{143} \mathrm{Nd} /{ }^{144} \mathrm{Nd}_{\mathrm{i}}$ entre 0,51218 e 0,51248 (média $=0,51228 \pm 0,00007 ; \mathrm{N}=$ 35); ${ }^{206} \mathrm{~Pb} / 204 \mathrm{~Pb}_{\mathrm{i}}$ entre 17,52 e 17,96 (medido: 17,74-18,25), ${ }^{207} \mathrm{~Pb} /{ }^{204} \mathrm{~Pb}$ i entre 15,49 e 15,55 (medido: 15,51-15,57), ${ }^{208} \mathrm{~Pb} /{ }^{204} \mathrm{~Pb}_{\text {i }}$ entre 37,76 e 38,16 (medido: 38,08-38,45), enquanto os derrames A-Ti localizados no sul (Urubici) possuem valores ligeiramente mais dispersos: ${ }^{87} \mathrm{Sr} /{ }^{86} \mathrm{Sr}_{\mathrm{i}}$ entre 0,70462 e 0,70733 (média =

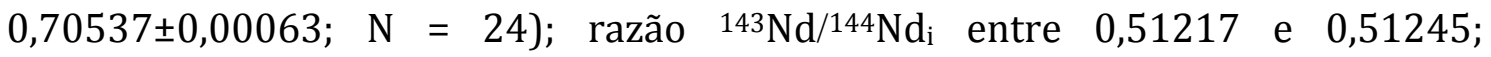
${ }^{206} \mathrm{~Pb} /{ }^{204} \mathrm{~Pb}_{\mathrm{i}}$ entre 16,42 e 17,94 (média $=17,28 \pm 0,33 ; \mathrm{N}=19$; medido: 16,6318,14 ), ${ }^{207} \mathrm{~Pb} /{ }^{204} \mathrm{~Pb}_{\mathrm{i}}$ entre 15,44 e 15,56 (média $=15,49 \pm 0,03 ; \mathrm{N}=19 ;$ medido: $15,45-15,57$ ), ${ }^{208} \mathrm{~Pb} / 204 \mathrm{~Pb}_{\mathrm{i}}$ entre 36,99 e 38,16 (média $=37,74 \pm 0,30 ; \mathrm{N}=19$; medido: 37,24-38,45) (Cordani et al., 1988; Piccirillo et al., 1989; Peate et al., 1992; Garland et al., 1996; Marques et al., 1999; Peate et al., 1999; Rocha-Júnior et al., 2013). As vulcânicas ácidas do tipo Chapecó, associadas ao grupo A-Ti, se caracterizam pelas razões inicias isotópicas de Sr ligeiramente mais elevadas do que as básicas: ${ }^{87} \mathrm{Sr} /{ }^{86} \mathrm{Sr}_{\mathrm{i}}$ entre 0,70488 e 0,70806 (média $=0,70674 \pm 0,00116 ; \mathrm{N}=$ 21); ${ }^{143} \mathrm{Nd} /{ }^{144} \mathrm{Nd}_{\text {i }}$ entre 0,51174 e 0,51228 (média $=0,51216 \pm 0,00015 ; \mathrm{N}=10$ ), sendo que os maiores valores pertencem ao subgrupo Ourinhos (em geral, ${ }^{87} \mathrm{Sr} /{ }^{86} \mathrm{Sr}_{\mathrm{i}}>0,70700$ ) (Piccirillo et al., 1987; Mantovani et al., 1985b; Garland et al., 1995; Freitas, 2009).

Em contrapartida, as rochas da PMP com baixo $\mathrm{TiO}_{2}$ mostram fortes indícios de contaminação para os litotipos básicos, intermediários e ácidos. Os basaltos e andesi-basaltos apresentam valores de razão inicial ${ }^{87} \mathrm{Sr} /{ }^{66} \mathrm{Sr}_{i}$ (corrigidos para $133 \mathrm{Ma}$ ) entre 0,70492 e 0,71375 (média $=0,70822 \pm 0,00177 ; \mathrm{N}=55$ ), 
${ }^{143} \mathrm{Nd} /{ }^{144} \mathrm{Nd}_{\text {i }}$ entre 0,51213 e 0,51266 (média $=0,51233 \pm 0,00014 ; \mathrm{N}=36$ ),

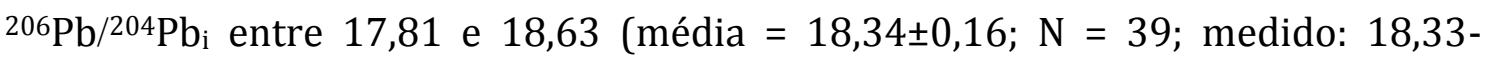
18,90 ), ${ }^{207} \mathrm{~Pb} /{ }^{204} \mathrm{~Pb}$ i entre 15,57 e 15,67 (média $=15,63 \pm 0,02 ; \mathrm{N}=39$; medido: $15,60-15,69$ ), ${ }^{208} \mathrm{~Pb} /{ }^{204} \mathrm{~Pb}_{\mathrm{i}}$ entre 37,94 e 38,70 (média $=38,45 \pm 0,14 ; \mathrm{N}=39$; medido: 38,50-39,03) (Cordani et al., 1988; Peate \& Hawkesworth, 1996; Peate, 1997; Marques et al., 1999); enquanto que as vulcânicas ácidas Palmas têm valores de razão inicial ${ }^{87} \mathrm{Sr} /{ }^{86} \mathrm{Sr}_{\mathrm{i}}$ entre 0,71254 e 0,72633 (média $=0,71985 \pm 0,00474 ; \mathrm{N}=$ 21) e ${ }^{143} \mathrm{Nd} / 144 \mathrm{Nd}_{\text {i }}$ entre 0,51200 e 0,51212 (média =0,51206 $\pm 0,00003 ; \mathrm{N}=17$ ), sendo os maiores valores de contaminação para o subgrupo Santa Maria (Cordani et al., 1988; Petrini et al., 1987; Garland et al., 1995; Polo, 2014). Dentre os magmas tipo B-Ti do sul da PMP apenas o Esmeralda é considerado não contaminado ou fracamente contaminado por possuir razões isotópicas iniciais de $\mathrm{Sr}$ abaixo de 0,7060 .

Diversos modelos têm sido propostos para geração e evolução dos magmas que compõem a Província Magmática do Paraná. Modelos mais antigos propuseram que a geração das rochas ácidas se deu por meio de processos de fusão parcial da crosta inferior (e.g.: Cordani et al., 1980), enquanto outros defendiam a evolução por meio de cristalização fracionada (Mantovani et al., 1985a). Marques (1988) propôs que a variabilidade de quimismo e das razões isotópicas da parte do sul poderia ser explicada por cristalização fracionada com assimilação crustal (AFC), e que a geração dos tipos ácidos Chapecó e Palmas poderia ser resultado de refusão de rochas básicas A-Ti e B-Ti, respectivamente, devido a processos de underplating, com contaminação crustal durante a subida dos magmas. Por outro lado, Garland et al. (1995) explicaram a gênese dos tipos Chapecó a partir de processos de underplating envolvendo fusão parcial de material básico com A-Ti e, no caso das vulcânicas do tipo Palmas, por cristalização fracionada com assimilação crustal a partir de magmas basálticos do tipo B-Ti.

\subsection{Enxame Serra do Mar}

Dentre as características apresentadas na Formação Serra Geral se destacam enxames de diques que bordejam a Bacia do Paraná, a saber, o Enxame da Serra do Mar, o Enxame de Florianópolis e o Enxame do Arco de Ponta Grossa, o 
qual é a exceção, que adentra o continente. Esses enxames de diques têm sido alvo de muitos estudos nos últimos anos por estarem diretamente ligados aos processos de origem e evolução da PMP (e.g.: Piccirillo \& Melfi, 1988; Piccirillo et al., 1990; Marques \& Ernesto, 2004; Guedes et al., 2005; Valente et al., 2007; Coutinho, 2008; Corval, 2009; Florisbal et al., 2014).

O Enxame Serra do Mar (ESM - Figura 2.2), objeto do presente estudo, constitui um importante feixe de diques de diabásio de natureza toleítica que se estende por todo o litoral centro-norte do estado de São Paulo, cobre o litoral do estado do Rio de Janeiro, adentra pelo Vale do Paraíba e com pouca intensidade alcança o litoral sul do Espírito Santo e leste de Minas Gerais (Almeida, 1986). Os diques são subverticais, orientados preferencialmente NE-SW, variando entre $50^{\circ}$ $65^{\circ}$, com espessuras médias inferiores a $50 \mathrm{~m}$ e chegando a ultrapassar $15 \mathrm{~km}$ extensão (Marques, 2001). A maior parte desses diques possui concentrações de $\mathrm{TiO}_{2}>3 \%$ (85\% das ocorrências), sendo que os de composição $\leq 3 \%$ são raros e restritos a algumas áreas específicas. Dentre as litologias presentes destacam-se as de caráter básico (basaltos toleíticos e andesi-basaltos), sendo que os intermediários a ácidos ocorrem restritos ao litoral norte de São Paulo (Bellieni et al., 1990; Garda, 1995; Garda \& Schorscher, 1996).

Estudos petrográficos realizados nos diques revelam que sua composição mineralógica é pouco variável, sendo compostos basicamente por plagioclásio e dois piroxênios, augita e pigeonita, envoltos por uma matriz essencialmente composta pelos mesmos minerais. As litologias básicas $\left(\mathrm{SiO}_{2}<55 \%\right)$ são caracterizadas ainda por minerais opacos e apatita como principais acessórios, bem como por quartzo e olivina alterada em alguns casos como minerais subordinados, enquanto que as intermediárias a ácidas $\left(55 \% \geq \mathrm{SiO}_{2}>63 \%\right.$ e $\mathrm{SiO}_{2} \geq$ 63\%, respectivamente) apresentam óxidos de Fe-Ti (titanomagnetita e ilmenita), além dos descritos anteriormente, e apatita como mineral acessório (Bellieni et al., 1990; Dutra, 2006; Corval, 2009; Garda, 1995; Coutinho, 2008).

Do ponto de vista geoquímico, os diques com $\mathrm{TiO}_{2}>3 \%$ são classificados em três grupos (Marques, 2001): o primeiro com características dos derrames A-Ti do norte da PMP (Pitanga), o segundo semelhante aos derrames A-Ti do sul (Urubici) e o terceiro grupo com características diferentes dos magma-tipo da PMP de acordo com a classificação de Peate et al. (1999), tais como $\mathrm{Sr}>550 \mu \mathrm{g} / \mathrm{g}$; 


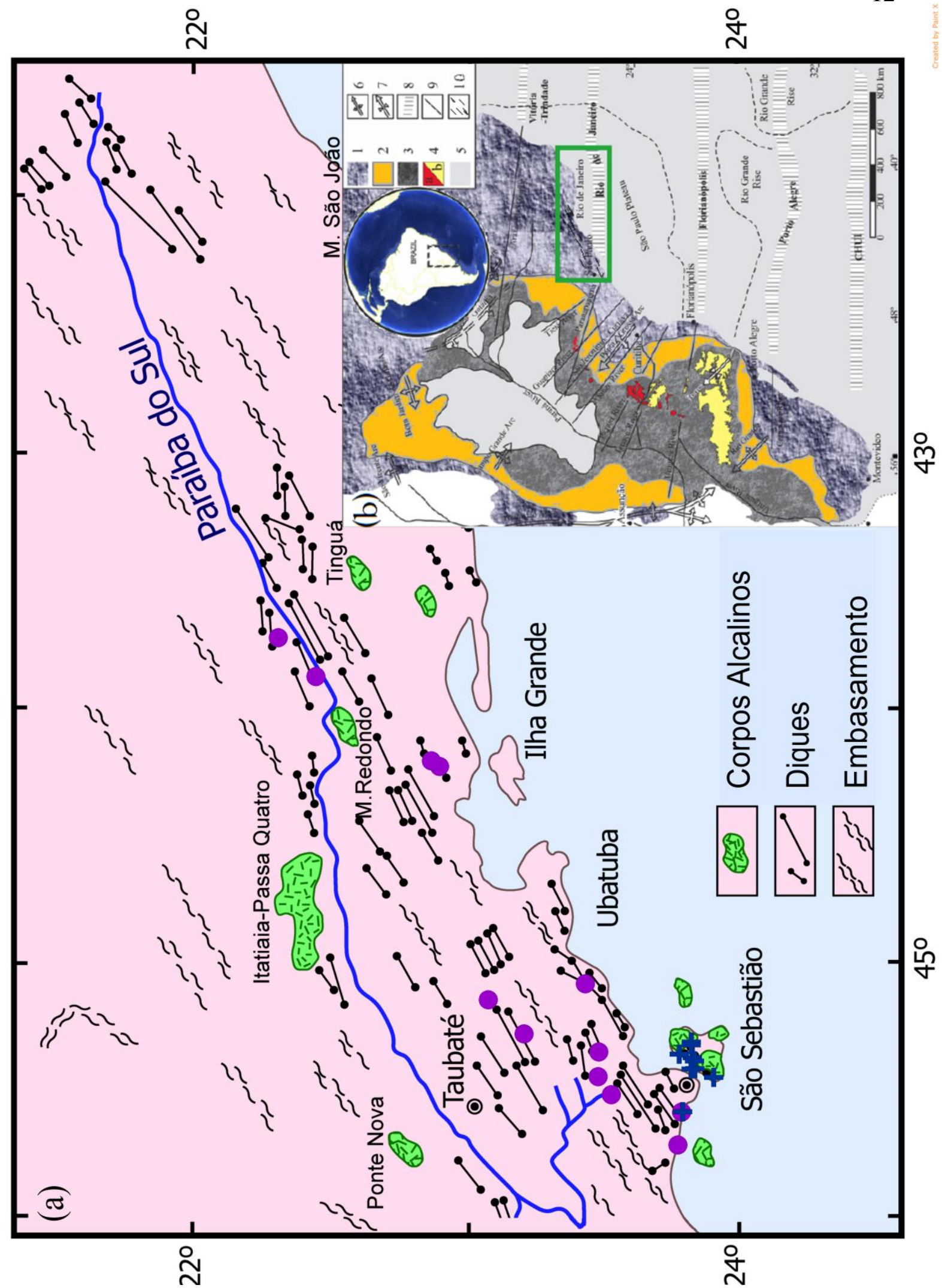

Figura 2.2.: (a) Mapa de localização dos diques do Enxame da Serra do Mar (simplificado de Almeida, 1986), mostrando a localização dos diques intermediários estudados. Legenda: círculo = lati-andesitos; cruz = dacitos e riodacitos. Extraído de Marques (2001). (b) Mapa geológico simplificado da Bacia do Paraná (simplificado de Nardy et al., 2008). Legenda: 1 - Embasamento adjacente; 2 - Sedimentos prévulcânicos; 3 - Derrames basálticos da Formação Serra Geral; 4 - Rochas ácidas da Formação Serra Geral (a: membro Chapecó; b: membro Palmas); 5 - Sedimentos pós-vulcânicos; 6 - Estruturas anticlinais; 7 - Estruturas sinclinais; 8 - Lineamentos oceânicos; 9 - Lineamento tectônico e/ou magnético; 10 - Enxame da Serra do Mar. Extraído de Luchetti et al. (2014). 
$\mathrm{Ti} / \mathrm{Y}<500$; maiores teores de $\mathrm{SiO}_{2}, \mathrm{~K}_{2} \mathrm{O}$ e $\mathrm{P}_{2} \mathrm{O}_{5}$ e menores de $\mathrm{FeO}_{\text {tot }}$ e $\mathrm{CaO}$; maiores concentrações de elementos incompatíveis como $\mathrm{Th}=5,3 \pm 0,2 \mu \mathrm{g} / \mathrm{g}, \mathrm{U}=$ $1,3 \pm 0,1 \mu \mathrm{g} / \mathrm{g}$ e $\mathrm{La}=56 \pm 8 \mu \mathrm{g} / \mathrm{g}$. Os diques com $\mathrm{TiO}_{2} \leq 2 \%$ possuem fortes semelhanças com os derrames B-Ti do sul que sofreram contaminação crustal, ou seja, aqueles que possuem razões ${ }^{87} \mathrm{Sr} /{ }^{86} \mathrm{Sr}_{\mathrm{i}}>0,7060$, com razões $(\mathrm{Ba} / \mathrm{Rb})_{\mathrm{PM}}<1 \mathrm{e}$ fortes anomalias negativas de $\mathrm{Ta}, \mathrm{Nb}, \mathrm{Sr}$ e $\mathrm{Ti}$.

Datações geocronológicas realizadas em litotipos A-Ti fornecem idades entre 129 e 133Ma (Turner et al., 1994; Deckart et al., 1998; Guedes et al., 2005; Corval, 2009), sendo, portanto, ligeiramente mais jovens que os derrames da PMP e também do que os diques tipo B-Ti. Entretanto, estudos realizados em alguns desses diques revelaram idades bem mais antigas do que as demais, atingindo

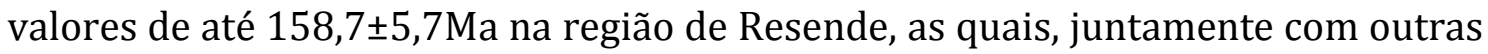
informações geoquímicas e geológicas parecem indicar a ocorrência de um enxame mais antigo na região (Guedes, et al., 2005; Guedes, 2007; Almeida et al., 2013). Algumas idades muito jovens $(60,7 \pm 4,6 \mathrm{Ma})$ foram encontradas por Corval (2009) em diques B-Ti e interpretadas por reaquecimento regional, causado um reset de Ar na amostra, devido ao magmatismo alcalino que ocorreu nessa mesma região no Cretáceo Superior (Almeida, 1986). Por outro lado, Bennio et al. (2003) encontraram na região de Cabo Frio e Arraial do Cabo diques B-Ti cujas idades ${ }^{40} \mathrm{Ar} /{ }^{39} \mathrm{Ar}$ situam-se em torno de 55Ma, sugerindo que tenha ocorrido um magmatismo toleítico neste período. Datações feitas em derrames e diques do tipo B-Ti da Bacia de Kwanza, Angola, que na configuração pré-ruptura do Gondwana estaria adjacente ao Enxame Serra do Mar, forneceram idades de 131,6 $\pm 1,4 \mathrm{Ma}$, $131,9 \pm 1,6 \mathrm{Ma}$ e $126,1 \pm 1,4 \mathrm{Ma}$, utilizando método ${ }^{40} \mathrm{Ar} /{ }^{39} \mathrm{Ar}$ (Marzoli et al., 1999).

Estudos isotópicos revelam que as suítes com $\mathrm{TiO}_{2} \leq 2 \%$ apresentam ${ }^{87} \mathrm{Sr} /{ }^{86} \mathrm{Sr}_{\mathrm{i}}$, corrigido para $130 \mathrm{Ma}$, variando de 0,70365 a 0,71047 (média $=0,70721$ $\pm 0,00241 ; \mathrm{N}=12$ ), ${ }^{143} \mathrm{Nd} /{ }^{144} \mathrm{Nd}_{\mathrm{i}}$ variando de 0,51212 a 0,51261 (média $=0,51233$ $\pm 0,00018 ; \mathrm{N}=10$ ), ${ }^{206} \mathrm{~Pb} /{ }^{204} \mathrm{~Pb}_{\mathrm{i}}$ medido variando de 16,83 a 18,69 (média $=17,93$ $\pm 0,58 ; \mathrm{N}=8$; medido: $17,71-18,39$ ), ${ }^{207} \mathrm{~Pb} /{ }^{204} \mathrm{~Pb}_{\text {i }}$ variando de 15,49 a 15,68 (média $=15,59 \pm 0,08 ; \mathrm{N}=8$; medido: $15,49-15,68),{ }^{208} \mathrm{~Pb} /{ }^{204} \mathrm{~Pb}_{\mathrm{i}}$ variando de 37,68 a 40,32 (média $=38,60 \pm 0,85 ; \mathrm{N}=9$; medido: 37,83-40,38). Já os diques com $\mathrm{TiO}_{2}>3 \%$ têm valores de ${ }^{87} \mathrm{Sr} /{ }^{86} \mathrm{Sr}_{\mathrm{i}}$ entre 0,70531 e 0,70710 (média $=0,70622 \pm 0,00048 ; \mathrm{N}=$ 29), ${ }^{143} \mathrm{Nd} /{ }^{144} \mathrm{Nd}_{\text {i }}$ entre 0,51220 e 0,51260 (média $=0,51231 \pm 0,00007 ; \mathrm{N}=31$ ), 
${ }^{206} \mathrm{~Pb} /{ }^{204} \mathrm{~Pb}$ i entre 16,66 e 18,37 (média $=17,98 \pm 0,39 ; \mathrm{N}=19$; medido: 17,71 18,39 ), ${ }^{207} \mathrm{~Pb} /{ }^{204} \mathrm{~Pb}$ i entre 15,51 e 15,60 (média $=15,56 \pm 0,02 ; \mathrm{N}=19$; medido: 15,52-15,63), ${ }^{208} \mathrm{~Pb} /{ }^{204} \mathrm{~Pb}_{\mathrm{i}}$ entre 35,90 e 38,77 (média $=38,18 \pm 0,58 ; \mathrm{N}=19$; medido: 38,23-38,77) (Garda, 1995; Marques, 2001; Corval, 2009; Marques et al., 2012; Carvas et al., 2014). Estes resultados, associados aos dados geoquímicos, foram interpretados como resultantes de heterogeneidades no manto litosférico subcontinental, e que, em ambos os grupos, processos de contaminação crustal estiveram atuando durante a gênese dessas rochas.

Ainda não há um consenso sobre as fontes mantélicas envolvidas em sua petrogênese, sendo o ESM, juntamente com o Enxame de Florianópolis e o Arco de Ponta Grossa, considerado por Coutinho (2008) como um dos braços da dita junção tríplice do Paraná, originada pelo impacto de uma pluma mantélica. Nesta linha, Garda (1995) defende que os processos de fusão geradores desses diques ocorreram em manto hidratado. Valente et al. (2007) propõem o envolvimento da pluma de Tristão da Cunha em locais onde a litosfera continental estava mais afinada, gerando basaltos toleíticos com assinatura sublitosférica fértil. Analisando suítes de A-Ti e B-Ti deste enxame, Corval (2009) sugere que essas rochas foram geradas por cristalização fracionada com assimilação crustal (AFC), estando envolvidos, em ordem cronológica, manto sublitosférico na geração do A-Ti (pluma) e manto litosférico no caso do B-Ti (calor transferido pelo contato com a pluma).

Guedes (2007) também aponta uma provável fonte enriquecida com pelo menos alguma contribuição do manto litosférico subcontinental, atentando para o fato de que o envolvimento de uma pluma pode ser menor do que o considerado em alguns modelos, uma vez que o magmatismo pode aproveitar, em sua colocação, antigas estruturas que são reativadas pelo evento tectono-magmático. Por outro lado, Marques (2001) aponta, baseado em reconstruções paleomagnéticas e com dados de anomalia de geóide, que a pluma de Tristão da Cunha estaria muito distante há 133Ma (cerca de $1000 \mathrm{~km})$, sendo uma anomalia térmica residual a grande responsável pela geração do calor para a fusão do manto. 


\subsection{Diques de São Sebastião}

Como mencionado anteriormente, na região da Ilha de São Sebastião e áreas adjacentes no litoral norte do estado paulista é observado um grande número de diques intermediários a ácidos, fenômeno bastante peculiar no ESM, por ser somente nesta região que ocorrem litotipos com tais características. Na ilha, esses diques são cortados por corpos mais jovens relacionados ao intenso magmatismo de caráter alcalino ocorrido na mesma região, datado do Cretáceo Superior e com manifestações tardias no Eoceno, representado principalmente por três stocks, na Ilha de São Sebastião, e por um grande número de diques (Almeida, 1986). Apesar de trabalhos de mapeamento haverem sido realizados na região (Freitas, 1947; Damasceno, 1966; Silva et al., 1977; Coutinho, 2008) apenas alguns estudos petrográficos, geoquímicos e isotópicos foram desenvolvidos nessa região (Bellieni et al., 1990; Garda, 1995; Montes-Lauar et al., 1995; Garda \& Schorscher, 1996; Marques et al., 2012; Vicentini et al., 2013, 2014).

Esta região faz parte da Faixa Costeira (ou Complexo Costeiro), unidade que acompanha o litoral de São Paulo e estende-se até o litoral do Espírito Santo, onde gnaisses, granitos e anfibolitos constituem o embasamento Pré-Cambriano (Coutinho, 2008), e está dividida em blocos que apresentam características geológicas distintas, sendo que o Bloco São Sebastião é constituído essencialmente por migmatitos e gnaisses do Pré-Cambriano, diques e sills de diabásio do Cretáceo Inferior e corpos alcalinos do Cretáceo Superior (Mesozóico), corpos alcalinos do Cenozoico e sedimentos de deposição marinha do Quaternário (Almeida, 1986; Almeida et al., 2013). Os diques ocorrem predominantemente nos costões adjacentes ao mar, sendo que na ilha tendem a apresentar maior alteração e na faixa costeira encontram-se geralmente pouco a não alterados, formando pequenos enxames, com espessuras que variam de poucos centímetros a vários metros, distribuídos de maneira irregular. Os diques mais básicos apresentam geralmente textura afanítica e cor cinza-escuro, enquanto os diques diferenciados são quase sempre porfiríticos com tonalidades mais claras de cinza (Garda, 1995; Coutinho, 2008).

Os estudos químicos anteriores realizados nos diques diferenciados (Bellieni et al., 1990; Garda, 1995) mostraram que, de acordo com a nomenclatura proposta por De La Roche et al., (1980), as litologias básicas correspondem a 
andesi-basaltos, latibasaltos e lati-andesitos, enquanto que as mais diferenciadas são definidas como dacitos e riodacitos. As descrições petrográficas, associadas a dados de química mineral, mostraram que a mineralogia dessas rochas é semelhante à dos demais diques do ESM, predominando plagioclásio, augita e titanomagnetita. Os diques básicos apresentam matriz composta pelos mesmos minerais, somados a titanomagnetita, ilmenita e apatita como acessórios, sendo encontrada como mineral subordinado biotita em raros casos. Já os diques mais diferenciados são caracterizados por possuírem cristais de plagioclásio de até $15 \mathrm{~mm}$ e poucos fenocristais de pigeonita, além dos minerais já citados (exceto ilmenita), imersos em matriz de mesma composição, com apatita como acessório. A ocorrência rara de pirita nos tipos porfiríticos, como também de xenólitos das encaixantes, foi também assinalada.

Os dados geoquímicos de elementos traço obtidos por Garda (1995) para essas rochas, no geral, mostram valores relativamente altos de $(\mathrm{La} / \mathrm{Yb})_{\mathrm{N}}$, entre 15 e 18 para as mais diferenciadas, sendo concordantes com Bellieni et al. (1990), que encontraram para os termos básicos $(\mathrm{La} / \mathrm{Yb})_{\mathrm{N}}=9,7 \pm 0,3(\mathrm{~N}=3)$ e para os ácidos $(\mathrm{La} / \mathrm{Yb})_{\mathrm{N}}=17,0 \pm 3,9(\mathrm{~N}=4)$, bem como valores de $\mathrm{Eu} / \mathrm{Eu}^{*}=0,92 \pm 0,04$ para os termos básicos e $\mathrm{Eu} / \mathrm{Eu}^{*}=0,85 \pm 0,09$ para os ácidos. Vicentini et al. (2014), utilizando um maior número de amostras, encontraram para os lati-andesitos $(\mathrm{La} / \mathrm{Lu})_{\mathrm{N}}=27 \pm 5(\mathrm{~N}=7)$, para os dacitos $(\mathrm{La} / \mathrm{Lu})_{\mathrm{N}}=23 \pm 3(\mathrm{~N}=4)$, e para os riodacitos $(\mathrm{La} / \mathrm{Lu})_{\mathrm{N}}=13 \pm 2(\mathrm{~N}=3)$, e anomalias negativas de Eu variando entre 0,74 e 0,99 , com as mais expressivas nos riodacitos. De acordo com esses estudos, são observadas também fortes anomalias de Ti e P, bem como de alguns elementos traço (Sr) e fortemente incompatíveis como $\mathrm{Nb}$ e Ta.

Análises isotópicas nos diques dessa região são escassas, sendo preferencialmente feitas nos alcalinos (e.g.: Bellieni et al. 1990; Garda \& Schorscher, 1996). Os poucos dados disponíveis na literatura mostram indícios de contaminação crustal (duas amostras diferenciadas analisadas por Garda (1995), e corrigidas para $133 \mathrm{Ma}$, têm ${ }^{87} \mathrm{Sr} /{ }^{86} \mathrm{Sr}_{\mathrm{i}}=0,70695$ e 0,70701 e ${ }^{143} \mathrm{Nd} /{ }^{144} \mathrm{Nd}_{\mathrm{i}}=$ 0,51223 e 0,51224; para uma delas foram obtidos ${ }^{206} \mathrm{~Pb} /{ }^{204} \mathrm{~Pb}_{\mathrm{i}}=18,11$, $\left.{ }^{207} \mathrm{~Pb} /{ }^{204} \mathrm{~Pb} \mathrm{~b}_{\mathrm{i}}=15,59,{ }^{208} \mathrm{~Pb} /{ }^{204} \mathrm{~Pb} \mathrm{~b}_{\mathrm{i}}=38,37\right)$.

A gênese dos diques básicos e intermediários dessa região é muito discutida, assim como ocorre no restante do ESM. Estes trabalhos mostram que a 
evolução dessas rochas não está associada a processos de cristalização fracionada simples, haja vista a lacuna composicional observada entre os litotipos básicos e os diferenciados. De modo geral, os dados da literatura sugerem que a gênese e evolução dos diques costeiros de São Sebastião devem estar ligadas diretamente com os mesmos processos ocorridos nos derrames do tipo A-Ti da PMP. 


\section{Metodologias}

Para o desenvolvimento deste estudo foram utilizadas quatro técnicas analíticas distintas: as rochas selecionadas para o estudo já possuíam dados de óxidos maiores, menores e alguns traços previamente obtidos por fluorescência de raios X (FRX), tais como, $\mathrm{Cr}, \mathrm{Ni}, \mathrm{Ba}, \mathrm{Rb}, \mathrm{Sr}, \mathrm{La}, \mathrm{Ce}, \mathrm{Nd}, \mathrm{Zr}$, Y e Nb. Depois de realizada a cominuição das amostras, foram selecionadas alíquotas para a determinação de elementos terras raras (ETR) e outros elementos traço por ativação com nêutrons térmicos ( $\mathrm{La}, \mathrm{Ce}, \mathrm{Nd}, \mathrm{Sm}, \mathrm{Eu}, \mathrm{Yb}, \mathrm{Lu}, \mathrm{Th}, \mathrm{Sc}$ e Co) e epitérmicos (Tb, U, Cs, Rb, Ta, $\mathrm{Ba}$ ). Para comparação, bem como para determinação de $\mathrm{Pb}$, um grupo de amostras foi submetido à espectrometria de massa com fonte de plasma induzido (ICP-MS), que além dos elementos analisados por ativação com nêutrons e do $\mathrm{Pb}$, permitiu determinar Sr, Y, Zr, Nb, Pr, Gd, Dy, Ho, Er e Tm. Finalmente, a espectrometria de massa termoiônica foi usada para a investigação isotópica dos sistemas $\mathrm{Rb}-\mathrm{Sr}$, Sm$\mathrm{Nd}$ e U-Pb. Dentre as técnicas citadas foi dada maior ênfase na ativação com nêutrons e em seus resultados, pelo envolvimento direto do autor na preparação, medidas e tratamento dos dados. As demais foram feitas por laboratórios especializados.

\subsection{Seleção e localização das amostras}

As amostras selecionadas foram aquelas em que já havia determinação de óxidos maiores, menores e alguns traços por meio da técnica de fluorescência de raios $\mathrm{X}$, realizados na Universidade de Trieste, Itália. Buscou-se investigar aquelas que possuíam $\mathrm{SiO}_{2}>55 \%$ ou $\mathrm{MgO}<3 \%$ e $\mathrm{TiO}_{2}>1,0 \%$ (5 amostras), incluindo-se alguns litotipos básicos para que fossem feitas as comparações nos modelos (6 amostras). Também se incluiu aquelas estudadas por Vicentini (2013) que apresentavam essas características, 13 no total, sendo que 6 amostras eram pertencentes à coleção investigada por Bellieni et al. (1990), constantes da litoteca do Instituto de Geofísica, Astronomia e Ciências Atmosféricas da Universidade de São Paulo (IAG-USP). No total, foram utilizadas 24 amostras neste estudo (dentre as quais 18 têm caráter mais diferenciado) e estão localizadas na região da Ilha de São Sebastião e na área costeira adjacente, conforme mostra a Figura 2.2. 


\subsection{Cominuição das amostras}

Seguindo a rotina experimental desenvolvida por Marques $(1988,2001)$ e Vicentini (2013), para a realização das análises químicas é necessário que a amostra seja reduzida a uma granulometria inferior a 100 mesh (cerca de 0,15mm de diâmetro). Para isso, as amostras foram primeiramente localizadas na litoteca do IAG-USP e, com auxílio de uma prensa mecânica EMIC, os maiores blocos de algumas amostras foram reduzidos para que se pudesse manuseá-los no copo de ferro (aproximadamente $15 \mathrm{~cm}$ de diâmetro). Com as frações em mãos, seguiu-se o trabalho utilizando martelo e copo de ferro para reduzir cuidadosamente estes fragmentos a grãos de aproximadamente $1,0 \mathrm{~cm}$, evitando-se ao máximo a pulverização do material, que mais tarde seria peneirado em malha de 60 mesh (abertura da malha: 0,250mm) e descartado. É importante destacar que durante estas duas etapas (prensa e martelo) removeu-se completamente as superfícies alteradas e/ou com serra, uma vez que seria determinado $\mathrm{Pb}$ para análises isotópicas, elemento contaminante nos processos de serragem (Marques et al., in press). Cerca de $150 \mathrm{~g}$ de cada rocha foram separados nesta fase.

Na próxima etapa, o material britado passou por uma primeira peneira de 60 mesh, de marca "a bronzinox", e o que ficou retido foi lavado com água comum e água deionizada. No trabalho anteriormente citado os autores sugerem que amostras com concentração de $\mathrm{Pb}<7 \mu \mathrm{g} / \mathrm{g}$ devem ser rigorosamente lavadas antes da pulverização, além da remoção das capas de alteração e/ ou superfícies contaminadas com serra. Porém, como as rochas investigadas possuem caráter intermediário as concentrações desse elemento são maiores do que o valor limite, optando-se por não realizar a lavagem. A amostra B-1111 (textura afanítica e com fratura conchoidal) foi a única exceção devido ao fato de apresentar muita alteração mesmo no interior do bloco, optando-se por lavá-la com ácido $\mathrm{HNO}_{3}$ $0,1 \mathrm{M}$, além da água comum e deionizada. Em seguida as amostras foram levadas à secura em estufa a $60^{\circ} \mathrm{C}$.

A seguir, os fragmentos foram quarteados, uma fração foi arquivada, e outra foi pulverizada em moinho de ágata mecânico e de marca Fritsh - modelo pulverisette. A fração foi colocada aos pouco no copo de ágata do moinho, ligandose o aparelho por cerca de 2 minutos; depois, o pó foi peneirado na malha de 100 mesh (abertura da malha: 0,150mm) e o que ficou retido foi depositado novamente 
no copo do moinho juntamente com mais material britado. Este procedimento foi repetido até que restasse uma pequena fração retida na malha, sendo inviável a utilização do moinho mecânico. Assim sendo, foi necessário pulverizar manualmente o restante, usando almofariz e pistilo de ágata, até que toda a fração atingisse granulometria igual ou inferior a 100 mesh.

Finalmente, o pó foi submetido a um processo de homogeneização dos grãos, no qual ele foi colocado em uma folha de papel, sendo dobrada repetidamente por 5 minutos para que os grãos dos diferentes minerais se misturassem. A separação das alíquotas que foram analisadas nos diferentes laboratórios (IPEN/CNEN e IGc) foi realizada novamente por um processo de quarteamento.

Antes de iniciar o procedimento de britagem e pulverização das amostras foi realizado o mesmo processo com uma rocha (diabásio) proveniente de um dique do Arco de Ponta Grossa, também pertencente à PMP, para evitar contaminação devido à pulverização de amostras anteriormente analisadas que ficaram impregnadas nos materiais utilizados (martelo, copo de ferro, pinça, pincel, peneiras de malhas 60 e 100 mesh, pistilo e almofariz de ágata). Além disso, uma pequena fração da própria amostra foi submetida a este processo imediatamente antes da cominuição, a fim de se evitar ao máximo a contaminação cruzada, ou seja, aquela oriunda de outra amostra previamente submetida à pulverização.

\subsection{Fluorescência de Raios X}

A espectrometria de fluorescência de raios X é uma técnica não destrutiva que busca obter espectros característicos ocasionados pela interação dos raios X (ondas eletromagnéticas da ordem de ângstrons - 10-10 m) com o material investigado. 0 princípio físico desta técnica baseia-se na interação entre as ondas eletromagnéticas emitidas por uma fonte externa e os elétrons das camadas mais internas dos átomos (K, L ou $\mathrm{M}$ em alguns casos). Quando um fóton de raios $\mathrm{X}$ energético interage com um átomo, pode ocorrer a energização de um elétron, culminando em sua expulsão dos orbitais. Com isso, acontecem transições internas 
e elétrons de camadas adjacentes migram para preencher as lacunas deixadas e, neste processo, é liberada energia em forma de raios X que são característicos de cada elemento e camada. Essa radiação permite investigar de modo qualitativo e quantitativo uma série de elementos químicos.

O equipamento utilizado foi um espectrômetro Philips PW 1404, tipo WDXRF (Wavelength Dispersive X-ray Fluorescence), da Universidade de Trieste, Itália, e os elementos identificados por este método foram: $\mathrm{Si}, \mathrm{Ti}, \mathrm{Al}, \mathrm{Fe}, \mathrm{Mn}, \mathrm{Mg}, \mathrm{P}$, $\mathrm{Ca}, \mathrm{Na}, \mathrm{K}, \mathrm{Cr}, \mathrm{Ni}, \mathrm{Ba}, \mathrm{Rb}, \mathrm{Sr}$, La, Ce, Nd, Zr, Y e Nb. Os valores de perda ao fogo foram obtidos por gravimetria, após aquecimento $\left(1100{ }^{\circ} \mathrm{C}\right)$ durante 12 horas, corrigidos para a oxidação do $\mathrm{Fe}^{2+}$. A precisão relativa é de 2-5\% para os óxidos de elementos maiores e menores, e inferior a 10\% para os traços.

\subsection{Ativação Neutrônica}

\subsubsection{Princípios}

O emprego da técnica de análise por ativação neutrônica permite que se obtenham valores de concentração dos elementos constituintes da amostra independentemente da forma química em que se encontrem. No caso do bombardeamento dos núcleos atômicos com nêutrons, pelo fato de estes não serem carregados eletricamente, não há interferência por parte dos prótons (cargas positivas) constituintes do núcleo atômico, diminuindo então a energia necessária para que haja interação. Desta forma, submetendo-se os núcleos dos isótopos presentes em um fluxo constante de nêutrons, ocorrerão colisões que desestabilizarão estes átomos, formando-se assim nuclídeos radioativos. Devido à desestabilidade gerada, o nuclídeo irá emitir partículas e/ou energia a fim de se tornar estável novamente, as quais podem ser detectadas, sendo características de cada elemento e proporcionais à sua quantidade.

Dependendo da energia dos nêutrons bombardeados e dos núcleos atingidos diferentes reações são observadas, sendo as mais comuns as seguintes (Handbook of Nuclear Chemistry, 2003):

- $\quad$ reação $(\mathrm{n}, \gamma): X_{Z}^{A}+n \rightarrow X_{Z}^{A+1}+\gamma$

- $\quad$ reação $(\mathrm{n}, 2 \mathrm{n}): X_{Z}^{A}+n \rightarrow X_{Z}^{A-1}+2 n$

- $\quad \operatorname{reação~(n,~p):~} X_{Z}^{A}+n \rightarrow X_{Z-1}^{A}+p$ 
- $\quad \operatorname{reação~}(\mathrm{n}, \alpha): X_{Z}^{A}+n \rightarrow X_{Z-2}^{A-3}+\alpha$

onde $\mathrm{A}=$ número de massa; $\mathrm{Z}=$ número atômico; $\mathrm{n}=$ nêutron; $\mathrm{p}=$ próton; $\alpha=$ partícula alfa; $\gamma=$ emissão gama.

Existem três faixas de energia que classificam os nêutrons em grupos, e cada uma delas favorece um tipo de reação (Alfassi, 1990). São eles:

- nêutrons térmicos - apresentam energias mais baixas, variando de 0 a 0,026 eV. Tratando-se de uma fonte de nêutrons de alta energia, pode-se gerar este tipo de nêutron usando uma barreira (moderador) entre a fonte e o alvo constituída de um elemento que possua alta seção de choque para tais partículas. Favorecem as reações do tipo (n, $\gamma$ ) por serem facilmente absorvidos;

- nêutrons epitérmicos - possuem energias intermediárias, as quais estão entre 0,027 e $1000 \mathrm{eV}$. São importantes pelo fato de vários isótopos possuírem altas seções de choque para nêutrons com essas energias, especialmente com $\mathrm{Z}>30$. Favorecem as reações do tipo $(\mathrm{n}, \gamma)$;

- nêutrons rápidos - correspondem às mais altas energias, ou seja, maiores que $1 \mathrm{keV}$. Caracterizam-se pelas baixas seções de choque de absorção, por isso induzem reações tipo $(n, 2 n),(n, p)$ e $(n, \alpha)$.

\subsubsection{Materiais de Referência}

No método comparativo, é possível calcular as concentrações dos elementos desejados utilizando a seguinte relação:

$$
C_{a}^{i}=\frac{A_{a}^{i} \cdot M_{p} \cdot C_{p}^{i} \cdot e^{\lambda t}}{A_{p}^{i} \cdot M_{a}}
$$

onde, $\mathrm{C}_{\mathrm{a}}^{\mathrm{i}}$ é a concentração do elemento $\mathrm{i}$ na amostra; $\mathrm{A}_{\mathrm{a}}^{\mathrm{i}}$ é a atividade do radioisótopo considerado na amostra no tempo $\mathrm{t}=\mathrm{t}$; $\mathrm{A}_{\mathrm{p}}^{\mathrm{i}}$ é a atividade do radioisótopo considerado no material de referência no tempo $t=0 ; M_{a}$ e $M_{p}$ são as massas, respectivamente da amostra e do material de referência; $\mathrm{C}_{\mathrm{p}}^{\mathrm{i}}$ é a concentração do elemento i no material de referência; t é o tempo decorrido entre 
a contagem da amostra e a do material de referência e $\lambda$ a constante de decaimento do radioisótopo formado.

Pelo fato de se tratar de uma técnica comparativa, é necessário introduzir materiais de referência certificados a cada conjunto de amostras que serão irradiadas, para que seja possível aplicar a equação (I) e calcular as concentrações. Deste modo, optou-se por utilizar os seguintes materiais geológicos de referência: basalto BE-N, fornecido pelo International Working Group - Group International de Travail (IWG-GIT) e o granito GS-N, fornecido pela Association Nationale de La Recherche Technique (ANRT) (Govindaraju, 1994), por se tratarem de silicatos com composições bem distintas, abrangendo as concentrações dos elementos investigados nas amostras deste estudo. Um terceiro padrão de basalto, denominado BRP-1 (Basalto Ribeirão Preto - lote 1), certificado pelo Instituto de Geociências da Universidade Estadual de Campinas (Cotta et al., 2008) foi também empregado para melhorar a qualidade estatística dos dados. Este padrão foi escolhido por se tratar de uma rocha basáltica da Província Magmática do Paraná, possuindo características geoquímicas bastante próximas às das rochas estudadas. A Tabela 3.1 mostra as concentrações de cada elemento analisado em cada um dos materiais de referência utilizados.

\subsubsection{Medidas da Atividade Gama Induzida}

No caso da irradiação em um reator nuclear, todas as reações ocorrem simultaneamente, sendo importante delimitar o tipo de medida que está se buscando (detecção de energia ou partícula). Para esta investigação, utilizou-se espectrometria de raios gama, portanto, os nêutrons interessantes ao estudo são os térmicos e os epitérmicos, que favorecem as reações $(n, \gamma)$. 0 segundo grupo (nêutrons mais energéticos) é usado para a determinação dos elementos $\mathrm{U}, \mathrm{Cs}, \mathrm{Rb}$, $\mathrm{Tb}$ e Ta pelo fato de serem muito mascarados pela radiação gama emitida pelo $\mathrm{K}$ nas ativações térmicas, por exemplo. Para barrar os nêutrons térmicos, empregase uma placa de cádmio como absorvedor de nêutrons desse tipo, colocando-a entre a fonte emissora de nêutrons e o alvo (amostras). Desse modo, permite-se que, preferencialmente, os nêutrons epitérmicos irradiem as amostra (Figueiredo \& Marques, 1989). Os elementos determinados por meio de irradiação térmica são 
La, Ce, Nd, Sm, Eu, Yb, Lu, Hf, Cs, Sc e Co. A Tabela 3.2 mostra as características principais dos radioisótopos que foram usados nas determinações de todos os elementos estudados, assim como o tipo de ativação utilizada para cada uma delas.

Tabela 3.1.: Valores certificados dos materiais de referência usados nas irradiações $(\mu \mathrm{g} / \mathrm{g})$ com valores de 1 desvio padrão (erro associado). Retirados de Govindaraju (1994) - BE-N e GS-N; e Cotta et al. (2008) - BRP-1.

\section{$\begin{array}{llll}\text { Elemento } & \text { BRP-1 } & \text { GS-N } & \text { BE-N }\end{array}$}

\begin{tabular}{|c|c|c|c|}
\hline La & $42,6 \pm 0,5$ & $75,00 \pm 1,35$ & $82,00 \pm 0,75$ \\
\hline Ce & $93,3 \pm 0,6$ & $135,0 \pm 3,5$ & $152 \pm 2$ \\
\hline Sm & $51,90 \pm 0,45$ & $49,00 \pm 0,75$ & $67,00 \pm 0,75$ \\
\hline Eu & $11,2 \pm 0,1$ & $7,50 \pm 0,11$ & $12,20 \pm 0,15$ \\
\hline Tb & $3,42 \pm 0,04$ & $1,70 \pm 0,03$ & $3,60 \pm 0,09$ \\
\hline Yb & $1,52 \pm 0,03$ & $0,60 \pm 0,02$ & $1,30 \pm 0,05$ \\
\hline Lu & $0,48 \pm 0,05$ & $1,40 \pm 0,08$ & $1,8 \pm 0,1$ \\
\hline U & $0,82 \pm 0,02$ & $7,5 \pm 0,4$ & $2,40 \pm 0,09$ \\
\hline Th & $3,97 \pm 0,05$ & $41,00 \pm 1,75$ & $10,40 \pm 0,33$ \\
\hline Ba & $555,0 \pm 3,5$ & $1400 \pm 22$ & $1025 \pm 15$ \\
\hline Hf & $8,0 \pm 0,1$ & $6,20 \pm 0,17$ & $5,60 \pm 0,08$ \\
\hline Cs & $0,37 \pm 0,02$ & $5,40 \pm 0,13$ & $0,80 \pm 0,05$ \\
\hline Sc & $28,5 \pm 0,4$ & $7,3 \pm 0,2$ & $22,00 \pm 0,75$ \\
\hline Rb & $35,4 \pm 0,5$ & $185,0 \pm 2,5$ & $47 \pm 1$ \\
\hline Co & $37,5 \pm 0,7$ & $65 \pm 2$ & $60 \pm 1$ \\
\hline Ta & $1,96 \pm 0,04$ & $2,6 \pm 0,1$ & $5,7 \pm 0,2$ \\
\hline & & & \\
\hline & & $0,22 \pm 0,02$ & 0,02 \\
\hline
\end{tabular}

Como pode ser observado na Tabela 3.2, os radioisótopos com os quais se calculam as concentrações de U e Th são, respectivamente, ${ }^{239} \mathrm{~Np}$ e ${ }^{233} \mathrm{~Pa}$, seguindo as seguintes reações: 


$$
\begin{aligned}
& { }_{92}^{238} U+{ }_{0}^{1} n \rightarrow{ }_{92}^{239} U \stackrel{\beta-}{\longrightarrow}{ }_{93}^{239} \mathrm{~Np} \stackrel{\beta-}{\longrightarrow}{ }_{94}^{239} \mathrm{Pu} \rightarrow \cdots \\
& { }_{90}^{232} \mathrm{Th}+{ }_{0}^{1} n \rightarrow{ }_{90}^{233} \mathrm{Th} \stackrel{\beta-}{\longrightarrow}{ }_{91}^{233} \mathrm{~Pa} \stackrel{\beta-}{\longrightarrow}{ }_{92}^{233} \mathrm{U} \rightarrow \ldots
\end{aligned}
$$

Tabela 3.2.: Elementos analisados e características principais de seus radioisótopos.

\begin{tabular}{|c|c|c|c|c|c|}
\hline $\mathrm{Ba}$ & ${ }^{131} \mathrm{Ba}$ & $11,5 d$ & 496,3 & $15-30$ & Epitérmica \\
\hline $\mathrm{Ce}$ & ${ }^{141} \mathrm{Ce}$ & $32,5 d$ & 145,4 & $15-30$ & Térmica \\
\hline Co & ${ }^{60} \mathrm{Co}$ & $5,24 a$ & 1332,2 & $15-30$ & Térmica \\
\hline Cs & ${ }^{134} \mathrm{Cs}$ & $2,7 a$ & 795,8 & $15-30$ & Epitérmica \\
\hline Eu & ${ }^{152} \mathrm{Eu}$ & $12,2 \mathrm{a}$ & 1407,5 & $15-30$ & Térmica \\
\hline Hf & ${ }^{181} \mathrm{Hf}$ & $44,6 d$ & 482,2 & $15-30$ & Térmica \\
\hline La & ${ }^{140} \mathrm{La}$ & $47,27 \mathrm{~h}$ & $\begin{array}{c}328,6 \\
1595,4\end{array}$ & $4-7$ & Térmica \\
\hline Lu & ${ }^{177} \mathrm{Lu}$ & $6,75 d$ & 208,4 & $4-7$ & Térmica \\
\hline Nd & ${ }^{147} \mathrm{Nd}$ & $11,1 \mathrm{~d}$ & $\begin{array}{l}91,4 \\
531\end{array}$ & $4-7$ & Térmica \\
\hline $\mathbf{R b}$ & ${ }^{86} \mathrm{Rb}$ & $18,66 \mathrm{~d}$ & 1076,6 & $15-30$ & Epitérmica \\
\hline Sc & ${ }^{46} \mathrm{SC}$ & $83,9 \mathrm{~d}$ & 889,4 & $15-30$ & Térmica \\
\hline Sm & ${ }^{153} \mathrm{Sm}$ & $47,1 \mathrm{~h}$ & 103,2 & $4-7$ & Térmica \\
\hline $\mathrm{Ta}$ & ${ }^{182} \mathrm{Ta}$ & $115,1 d$ & $\begin{array}{l}1188,8 \\
1221,6\end{array}$ & $15-30$ & Epitérmica \\
\hline Tb & ${ }^{160} \mathrm{~Tb}$ & $73 d$ & 879,4 & $15-30$ & Epitérmica \\
\hline Th & ${ }^{233} \mathrm{~Pa}$ & $27 d$ & 311,8 & $15-30$ & Térmica \\
\hline $\mathbf{U}$ & ${ }^{239} \mathrm{~Np}$ & $2,35 d$ & 277,5 & $4-7$ & Epitérmica \\
\hline Yb & ${ }^{175} \mathrm{Yb} \quad{ }^{169} \mathrm{Yb}$ & $\begin{array}{l}101 \mathrm{~h} \\
30,6 \mathrm{~d}\end{array}$ & $\begin{array}{l}396,1 \\
197,8\end{array}$ & $\begin{array}{lll}4-7 & & 15- \\
& 30 & \end{array}$ & Térmica \\
\hline
\end{tabular}

$\begin{array}{cccccc}\text { Elemento } & \begin{array}{c}\text { Radioisótopo } \\ \text { medido }\end{array} & \text { Meia-vida } & \begin{array}{c}\text { Principais } \\ \text { Energias } \\ (\mathrm{keV})\end{array} & \begin{array}{c}\text { Tempo de } \\ \text { decaimento } \\ \text { para } \\ \text { contagem } \\ \text { (d) }\end{array} & \begin{array}{c}\text { Tipo de } \\ \text { irradiação } \\ \text { usada }\end{array} \\ \end{array}$




\subsubsection{Rotina Experimental}

A rotina experimental adotada para irradiação foi desenvolvida segundo Marques (1988), Figueiredo \& Marques (1989) e Vicentini (2013). Após o processo de cominuição no Laboratório de Geofísica Nuclear do IAG-USP (seção 3.4.2.), o material separado para a análise por ativação com nêutrons, cerca de $50 \mathrm{~g}$, foi encaminhado para o laboratório de preparação de amostras do Centro de Reator de Pesquisa (CRPq) do Instituto de Pesquisas Energéticas Nucleares (IPENCNEN/SP).

Primeiramente foi necessário confeccionar os envoltórios plásticos onde o pó é depositado. Para isso, pegou-se um invólucro plástico grande do tipo "ZipLock" e, envolvendo-o em papel celofane para que não derretesse, fez-se as marcações no plástico, com auxílio de uma seladora "Selapack", de forma a confeccionar "saquinhos" de aproximadamente $2 \mathrm{~cm} \mathrm{X} 3 \mathrm{~cm}$. Com os saquinhos em mãos, o material foi inserido nos mesmos, com auxílio de pinças e uma espátula de metal, e foi pesado com exatidão cerca de 0,100g em balança analítica OHAUS (modelo AR2140, ano 2006), sendo, depois, o invólucro plástico lacrado com a seladora sem deixar bolhas de ar dentro. Para evitar que o plástico derretesse durante o aquecimento na irradiação e rasgasse no momento de preparar as amostras para contagem, foram utilizados dois saquinhos por amostra, um dentro do outro. A fim de evitar que a amostra fosse contaminada pela água do reator, verificou-se a presença de furos esguichando-se um pouco de álcool nos invólucros, buscando-se observar se havia mudança na coloração do pó devido à absorção do álcool.

Uma vez devidamente embaladas, as amostras foram codificadas e embrulhadas em papel alumínio, que também recebeu a mesma codificação, evitando-se, também dessa forma, o contato e a possível fusão entre os diferentes plásticos. A seguir, os embrulhos foram alinhados e colocaram-se, entre as amostras, nas posições centrais da fileira de saquinhos, os padrões a serem irradiados juntamente com o material a ser investigado, preparando-os da mesma forma que as demais. Este conjunto foi embrulhado novamente com papel alumínio, para que ficasse fixo, e foi colocado em um cilindro também de alumínio 
denominado "coelho". O alumínio foi escolhido como elemento envoltório por ter meia vida curta (minutos) e, portanto, por perder atividade rapidamente após sua ativação, sendo simples de lidar como lixo radioativo. Nos casos de irradiação epitérmica, foi inserido um envoltório de cádmio dentro do coelho de forma a envolver em todas a direções as amostras (dois discos, um por cima e outro por baixo, e uma folha de Cd enrolada em forma cilíndrica).

Finalmente, o coelho contendo as amostras e os padrões certificados é entregue para ser submetido à irradiação no reator nuclear de pesquisas do IPEN, IEA-R1, por um período de $8 \mathrm{~h}$, sob um fluxo de 3 a $5 \times 10^{12} \mathrm{n} / \mathrm{cm}^{-2} \mathrm{~s}^{-1}$. Após um período mínimo de espera de 5 dias os elementos mais ativos diminuem significativamente sua atividade e é possível manusear as amostras. Então, abre-se o coelho, os saquinhos são desembrulhados e colocados em discos que serão levados ao detector.

Para se medir a atividade gama induzida foi usado um detector de Ge hiperpuro GX20190, Canberra, com resolução nominal de 1,90 keV para o pico de $1332 \mathrm{keV}$ do ${ }^{60} \mathrm{Co}$, ligado a uma placa multicanal 8192 Canberra S-100 e eletrônica associada, e o software de análise de espectro de raios gama utilizado foi o VISPECT, desenvolvido pelo Laboratório de Análise por Ativação Neutrônica (LANIPEN). 0 detector possui 4 níveis para se realizarem as contagens, ou seja, prateleiras onde os discos contendo as amostras podem ser colocados de acordo com sua atividade no momento da contagem. 0 parâmetro determinante para a escolha do nível é o "tempo morto", fornecido pelo próprio software de análise espectral, sendo aceitável níveis de até 5-10\%. Este parâmetro indica o quanto o detector é capaz de separar a leitura de duas emissões beta, ou seja, quanto tempo é "perdido" entre uma detecção e outra. Assim, quanto maior a atividade de um material a ser analisado mais distante do detector ele deve estar, porém esta distância deve ser a menor possível para que se respeite a geometria de análise do detector.

Nas irradiações térmicas, durante a primeira contagem (5-7 dias após a irradiação), foi medida a atividade gama na primeira prateleira e o tempo de contagem foi de aproximadamente 50 minutos, enquanto que na segunda contagem (12-15 dias após a irradiação) a atividade gama foi medida a partir da prateleira zero (nível mais próximo do detector) com o mesmo tempo de 
contagem. Já nas irradiações epitérmicas, pelo fato das amostras estarem menos ativas, as contagens foram realizadas na prateleira zero e o tempo de contagem variou de 50 minutos, nos casos em que os picos dos elementos desejados eram detectados com maior facilidade, até 120 minutos, nos casos mais difíceis de se detectar. Nestes casos mais complicados foi deixado, pelo menos uma vez, a amostra em contagem durante toda a noite ( 6 a 8 horas). Vale ressaltar que todas as amostras foram analisadas pelo menos três vezes em irradiações diferentes, com três materiais de referências distintos em todas elas, para que houvesse parâmetros estatísticos na determinação de cada elemento a ser investigado.

\subsection{Espectrometria de Massa com Fonte de Plasma Induzido (ICP-MS)}

A espectrometria de massa com fonte de plasma induzido, ou ICP-MS, é uma técnica de análise elementar que foi comercialmente introduzida em 1983 e tem grande utilidade para geoquímica analítica, devido aos baixos limites de detecção que consegue atingir, principalmente para elementos terras raras $(0,1$ a 1 ng/g - Wolf, 2005 - USGS). A fonte de plasma induzido utiliza-se basicamente de uma fonte de rádio frequência oscilante que está acoplada a uma bobina na extremidade de uma tocha de quartzo. Este mecanismo foi usado inicialmente como fonte de excitação de elétrons (ICP-AES), sendo que o plasma tinha seu início numa descarga elétrica e era sustentado pela oscilação do campo magnético gerado pela fonte de rádio num ambiente com gás inerte, geralmente argônio. Mais tarde, buscando aliar a rapidez do sistema AES a uma técnica mais sensível que apresentasse espectros mais simples, adaptou-se o ICP para que ionizasse átomos, passando então a medir a relação massa/carga dos íons gerados.

Nas análises por ICP-MS as amostras podem ser introduzidas em estado sólido, líquido ou gasoso, sendo mais comum em estado líquido (via líquida ou via úmida), onde se faz uso de uma bomba peristáltica que bombeia o líquido até um nebulizador que o transforma em uma fina névoa. 0 plasma é gerado por uma descarga elétrica e se sustenta devido à oscilação do campo magnético, geralmente na frequência de 27 ou $40 \mathrm{MHz}$, o que acelera íons e elétrons do plasma, gerando colisões entre si e com os átomos presentes na tocha, e ionizando o gás. As 
temperaturas típicas do plasma de argônio variam entre 6000 - $10000 \mathrm{~K}$ e geram íons os quais são tipicamente positivos $\left(\mathrm{M}^{+}\right.$ou $\left.\mathrm{M}^{+2}\right)$, sendo, portanto, muito difícil a detecção de elementos que formam ânions como $\mathrm{Cl}$, I e F.

A interface é constituída de dois cones que são responsáveis por transferir os íons do plasma para uma região de médio vácuo $\left(10^{-4} \mathrm{mbar}\right)$ para uma região de alto vácuo $\left(10^{-7} \mathrm{mbar}\right)$, onde se encontra o sistema analisador, que é responsável por separar os íons de acordo com a sua razão massa/carga (m/e).

O equipamento utilizado foi o ICP-MS Perkin Elmer, modelo Elan 6100, analisador quadrupolo, do Laboratório de Química e ICP do Instituto de Geociências da Universidade de São Paulo, e os elementos analisados foram: $\mathrm{Rb}, \mathrm{Sr}$, Y, Zr, Nb, Cs, Ba, La, Ce, Pr, Nd, Sm, Eu, Gd, Tb, Dy, Ho, Er, Tm, Yb, Lu, Hf, Ta, Pb, Th e U.

0 erro das análises (precisão) foi de até 7\% para os elementos traço (maioria abaixo de 4\%). Para o cálculo da precisão foram utilizados os valores fornecidos no laudo do laboratório (o valor da concentração de cada elemento é a média de três medidas, e a precisão o desvio padrão relativo). Já para o cálculo da exatidão foi utilizado o desvio relativo em relação ao basalto BR analisados juntamente com as amostras, material de referência geológico certificado pelo CRPG, Centre de Rechèrches Pétrographiques et Géochimiques (França). Os desvios em relação aos valores recomendados foram inferiores a 3\% para a maior parte dos elementos, atingindo $11 \%$ apenas em um caso, o $\mathrm{Pb}$.

\subsection{Espectrometria de Massa de Termoionização (TIMS)}

A espectrometria de massa de termoionização difere do ICP-MS apenas devido à fonte ionizante (fonte térmica, neste caso), apresentando os mesmos princípios. As medidas das razões isotópicas de $\mathrm{Sr}, \mathrm{Nd}$ e $\mathrm{Pb}$ foram realizadas no Centro de Pesquisas Geocronológicas do Instituto de Geociências da Universidade de São Paulo (CPGeo - USP), seguindo os procedimentos descritos em Kawashita (1972), para separação do elemento Sr, em Sato et al. (1995), para Nd, e Babinski et al. (1999) e Marques et al. (1999; 2003) para Pb. Neste último caso, existe uma preocupação maior devido à possibilidade da contaminação durante os processos de cominuição, porém, como já citado anteriormente, para concentrações mais 
elevadas desse elemento ( > $10 \mu \mathrm{g} / \mathrm{g}$ para as intermediárias analisadas), não é necessário o procedimento de lavagem das amostras com ácido.

A separação química envolve o ataque das amostras com ácidos $\left(\mathrm{HNO}_{3}, \mathrm{HF}\right.$ e $\mathrm{HCl}$ ) e a passagem das soluções em colunas de troca aniônica específicas para cada um dos elementos. A solução retirada das colunas é depositada em um filamento metálico, o qual é aquecido a altas temperaturas fazendo com que os átomos ou moléculas neste metal evaporem e produzam íons (efeito termoiônico). O elemento Re (rênio) é escolhido como metal mais indicado para tal por ser um material que possui alta função trabalho, ou seja, pode ser aquecido a altas temperaturas sem que os elétrons sejam ionizados devido ao efeito termoiônico, e ao mesmo tempo apresenta um alto ponto de fusão, uma vez que os íons são produzidos no espectrômetro, a análise ocorre da mesma forma que no ICP-MS.

As medidas das razões de $\mathrm{Sr}$ foram obtidas com um espectrômetro TIMS TRITON, sendo que as razões isotópicas ${ }^{87} \mathrm{Sr} /{ }^{86} \mathrm{Sr}$ foram normalizadas para o valor de ${ }^{86} \mathrm{Sr} /{ }^{88} \mathrm{Sr}=0,1194$. 0 branco de $\mathrm{Sr}$ durante as análises foi de $215 \mathrm{pg}$, a precisão foi de até $0,007 \%(2 \sigma)$ e o padrão de referência NBS-987, analisado para comparação, forneceu um valor médio de 0,710233 $\pm 0,000022$ durante o período de junho/2014 a maio/2015 (exatidão de 0,003\%). Já as medidas das razões de $\mathrm{Nd}$ foram obtidas com um espectrômetro ICP-MS - THERMO NEPTUNE, sendo que as razões isotópicas ${ }^{146} \mathrm{Nd} /{ }^{144} \mathrm{Nd}$ foram normalizadas para o valor de ${ }^{146} \mathrm{Nd} /{ }^{144} \mathrm{Nd}=$ 0,7219 (De Paolo, 1981). 0 branco de Nd durante as análises foi de 177pg, a precisão foi inferior a 0,0017\% (2б) e o padrão de referência JNDi, analisado para comparação, forneceu um valor médio de 0,512099£0,000005 durante o período de junho/2014 a junho/2015 (exatidão de 0,0010\%). Por fim, as medidas das razões de $\mathrm{Pb}$ foram obtidas com um espectrômetro TIMS - FINNIGAN MAT 262, sendo que as razões isotópicas foram corrigidas para fracionamento de massa de 0,095\%/u.m.a.. 0 branco total durante as análises foi de 72pg, a precisão foi de no máximo 0,005\% $(2 \sigma)$ e o padrão de referência NBS-981, analisado para comparação, forneceu valores médios de ${ }^{206} \mathrm{~Pb} /{ }^{204} \mathrm{~Pb}=16,894 \pm 0,005 ;{ }^{207} \mathrm{~Pb} /{ }^{204} \mathrm{~Pb}$ $=15,430 \pm 0,006$ e ${ }^{208} \mathrm{~Pb} /{ }^{204} \mathrm{~Pb}=36,519 \pm 0,019$ durante o período de maio/2014 $\mathrm{a}$ maio/2015 (exatidão de 0,030\%, 0,039\% e 0,052\%, respectivamente). 


\section{Resultados}

Os resultados da ativação com nêutrons apresentados a seguir foram obtidos a partir da análise das onze amostras deste estudo, somadas à nova análise de cinco das treze amostras estudadas por Vicentini et al. (2013), as quais foram submetidas à irradiação com apenas dois materiais de referência, BE-N e GS-N. Estas cinco (a saber: RJ-7525, RJ-7544, RJ-7551, B-1097 e SSA-56) foram escolhidas pelo fato de também terem sido selecionadas para análise por ICP-MS, portanto desejou-se refinar os dados analisando-as com três padrões, como as demais.

\subsection{Ativação com Nêutrons}

Como já mencionado anteriormente, a análise por ativação com nêutrons (AAN) é uma técnica em que se pode usar o método comparativo, ou seja, pode ser utilizado um arranjo que dependa da análise conjunta das amostras e de materiais de referência certificados (neste estudo BRP-1, GS-N e BE-N). Com o objetivo de determinar a precisão e a exatidão do método, nas condições experimentais adotadas, foram utilizadas as atividades dos picos do espectro de raios gama emitidos pelos radioisótopos de interesse no basalto BRP-1 (como se fosse uma amostra), comparando-as com aquelas dos outros dois materiais de referência, para calcular as concentrações dos elementos. 0 material de referência BRP-1 foi utilizado para essa comparação por se tratar de um basalto com alto titânio (tipo Pitanga) da Província Magmática do Paraná, tendo composição semelhante às estudadas (Cotta et al., 2008). 0 mesmo procedimento foi repetido para o granito GS-N (utilizando como referência os basaltos BE-N e BRP-1) e para o basalto BE-N (utilizando como referência o basalto BE-N e o granito GS-N). As concentrações determinadas em cada um dos três materiais de referência foram comparadas aos valores certificados para cada elemento investigado em todas as 12 irradiações realizadas, totalizando até 16 medições e mais de 50 resultados para alguns elementos (incluindo repetição da contagem de uma mesma alíquota irradiada e/ou cálculo através de dois picos de energia para um dado elemento, em alguns casos). 
Este simples procedimento permite verificar se há algum tipo de problema com um dado resultado, uma vez que as comparações entre os três materiais de referência não deveriam apresentar inconsistências entre si. Entretanto, verificouse que, às vezes, esse tipo de problema ocorreu, sendo que as possíveis fontes de problemas são muitas, desde a posição das amostras no reator, tempo de exposição ao fluxo de nêutrons, contaminação da amostra nos processos de preparação, pesagem incorreta da alíquota, eventual contaminação pela água do reator, sobreposição de picos no espectro, interferências de elementos com maior secção de choque para determinados tipos de nêutrons, tempo de resfriamento da amostra e até mesmo fatores que fogem totalmente ao controle do pesquisador, como a própria natureza da amostra. Desta forma, é necessário que haja um critério para avaliar a confiabilidade do resultado e, para isso, os materiais de referência foram utilizados, pois são medidos muitas vezes e apresentam concentrações certificadas, geralmente incluindo dados determinados por diferentes técnicas analíticas.

A atividade de cada radioisótopo presente no espectro de raios gama, da amostra ou material de referência irradiado, é associada a um erro. Essa incerteza é calculada por um programa de análise espectral, que leva em conta a estatística de contagem, a radiação de fundo e o ajuste do pico a uma gaussiana. Para a obtenção de concentrações com os níveis de precisão e exatidão requeridos para as interpretações petrogenéticas, foram adotados os critérios apresentados a seguir.

Inicialmente, os valores de atividade gama que apresentaram erro relativo maior do que $15 \%$ foram rejeitados. 0 próximo passo foi analisar apenas os resultados das concentrações determinadas nas análises dos três materiais de referência utilizados, para verificar se havia consistência entre as análises, conforme descrito anteriormente. Nesta etapa foram excluídos os dados que resultaram em concentrações cujos valores de exatidão excederam 15\%, indicativo da ocorrência de algum problema naquela determinação. Após esta filtragem, os dados foram submetidos a dois testes estatísticos para verificar a homogeneidade do conjunto: teste $\mathrm{r}$ (Nalimov, 1963) e teste U (certeza expandida; Govindaraju, 1994; Cotta et al., 2008). 


\subsubsection{Teste $r$}

O teste r é um critério estatístico para aceitação ou rejeição de resultados quando há poucos graus de liberdade ( $\mathrm{f}=\mathrm{n}-2$, com $\mathrm{n} \leq 25)$, e ele depende apenas do conjunto de medidas com o qual se trabalha, supondo uma distribuição normal. Com $n>25$ a aceitação ou rejeição de um resultado não altera substancialmente os valores da média e desvio padrão do conjunto, sendo adotado o critério do $3 \sigma$ para o teste de homogeneidade (verificação se a diferença entre um valor do conjunto e a média está dentro de um intervalo de até $3 \sigma$ ), conforme descrito em Nalimov (1963).

Calculando, primeiramente, a média e desvio padrão, através das equações (IV) e (V), é calculado um fator "r" usando os valores mais distantes da média, o

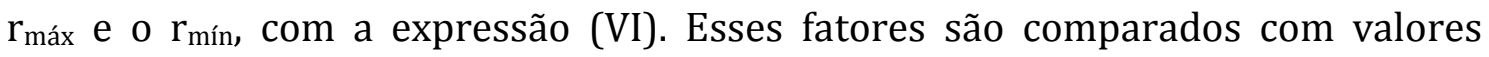
tabelados (Apêndice A), que dependem do número de graus de liberdade para um certo nível de confiança desejado e, caso "r" calculado seja menor que o tabelado, o valor é aceito, caso contrário ele é rejeitado. 0 valor mais distante, seja ele máximo ou mínimo, é primeiramente testado e, uma vez rejeitado, calcula-se novamente a média e desvio padrão do novo conjunto para repetir os cálculos de $r_{\text {máx }} \mathrm{e} / \mathrm{ou} \mathrm{r}_{\text {mín}}$. Caso seja aceito significa que, estatisticamente, para aquele nível de confiança, todos os valores estatisticamente pertencem ao conjunto. Neste trabalho foi adotado o nível de confiança de 95\% . As expressões utilizadas para a aplicação do teste são (Nalimov, 1963):

$$
\begin{gathered}
\bar{x}=\frac{\sum_{1}^{n} x_{i}}{n} \\
s_{x}=\sqrt{\frac{\sum_{1}^{n}\left(x_{i}-\bar{x}\right)^{2}}{n-1}} \\
r_{\text {máx }}=\frac{x_{\text {máx }-\bar{x}}}{s_{x} \sqrt{\frac{n-1}{n}}} \text { e } \quad r_{\text {mín }}=\frac{\left|x_{\min n}-\bar{x}\right|}{s_{x} \sqrt{\frac{n-1}{n}}}
\end{gathered}
$$

onde, $x_{i}$ é o valor determinado e n o número de determinações. 


\subsubsection{Teste U}

O teste $\mathrm{U}$ é basicamente um critério de compatibilidade de dois valores considerando suas incertezas expandidas $U=2 \mathrm{u}$, ou seja, dentro de um intervalo de dois desvios padrão. Essa escolha foi feita tendo em vista que os dados disponíveis na literatura, bem como os entregues nas análises pela maioria dos laboratórios, são comumente apresentados com a incerteza expandida U (referências citadas). Desse modo, foi feita a comparação de cada valor determinado e sua incerteza com o valor certificado e sua incerteza, utilizando para isso a equação (VII) (teste Z ou Z score). Esta equação retorna um fator que indica o intervalo de incertezas em que os valores comparados são estatisticamente iguais considerando uma distribuição normal, portanto foram aceitos valores que estivessem entre - 2 e 2 . A expressão utilizada para este teste é:

$$
z=\frac{x_{c e r t}-x_{d e t}}{\sqrt{s_{c e r t}^{2}+s_{d e t}^{2}}}
$$

onde $\mathrm{x}_{\text {det }}$ e $\mathrm{S}_{\text {det }} \mathrm{São}$, respectivamente, o valor determinado e o erro associado, e $\mathrm{x}_{\mathrm{cert}}$ e scert são, respectivamente, o valor certificado e o erro associado.

\subsubsection{Comparação entre os Testes}

A Tabela 4.1 traz os valores médios e os erros relativos obtidos, após as filtragens, nas análises do basalto BRP-1 utilizando os dois testes estatísticos de verificação da homogeneidade do conjunto, bem como sua comparação com os valores certificados. Quando comparados os dois testes, percebe-se que as médias praticamente não variam, porém que o desvio padrão pode sofrer alterações significativas. De modo geral, observa-se que a aplicação do teste U resulta em médias que apresentam menores erros relativos do que aquelas calculadas após a aplicação do teste r, exceto para Th e Lu.

No caso do teste $r$, para sete elementos o número de determinações válidas aumentou em pelo menos cinco, porém em todas elas houve também um aumento considerável do desvio padrão. Além disso, para seis elementos os erros percentuais ficaram acima dos 15\%, ou seja, com incerteza maior do que aquela desejável para estudos de petrogênese de rochas ígneas. 
Tabela 4.1.: Resultados dos testes estatísticos realizados para avaliação da qualidade e confiabilidade dos resultados das análises do material de referência BRP-1. 0 teste $\mathrm{z}$ foi utilizado para comparar as médias obtidas com os valores certificados, aceitando-se aqueles que se encontram no intervalo $-2<\mathrm{z}<2$. Observa-se que, no caso do teste $r$, os casos com $n>25$ seguem o critério dos $3 \sigma$.

\begin{tabular}{|c|c|c|c|c|c|c|c|c|c|c|c|c|c|}
\hline & \multicolumn{3}{|c|}{ Certificado } & \multicolumn{3}{|c|}{ Teste U } & \multicolumn{2}{|r|}{ Comp. } & \multicolumn{3}{|c|}{ Teste $r$} & \multicolumn{2}{|r|}{ Comp. } \\
\hline & $\mu$ & $1 \sigma$ & $\begin{array}{l}1 \sigma \\
(\%)\end{array}$ & $\bar{x}$ & $1 \sigma$ & $\begin{array}{l}1 \sigma \\
(\%)\end{array}$ & $\mathrm{n}$ & teste $z$ & $\bar{x}$ & $1 \sigma$ & $\begin{array}{l}1 \sigma \\
(\%)\end{array}$ & $\mathrm{n}$ & teste $z$ \\
\hline U & 0,82 & 0,02 & 1,8 & 0,79 & 0,08 & 10 & 6 & $-0,40$ & 0,74 & 0,10 & 14 & 9 & $-0,83$ \\
\hline Th & 3,97 & 0,05 & 1,3 & 3,82 & 0,28 & 7,2 & 17 & $-0,55$ & 3,77 & 0,22 & 5,8 & 16 & $-0,86$ \\
\hline Sc & 28,50 & 0,40 & 1,4 & 28,6 & 2,1 & 7,3 & 19 & 0,05 & 28,6 & 2,1 & 7,3 & 19 & 0,05 \\
\hline $\mathrm{Zn}$ & 142,0 & 1,0 & 0,7 & 136,4 & 8,8 & 6,4 & 3 & $-0,63$ & 101 & 39 & 39 & 7 & $-1,1$ \\
\hline $\mathrm{Ba}$ & 555 & 3,5 & 0,6 & 551 & 39 & 7,0 & 19 & $-0,11$ & 545 & 56 & 10 & 22 & $-0,18$ \\
\hline $\mathrm{Rb}$ & 35,40 & 0,50 & 1,4 & 35,8 & 1,3 & 3,7 & 6 & 0,31 & 34,7 & 5,1 & 15 & 9 & $-0,14$ \\
\hline $\mathrm{Cr}$ & 12,40 & 0,50 & 4,0 & 13,7 & 1,3 & 9,8 & 12 & 0,89 & 15,0 & 2,4 & 16 & 17 & 1,0 \\
\hline Co & 37,50 & 0,70 & 1,9 & 38,4 & 1,9 & 4,9 & 33 & 0,46 & 38,4 & 1,5 & 4,0 & 18 & 0,52 \\
\hline Cs & 0,37 & 0,02 & 5,4 & & & & 0 & & & & & 0 & \\
\hline $\mathrm{Hf}$ & 8 & 0,1 & 1,3 & 7,76 & 0,41 & 5,2 & 24 & $-0,57$ & 7,64 & 0,86 & 11 & 36 & $-0,42$ \\
\hline La & 42,60 & 0,50 & 1,2 & 41,2 & 1,2 & 3,0 & 9 & $-1,1$ & 40,1 & 1,4 & 3,6 & 20 & $-1,6$ \\
\hline $\mathrm{Ce}$ & 93,30 & 0,60 & 0,6 & 90,9 & 4,0 & 4,4 & 13 & $-0,60$ & 91,6 & 6,5 & 7,1 & 18 & $-0,26$ \\
\hline Nd & 51,9 & 0,45 & 0,9 & & & & 0 & & 49 & 19 & 39 & 14 & $-0,14$ \\
\hline Sm & 11,20 & 0,10 & 0,9 & 11,07 & 0,48 & 4,4 & 2 & $-0,26$ & 10,21 & 0,73 & 7,1 & 9 & $-1,4$ \\
\hline $\mathrm{Eu}$ & 3,42 & 0,04 & 1,2 & 3,43 & 0,19 & 5,4 & 27 & 0,03 & 3,51 & 0,34 & 9,7 & 31 & 0,25 \\
\hline $\mathrm{Tb}$ & 1,52 & 0,03 & 1,6 & 1,55 & 0,19 & 12 & 6 & 0,18 & 1,49 & 0,23 & 16 & 7 & $-0,12$ \\
\hline $\mathrm{Yb}$ & 3,48 & 0,05 & 1,3 & 3,43 & 0,48 & 14 & 22 & $-0,10$ & 3,15 & 0,64 & 20 & 30 & $-0,51$ \\
\hline $\mathrm{Lu}$ & 0,5 & 0,01 & 2,0 & 0,49 & 0,06 & 12 & 5 & $-0,21$ & 0,51 & 0,03 & 5,1 & 4 & 0,41 \\
\hline Ta & 1,96 & 0,04 & 2,0 & 1,99 & 0,24 & 12 & 33 & 0,12 & 2,03 & 0,32 & 16 & 39 & 0,21 \\
\hline
\end{tabular}

$\mu=$ valor certificado; $\sigma=1$ desvio padrão; $\bar{x}=$ media das determinações

\subsubsection{Precisão e Exatidão}

Com a análise dos materiais de referência, buscou-se averiguar a reprodutibilidade da técnica, nas condições experimentais adotadas, independentemente da amostra a ser investigada. Uma vez que os padrões foram irradiados em muitas situações diferentes, sujeitas a preparações em momentos distintos, a variação destes resultados representa de forma mais geral os erros 
associados à AAN, pois são totalmente independentes entre si. Os resultados aqui apresentados representam, estatisticamente, qual é probabilidade de que uma nova determinação obtida para esse padrão, e nessas condições, caia dentro do intervalo de confiança adotado (neste caso 95\%).

Na maioria dos casos, a flutuação dos dados dos materiais de referência é maior do que a flutuação observada nas análise das alíquotas de uma mesma amostra e, por esse motivo, é mais representativa. Em alguns casos as amostras mostraram uma variação maior para elementos mais difíceis de determinar, como o U por exemplo. Em geral isso acontece com elementos de baixa concentração (caso do $\mathrm{U}$ ) e elementos que se encontram na região mais complexa do espectro gama (caso do $\mathrm{Sm}$ e $\mathrm{Yb}$ ), devido ao grande número de picos de baixa energia, o que dificulta a determinação. Mesmo para estes casos, foi adotado o erro associado à análise dos materiais de referência, pois, como já mencionado anteriormente, as variações podem representar exclusivamente características intrínsecas à determinação de um elemento em uma dada amostra (uma vez que os valores dos materiais de referência se mostraram compatíveis), efeito que é minimizado no cálculo das médias.

Portanto, considerou-se a precisão do método o desvio padrão percentual calculado a partir do teste $U$, com valores até $14 \%$, e a exatidão o desvio relativo das médias obtidas em relação ao valor certificado, com valores até 4\% (o valor calculado de $10 \%$ para Cr não foi considerado, uma vez que este elemento não foi utilizado na modelagem). A Tabela 4.2 mostra estes valores calculados para cada um do elementos analisados.

Tabela 4.2.: valores de precisão (\%) e exatidão (\%) inferidos para as determinações calculados através das análises do material de referência BRP-1.

\begin{tabular}{|l|l|l|}
5,2 & 3,0 & 4,4
\end{tabular}

$\mathrm{Nd} \quad \mathrm{Sm} \quad \mathrm{Eu} \quad \mathrm{Tb} \quad \mathrm{Yb}$ Lu Ta

\begin{tabular}{ll|l|l|l|l|l|l|}
\hline 4,0 & 3,9 & 0,4 & 3,9 & 0,8 & 1,2 & 10 & 1,9
\end{tabular}

\begin{tabular}{l|l|l}
3,0 & 3,3 & 2,6
\end{tabular}

$\begin{array}{llllll}1,1 & 0,2 & 2,2 & 1,3 & 2,5 & 1,5\end{array}$




\subsubsection{Concentrações das amostras}

A AAN é uma técnica que permite determinar uma grande quantidade de elementos a cada análise, sem que haja necessidade de uma preparação muito sofisticada (e.g.: dissolução das amostras). Ela mostrou ser satisfatória para a determinação dos elementos em questão, fornecendo dados com precisão e exatidão requeridas neste tipo de estudo (abaixo dos 15\%). 0 fato de o pesquisador poder realizar e retomar as medidas, quando necessário, de maneira a refinar os dados também se mostrou uma ótima vantagem sobre outras técnicas analíticas que dependem exclusivamente da obtenção dos dados por terceiros. Juntamente com esses fatores, o grande volume de dados disponíveis na literatura obtidos por AAN permite que aqueles obtidos neste estudo sejam comparados diretamente com a literatura sem a necessidade de ressalvas ou adaptações.

A Tabela 4.3 mostra os resultados dos cálculos das médias das "n" determinações das concentrações realizadas para cada elemento de cada amostra, onde os erros apresentados correspondem ao desvio padrão observado. Para os dados extraídos de Vicentini et al. (2013) foram inferidos os erros obtidos nas análises dos materiais de referência ou, no caso específico do $\mathrm{Nd}$, cuja análise no material de referência não foi possível, foi usada a média dos erros percentuais das demais amostras.

Observa-se na Tabela 4.1 dois casos em que não houve determinações válidas: Cs, nos dois métodos, e $\mathrm{Nd}$, no teste $\mathrm{U}$. O Cs é um elemento de difícil determinação em rochas básicas e ultrabásicas por meio da AAN (mesmo com ativações com nêutrons epitérmicos), devido às baixas concentrações, sendo difícil detectá-lo até mesmo nos materiais de referência. No caso desta investigação, apenas o granito GS-N forneceu valores aceitáveis para o Cs, pelo fato de possuir uma concentração mais elevada $(5,40 \pm 0,13 \mu \mathrm{g} / \mathrm{g})$ deste elemento. Porém, na ausência de valores confiáveis para os outros dois materiais de referência, não foi possível fazer comparações, e assim não foi possível avaliar a qualidade e a confiabilidade das determinações para este elemento. 
Tabela 4.3.: Resultado das análises por ativação com nêutrons obtidas no Centro do Reator de Pesquisas (CRPq) do Instituto de Pesquisas Energéticas Nucleares (IPEN-CNEN/SP). 0 desvio padrão apresentado " $\sigma$ " se refere ao desvio padrão da análise elementar de cada amostra e "n" é o número de determinações que compõe a média " $\bar{x}$ ".

\begin{tabular}{|c|c|c|c|c|c|c|c|c|c|c|c|c|c|c|c|c|c|c|c|c|c|c|c|c|}
\hline \multirow{2}{*}{$\begin{array}{l}\text { Amostra } \\
\text { Elemento }\end{array}$} & \multicolumn{4}{|c|}{ B-1097 } & \multicolumn{4}{|c|}{ B-1111 } & \multicolumn{4}{|c|}{ RJ-7516 } & \multicolumn{4}{|c|}{ RJ-7517 } & \multicolumn{4}{|c|}{ RJ-7519 } & \multicolumn{4}{|c|}{ RJ-7520 } \\
\hline & $\bar{x}$ & $1 \sigma$ & $\begin{array}{l}1 \sigma \\
(\%)\end{array}$ & $\mathrm{n}$ & $\bar{x}$ & $1 \sigma$ & $\begin{array}{l}1 \sigma \\
(\%)\end{array}$ & $\mathrm{n}$ & $\bar{x}$ & $1 \sigma$ & $\begin{array}{l}1 \sigma \\
(\%)\end{array}$ & $\mathrm{n}$ & $\bar{x}$ & $1 \sigma$ & $\begin{array}{l}1 \sigma \\
(\%)\end{array}$ & $\mathrm{n}$ & $\bar{x}$ & $1 \sigma$ & $\begin{array}{l}1 \sigma \\
(\%)\end{array}$ & $\mathrm{n}$ & $\bar{x}$ & $1 \sigma$ & $\begin{array}{l}1 \sigma \\
(\%)\end{array}$ & $n$ \\
\hline$U$ & 3,22 & 0,33 & 10 & 5 & 0,86 & 0,09 & 10 & 12 & 1,36 & 0,15 & 11 & 9 & 1,34 & 0,08 & 5,6 & 9 & 0,98 & 0,08 & 7,6 & 9 & 0,97 & 0,08 & 8,0 & 9 \\
\hline Th & 13,33 & 0,06 & 0,45 & 4 & 4,29 & 0,30 & 7,1 & 19 & 5,96 & 0,61 & 10 & 11 & 5,95 & 0,41 & 6,8 & 13 & 4,67 & 0,31 & 6,6 & 14 & 4,49 & 0,23 & 5,2 & 10 \\
\hline Sc & 13,5 & 0,41 & 3,0 & 8 & 27,6 & 1,2 & 4,4 & 20 & 27,5 & 1,1 & 4,0 & 12 & 28,4 & 0,98 & 3,4 & 15 & 27,7 & 1,2 & 4,4 & 15 & 27,6 & 0,88 & 3,2 & 12 \\
\hline $\mathrm{Zn}$ & 109,0 & 4,5 & 4,1 & 4 & 147,5 & 1,0 & 0,7 & 3 & 140 & 5,0 & 3,5 & 4 & 144 & 16 & 11 & 6 & 148 & 13 & 9,0 & 6 & 145,9 & 4,0 & 2,8 & 4 \\
\hline $\mathrm{Ba}$ & 1314 & 25 & 1,9 & 3 & 588 & 73 & 12,4 & 14 & 634 & 63 & 9,9 & 17 & 620 & 58 & 9,4 & 16 & 572 & 64 & 11 & 18 & 567 & 91 & 16 & 15 \\
\hline $\mathrm{Rb}$ & 111 & 12 & 11 & 3 & 95 & 13 & 13 & 11 & 50,1 & 6,8 & 14 & 1 & 56,1 & 4,5 & 8 & 9 & 43,3 & 1,4 & 3,2 & 3 & 49,3 & 4,2 & 8,5 & 11 \\
\hline $\mathrm{Cr}$ & 55,3 & 4,2 & 7,5 & 9 & 46,2 & 2,4 & 5,1 & 9 & n.d. & n.d. & n.d. & & n.d. & n.d. & n.d. & & 31,9 & 6,4 & 20 & 6 & 33,7 & 6,9 & 20 & 8 \\
\hline Co & $25,60 *$ & 0,92 & 3,6 & & 40,7 & 1,8 & 4,4 & 30 & 37,2 & 1,7 & 4,4 & 23 & 39,0 & 1,78 & 4,6 & 30 & 38,3 & 1,9 & 5,0 & 30 & 38,4 & 1,9 & 4,9 & 24 \\
\hline Cs & 1,84 & 0,16 & 8,9 & 1 & 20,2 & 1,9 & 10 & 7 & 1,74 & 0,18 & 10 & 1 & 1,87 & 0,21 & 11 & 1 & 0,97 & 0,08 & 8,3 & 1 & 1,07 & 0,18 & 16 & 2 \\
\hline $\mathrm{Hf}$ & 10,67 & 0,71 & 6,7 & 13 & 6,26 & 0,62 & 10 & 35 & 8,46 & 0,55 & 6,5 & 18 & 8,13 & 1,1 & 14 & 26 & 7,76 & 0,47 & 6,1 & 24 & 7,77 & 0,65 & 8,4 & 20 \\
\hline La & 92,5 & 3,8 & 4,1 & 12 & 36,9 & 2,7 & 7,2 & 24 & 48,1 & 1,9 & 3,9 & 17 & 48,8 & 1,8 & 3,7 & 18 & 41,4 & 1,6 & 4,0 & 18 & 42,1 & 1,3 & 3,0 & 17 \\
\hline $\mathrm{Ce}$ & 187,9 & 9,1 & 4,9 & 8 & 82,1 & 4,0 & 4,8 & 18 & 104,0 & 4,9 & 4,7 & 11 & 103,1 & 3,8 & 3,7 & 14 & 90,2 & 5,4 & 6,0 & 14 & 93,8 & 4,7 & 5,0 & 11 \\
\hline $\mathrm{Nd}$ & 86,2 & 2,4 & 2,8 & 1 & 59,4 & 9,0 & 15 & 6 & 53,4 & 9,3 & 17 & 4 & 50,6 & 8,5 & 17 & 7 & 63 & 23 & 37 & 6 & 68 & 13 & 20 & 7 \\
\hline Sm & 13,55 & 0,51 & 3,7 & 4 & 10,02 & 0,47 & 4,6 & 7 & 12,00 & 0,54 & 4,5 & 5 & 12,22 & 0,55 & 4,5 & 5 & 11,43 & 0,53 & 4,6 & 5 & 11,69 & 0,60 & 5,1 & 5 \\
\hline $\mathrm{Eu}$ & 3,27 & 0,37 & 11 & 16 & 3,14 & 0,23 & 7,2 & 15 & 3,33 & 0,24 & 7,3 & 19 & 3,43 & 0,24 & 7,1 & 25 & 3,35 & 0,39 & 12 & 25 & 3,49 & 0,16 & 4,5 & 17 \\
\hline $\mathrm{Tb}$ & 1,46 & 0,03 & 2,1 & 3 & 1,30 & 0,10 & 8,0 & 6 & 1,76 & 0,18 & 11 & 4 & 1,79 & 0,06 & 3,5 & 8 & 1,59 & 0,16 & 10 & 6 & 1,60 & 0,16 & 10 & 11 \\
\hline $\mathrm{Yb}$ & 2,66 & 0,40 & 15 & 22 & 2,72 & 0,28 & 10 & 24 & 3,88 & 0,40 & 10 & 12 & 3,91 & 0,51 & 13 & 24 & 3,49 & 0,49 & 14 & 13 & 3,62 & 0,37 & 10 & 11 \\
\hline $\mathrm{Lu}$ & 0,41 & 0,01 & 2,6 & 4 & 0,38 & 0,04 & 10 & 7 & 0,57 & 0,04 & 6,7 & 4 & 0,55 & 0,06 & 11 & 7 & 0,53 & 0,01 & 2,7 & 3 & 0,50 & 0,01 & 2,1 & 4 \\
\hline $\mathrm{Ta}$ & 4,12 & 0,20 & 4,9 & 6 & 1,62 & 0,19 & 11 & 31 & 2,15 & 0,27 & 13 & 23 & 2,09 & 0,24 & 12 & 39 & 1,79 & 0,15 & 8,4 & 22 & 1,81 & 0,20 & 11 & 44 \\
\hline
\end{tabular}


Tabela 4.3. (cont.): Resultado das análises por ativação com nêutrons obtidas no Centro do Reator de Pesquisas (CRPq) do Instituto de Pesquisas Energéticas Nucleares (IPEN-CNEN/SP). 0 desvio padrão apresentado " $\sigma$ " se refere ao desvio padrão da análise elementar de cada amostra e "n" é o número de determinações que compõe a média " $\bar{x}$ ".

\begin{tabular}{|c|c|c|c|c|c|c|c|c|c|c|c|c|c|c|c|c|c|c|c|c|}
\hline \multirow{2}{*}{$\begin{array}{l}\text { Amostra } \\
\text { Elemento }\end{array}$} & \multicolumn{4}{|c|}{ RJ-7525 } & \multicolumn{4}{|c|}{ RJ-7526 } & \multicolumn{4}{|c|}{ RJ-7527 } & \multicolumn{4}{|c|}{ RJ-7532 } & \multicolumn{4}{|c|}{ RJ-7535 } \\
\hline & $\bar{x}$ & $1 \sigma$ & $1 \sigma(\%)$ & $\mathrm{n}$ & $\bar{x}$ & $1 \sigma$ & $1 \sigma(\%)$ & $\mathrm{n}$ & $\bar{x}$ & $1 \sigma$ & $1 \sigma(\%)$ & $\mathrm{n}$ & $\bar{x}$ & $1 \sigma$ & $1 \sigma(\%)$ & $\mathrm{n}$ & $\bar{x}$ & $1 \sigma$ & $1 \sigma(\%)$ & $\mathrm{n}$ \\
\hline U & 3,51 & 0,25 & 7,2 & 3 & 1,76 & 0,30 & 17 & 9 & 1,39 & 0,06 & 4,6 & 8 & 1,21 & 0,07 & 6,2 & 8 & 1,05 & 0,04 & 3,7 & 7 \\
\hline Th & 9,34 & 0,58 & 6,2 & 9 & 9,72 & 0,54 & 5,5 & 10 & 6,07 & 0,74 & 12 & 14 & 5,59 & 0,20 & 3,6 & 12 & 4,81 & 0,34 & 7,0 & 16 \\
\hline Sc & 15,5 & 0,66 & 4,3 & 9 & 15,8 & 0,70 & 4,4 & 12 & 23,52 & 0,82 & 3,5 & 15 & 21,48 & 0,87 & 4,0 & 15 & 22,26 & 0,69 & 3,1 & 18 \\
\hline $\mathrm{Zn}$ & 157 & 47 & 30 & 5 & 131 & 1,4 & 1,1 & 4 & 146,0 & 6,4 & 4,4 & 6 & 142 & 8,0 & 5,6 & 6 & 161,4 & 1,5 & 0,9 & 6 \\
\hline $\mathrm{Ba}$ & 1074 & 54 & 5,0 & 3 & 992 & 104 & 10 & 15 & 711 & 79 & 11 & 21 & 683 & 75 & 11 & 16 & 682 & 46 & 6,8 & 21 \\
\hline $\mathrm{Rb}$ & $84,4 *$ & 3,1 & 3,7 & & 76,5 & 6,3 & 8,2 & 5 & 50,6 & 7,6 & 15 & 7 & 61,7 & 7,1 & 12 & 4 & 46,0 & 2,2 & 4,7 & 4 \\
\hline $\mathrm{Cr}$ & $14,0 *$ & 1,4 & 10 & & 9,84 & 0,63 & 6,4 & 2 & 6,41 & 0,94 & 15 & 1 & 15,77 & 0,72 & 4,6 & 4 & 19,25 & 2,9 & 15 & 4 \\
\hline Co & $32,6 *$ & 1,2 & 3,6 & & 31,0 & 1,7 & 5,6 & 24 & 29,9 & 1,5 & 4,8 & 30 & 36,6 & 1,8 & 4,8 & 30 & 41,0 & 1,9 & 4,7 & 36 \\
\hline Cs & 0,87 & 0,06 & 7,4 & 1 & 0,83 & 0,10 & 12 & 1 & 1,39 & 0,17 & 12 & 1 & 2,29 & 0,44 & 19 & 2 & 1,07 & 0,13 & 12 & 1 \\
\hline $\mathrm{Hf}$ & 8,17 & 0,55 & 6,7 & 13 & 8,50 & 1,1 & 13 & 21 & 8,40 & 0,76 & 9,1 & 24 & 8,58 & 0,50 & 5,8 & 24 & 6,96 & 0,81 & 12 & 32 \\
\hline La & 69,3 & 2,2 & 3,2 & 6 & 72,7 & 2,7 & 3,8 & 17 & 53,1 & 1,8 & 3,3 & 18 & 54,7 & 4,1 & 7,5 & 18 & 51,3 & 1,1 & 2,2 & 16 \\
\hline $\mathrm{Ce}$ & 145,8 & 7,1 & 4,9 & 8 & 150,4 & 7,9 & 5,3 & 11 & 115,9 & 5,2 & 4,5 & 13 & 112,8 & 8,0 & 7,1 & 14 & 112,3 & 8,8 & 7,9 & 17 \\
\hline $\mathrm{Nd}$ & $73^{*}$ & 12 & 16 & & 74,4 & 4,3 & 5,8 & 5 & 59 & 13 & 22 & 5 & 65,7 & 4,7 & 7,2 & 5 & 60 & 14 & 24 & 6 \\
\hline $\mathrm{Sm}$ & 11,99 & 0,36 & 3,0 & 2 & 12,39 & 0,71 & 5,7 & 5 & 12,96 & 0,64 & 4,9 & 5 & 12,43 & 0,56 & 4,5 & 5 & 12,38 & 0,78 & 6,3 & 5 \\
\hline $\mathrm{Eu}$ & 3,27 & 0,26 & 7,8 & 16 & 3,33 & 0,21 & 6,3 & 19 & 3,93 & 0,23 & 5,9 & 24 & 3,66 & 0,22 & 5,9 & 25 & 3,72 & 0,31 & 8,3 & 27 \\
\hline $\mathrm{Tb}$ & 1,17 & 0,08 & 6,7 & 4 & 1,05 & 0,15 & 14 & 1 & 1,59 & 0,19 & 12 & 4 & 1,52 & 0,17 & 11 & 2 & 1,48 & 0,15 & 10 & 4 \\
\hline $\mathrm{Yb}$ & 2,38 & 0,38 & 16 & 19 & 2,60 & 0,31 & 12 & 10 & 3,63 & 0,45 & 12 & 12 & 3,22 & 0,38 & 12 & 15 & 2,89 & 0,42 & 14 & 14 \\
\hline Lu & 0,30 & 0,05 & 17 & 2 & 0,32 & 0,03 & 8,1 & 4 & 0,49 & 0,02 & 3,2 & 4 & 0,46 & 0,03 & 7,4 & 4 & 0,41 & 0,02 & 6,1 & 4 \\
\hline $\mathrm{Ta}$ & 2,99 & 0,21 & 6,9 & 11 & 3,41 & 0,43 & 13 & 28 & 2,23 & 0,30 & 13 & 28 & 2,26 & 0,17 & 7,6 & 16 & 2,13 & 0,26 & 12 & 35 \\
\hline
\end{tabular}

* = dados extraídos de Vicentini et al. (2013) e erros inferidos a partir deste estudo 
Tabela 4.3. (cont.): Resultado das análises por ativação com nêutrons obtidas no Centro do Reator de Pesquisas (CRPq) do Instituto de Pesquisas Energéticas Nucleares (IPEN-CNEN/SP). 0 desvio padrão apresentado " $\sigma$ " se refere ao desvio padrão da análise elementar de cada amostra e "n" é o número de determinações que compõe a média " $\bar{x}$ ".

\begin{tabular}{|c|c|c|c|c|c|c|c|c|c|c|c|c|c|c|c|c|c|c|c|c|}
\hline \multirow{2}{*}{$\begin{array}{l}\text { Amostra } \\
\text { Elemento }\end{array}$} & \multicolumn{4}{|c|}{ RJ-7544 } & \multicolumn{4}{|c|}{ RJ-7548 } & \multicolumn{4}{|c|}{ RJ-7551 } & \multicolumn{4}{|c|}{ SSA-56 } & \multicolumn{4}{|c|}{ SSA-64 } \\
\hline & $\bar{x}$ & $1 \sigma$ & $\begin{array}{c}1 \sigma \\
(\%)\end{array}$ & $n$ & $\bar{x}$ & $1 \sigma$ & $\begin{array}{l}1 \sigma \\
(\%)\end{array}$ & $n$ & $\bar{x}$ & $1 \sigma$ & $\begin{array}{l}1 \sigma \\
(\%)\end{array}$ & $\mathrm{n}$ & $\bar{x}$ & $1 \sigma$ & $\begin{array}{l}1 \sigma \\
(\%)\end{array}$ & $n$ & $\bar{x}$ & $1 \sigma$ & $\begin{array}{l}1 \sigma \\
(\%)\end{array}$ & $n$ \\
\hline $\mathrm{U}$ & 2,91 & 0,21 & 7,2 & 3 & 1,40 & 0,08 & 5,6 & 8 & 1,29 & 0,11 & 8,7 & 6 & 3,37 & 0,33 & 10 & 4 & 1,05 & 0,16 & 15 & 5 \\
\hline Th & 12,88 & 0,83 & 6,4 & 9 & 6,73 & 0,25 & 3,7 & 9 & 5,99 & 0,24 & 4,0 & 6 & 12,72 & 0,73 & 5,7 & 6 & 4,23 & 0,35 & 8,4 & 5 \\
\hline $\mathrm{Sc}$ & 17,0 & 0,76 & 4,5 & 9 & 27,8 & 1,0 & 3,8 & 12 & 28,4 & 1,8 & 6,5 & 6 & 11,16 & 0,34 & 3,0 & 5 & 25,6 & 0,52 & 2,0 & 4 \\
\hline $\mathrm{Zn}$ & 210,4 & 5,8 & 2,8 & 3 & 142 & 1,6 & 1,2 & 4 & 137 & 57 & 41,3 & 4 & 95 & 32 & 33,4 & 4 & 218,4 & 6,1 & 2,8 & 3 \\
\hline $\mathrm{Ba}$ & 1224 & 48 & 3,9 & 6 & 661 & 88 & 13,3 & 20 & 672 & 46 & 6,8 & 6 & 1201 & 25 & 2,1 & 8 & 509 & 40 & 7,8 & 6 \\
\hline $\mathrm{Rb}$ & 110,0 & 2,1 & 1,9 & 3 & 58,3 & 8,8 & 15 & 4 & 54,8 & 1,8 & 3,3 & 5 & 125 & 14 & 11 & 6 & 34,5 & 3,6 & 11 & 3 \\
\hline $\mathrm{Cr}$ & 146,6 & 9,1 & 6,2 & 3 & n.d. & n.d. & n.d. & 0 & 6,99 & 0,35 & 5,0 & 2 & 6,83 & 0,45 & 6,6 & 3 & 11,6 & 1,3 & 10,9 & 3 \\
\hline Co & $36,0 *$ & 1,3 & 3,6 & & 37,9 & 1,5 & 3,9 & 23 & $40,3^{*}$ & 1,4 & 3,6 & & 7,4 & 0,61 & 8,3 & 12 & 39,6 & 3,0 & 7,6 & 9 \\
\hline Cs & 1,93 & 0,21 & 11 & 1 & 1,61 & 0,18 & 11 & 1 & 1,15 & 0,21 & 18 & 2 & 2,78 & 0,20 & 7,1 & 1 & 1,52 & 0,16 & 10 & 1 \\
\hline $\mathrm{Hf}$ & 10,51 & 0,58 & 5,6 & 14 & 8,69 & 0,73 & 8,5 & 20 & 8,30 & 0,31 & 3,8 & 9 & 13,6 & 1,0 & 7,5 & 9 & 7,16 & 0,43 & 6,1 & 7 \\
\hline La & 89,6 & 2,7 & 3,0 & 6 & 51,0 & 1,9 & 3,7 & 18 & 49,6 & 1,6 & 3,1 & 6 & 77,5 & 2,3 & 3,0 & 6 & 42,0 & 1,3 & 3,1 & 6 \\
\hline $\mathrm{Ce}$ & 182 & 11 & 6,0 & 8 & 108,1 & 3,6 & 3,3 & 11 & 105,2 & 2,6 & 2,4 & 5 & 173,5 & 9,8 & 5,7 & 6 & 86,0 & 5,8 & 6,8 & 3 \\
\hline $\mathrm{Nd}$ & $77^{*}$ & 12 & 16 & & 67 & 10 & 16 & 4 & 64 & 11 & 17 & 3 & 77,5 & 3,5 & 4,5 & 1 & n.d. & n.d. & n.d. & 0 \\
\hline $\mathrm{Sm}$ & 11,99 & 0,36 & 3,0 & 2 & 12,51 & 0,57 & 4,6 & 5 & 12,27 & 0,37 & 3,0 & 2 & 15,32 & 0,46 & 3,0 & 2 & 10,81 & 0,33 & 3,0 & 2 \\
\hline $\mathrm{Eu}$ & 3,18 & 0,31 & 9,8 & 15 & 3,42 & 0,26 & 7,6 & 19 & 3,42 & 0,21 & 6,2 & 9 & 3,79 & 0,45 & 12,0 & 10 & 3,38 & 0,32 & 9,5 & 9 \\
\hline $\mathrm{Tb}$ & 1,33 & 0,09 & 6 & 5 & 1,48 & 0,30 & 20 & 3 & 1,56 & 0,11 & 7,3 & 4 & 2,01 & 0,14 & 7,2 & 7 & 1,20 & 0,07 & 6,0 & 5 \\
\hline $\mathrm{Yb}$ & 2,82 & 0,44 & 16 & 16 & 4,01 & 0,55 & 14 & 12 & 3,78 & 0,43 & 11 & 14 & 4,41 & 0,62 & 14 & 15 & 3,23 & 0,28 & 8,8 & 6 \\
\hline Lu & 0,37 & 0,04 & 11 & 4 & 0,57 & 0,03 & 4,7 & 4 & 0,56 & 0,07 & 13 & 3 & 0,62 & 0,09 & 14 & 3 & 0,42 & 0,07 & 17 & 2 \\
\hline $\mathrm{Ta}$ & 3,82 & 0,19 & 4,9 & 11 & 2,27 & 0,24 & 11 & 28 & 2,14 & 0,10 & 4,7 & 12 & 3,65 & 0,30 & 8,1 & 19 & 1,84 & 0,14 & 7,7 & 9 \\
\hline
\end{tabular}

$\mu=$ valor certificado; $\sigma=1$ desvio padrão; $\bar{x}=$ media das determinações 
No caso do $\mathrm{Nd}$, determinado nas irradiações térmicas, existe uma variação muito grande nas concentrações determinadas, associada a erros altos na atividade calculada, pois o pico do ${ }^{147} \mathrm{Nd}(91,1 \mathrm{keV})$ se localiza em uma região do espectro onde há muitas interferências, tanto pelo efeito Compton (interação dos fótons com elétrons livres), quanto por causa de outros elementos que ficam mais ativos neste tipo de irradiação e estão nessa região espectral. Por este motivo o teste $U$, que usa na comparação os erros das concentrações dos elementos nos materiais de referência, acabou rejeitando todos os valores determinados para o $\mathrm{Nd}$, enquanto o teste $\mathrm{r}$, por levar em consideração apenas o conjunto de dados em si (sem as incertezas), aceitou uma grande quantidade de determinações, porém resultou num desvio padrão muito acima do desejável (39\%).

As determinações do Sm, através do radioisótopo ${ }^{153} \mathrm{Sm}$, cujo pico está em $103 \mathrm{keV}$, bem como do Lu, através do pico de $208 \mathrm{keV}$ do ${ }^{177} \mathrm{Lu}$, também foram afetadas pelos mesmos fatores do caso anterior. Apesar dos dados de Sm no basalto BRP-1 apresentarem erros muito inferiores a 15\% no ajuste do pico, as dificuldades citadas fizeram com que poucas determinações fossem aceitas pelo critério do teste $U(n=2)$. Já para o $\mathrm{Lu}$, soma-se o fato que a atividade do ${ }^{177} \mathrm{Lu}$ é geralmente menor que a do ${ }^{153} \mathrm{Sm}$, conferindo-lhe poucas determinações válidas (n $=5)$.

Da mesma forma, o Yb possui picos em $282 \mathrm{keV}$ e $396 \mathrm{keV}$ para o radioisótopo ${ }^{175} \mathrm{Yb}$, enquanto os picos do ${ }^{169} \mathrm{Yb}$ são em $177 \mathrm{keV}$ e $197 \mathrm{keV}$ que sofrem interferência do Ce (145 keV) e Eu (121 keV), pois possuem atividades bem mais elevadas. Estes fatores resultam na maior dispersão entre os elementos investigados, 14\%, muito embora haja um grande número de determinações válidas $(\mathrm{n}=33)$.

Dentre os outros elementos determinados nas irradiações epitérmicas, Tb e U mostram os resultados mais afetados pelas interferências. 0 pico do ${ }^{239} \mathrm{~Np}$ (usado para o cálculo da concentração do U) que melhor aparece no espectro é o de $228 \mathrm{keV}$, porém, além do efeito Compton, as baixas concentrações deste elemento nas rochas basálticas prejudicam muito a sua determinação. No caso do ${ }^{160} \mathrm{~Tb}$, cujo pico é em $879 \mathrm{keV}$, há uma grande interferência por parte do ${ }^{46} \mathrm{Sc}$, cujo pico de $889 \mathrm{keV}$ e apresenta atividade mais de uma ordem de grandeza maior. Além desses, há o ${ }^{86} \mathrm{Rb}(1076 \mathrm{keV})$, que mesmo nas irradiações epitérmicas é difícil 
de detectar na AAN principalmente nos basaltos, que possuem baixas

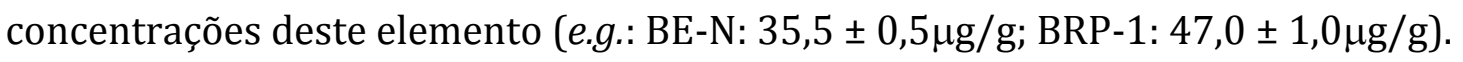

Uma das formas que se buscou para compensar estes efeitos foi aumentando o tempo de contagem no detector, porém avaliando o custo benefício desse aumento, uma vez que se torna inviável usar todo o tempo disponível para medir a atividade de poucas amostras por vez (lembrando que os três materiais de referência sempre têm que ser submetidos à contagem também). Outro ponto relevante que foi observado para melhorar as análises foi efetuar a contagem após o período de decaimento ideal (e.g.: 4-5 dias para o caso do ${ }^{239} \mathrm{U}$ e $\left.{ }^{153} \mathrm{Sm}\right)$, pois neste momento a atividade gama desses elementos está maior. Porém, nem sempre foi possível adotar tais medidas, uma vez que isto depende de vários fatores externos como a atividade da amostra (e consequente liberação para manuseio pelo serviço de radioproteção), logística relacionada ao reator (data de irradiação, posição no reator, número de horas sob irradiação, data de abertura da amostra) e disponibilidade do equipamento para as medidas.

Aliado a esses procedimentos laboratoriais, a utilização dos testes estatísticos permitiu selecionar o melhor conjunto de dados para análise, dada a condição experimental, o que culminou em resultados finais com a precisão e a exatidão desejadas. Como já mencionado, para os elementos $\mathrm{Nd}$ e Cs não foi possível atestar a qualidade e a confiabilidade em suas determinações, portanto os valores obtidos para as amostras serão apenas valores sugeridos, considerando-se apenas a reprodutibilidade das determinações para cada amostra, o que nem sempre representa a reprodutibilidade do método.

\subsection{Espectrometria de massa com fonte de plasma induzido}

Além dos dados obtidos por ativação com nêutrons, 16 amostras foram submetidas a análise por espectrometria de massa com fonte de plasma induzido (ICP-MS). Esta técnica permitiu determinar Th, U, Pb, Rb, Sr, Y, Zr, Hf, Nb, Cs, Ba e toda a família dos terras raras, La, Ce, Pr, Nd, Sm, Eu, Gd, Tb, Dy, Ho, Er, Tm, Yb e Lu. Os dados obtidos na análise por ICP-MS se encontram na Tabela 4.4, sendo os valores apresentados correspondentes à média de três medidas realizadas em 
sequência no espectrômetro e o erro associado adotado de acordo com os critérios discutidos a seguir.

\subsubsection{Precisão e exatidão}

Como forma de avaliar a qualidade e a confiabilidade das medidas realizadas por ICP-MS, foram cedidas pelo Laboratório de Química e ICP do Instituto de Geociências da Universidade de São Paulo dez resultados de análises independentes do material de referência BR (basalto), realizadas no ano de 2014, além de outras duas realizadas, no ano de 2015, durante as medidas das amostras do presente estudo. Da mesma forma como foi feito para a técnica da ativação neutrônica, os erros associados aos resultados obtidos por ICP-MS correspondem à precisão relativa obtida nas análises do basalto $B R$, e a exatidão foi calculada como sendo o desvio relativo do valor médio do padrão BR em relação ao valor certificado para cada elemento.

As doze análises do material de referência mostram que a precisão relativa da técnica não ultrapassou 7,0\% (caso do Er), e a exatidão foi inferior a 5\% para a grande maioria dos elementos analisados, chegando aos $11 \%$ apenas no caso do $\mathrm{Pb}$. Os resultados das análises estão dispostos na Tabela 4.5. Os valores do branco do laboratório foram inferiores a $0,01 \mu \mathrm{g} / \mathrm{g}$ para todos os elementos analisados, exceto $\mathrm{Pb}(<0,02 \mu \mathrm{g} / \mathrm{g}), \mathrm{Zr}(<0,03 \mu \mathrm{g} / \mathrm{g}), \mathrm{Nd}(<0,08 \mu \mathrm{g} / \mathrm{g})$ e $\mathrm{Ba}(<0,5 \mu \mathrm{g} / \mathrm{g})$. 
Tabela 4.4.: Resultado das análises por ICP-MS obtidas no Laboratório de Química e ICP do Instituto de Geociências da USP.

\begin{tabular}{|c|c|c|c|c|c|c|c|c|c|c|c|c|c|c|c|c|}
\hline Amostra & \multicolumn{2}{|c|}{ B-1097 } & \multicolumn{2}{|c|}{ B-1111 } & \multicolumn{2}{|c|}{ RJ-7516 } & \multicolumn{2}{|c|}{ RJ-7517 } & \multicolumn{2}{|c|}{ RJ-7519 } & \multicolumn{2}{|c|}{ RJ-7520 } & \multicolumn{2}{|c|}{ RJ-7525 } & \multicolumn{2}{|c|}{ RJ-7526 } \\
\hline Elemento & $\bar{x}$ & $1 \sigma$ & $\bar{x}$ & $1 \sigma$ & $\bar{x}$ & $1 \sigma$ & $\bar{x}$ & $1 \sigma$ & $\bar{x}$ & $1 \sigma$ & $\bar{x}$ & $1 \sigma$ & $\bar{x}$ & $1 \sigma$ & $\bar{x}$ & $1 \sigma$ \\
\hline $\mathbf{R b}$ & 116 & 4,0 & 94,1 & 3,3 & 53,8 & 1,9 & 51,6 & 1,8 & 39,5 & 1,4 & 42,1 & 1,5 & 78,6 & 2,7 & 80,5 & 2,8 \\
\hline $\mathrm{Sr}$ & 860 & 30 & 836 & 30 & 471 & 17 & 469 & 17 & 504 & 18 & 516 & 18 & 1063 & 38 & 1041 & 37 \\
\hline $\mathrm{Y}$ & 34,8 & 1,2 & 33,7 & 1,2 & 45,8 & 1,6 & 44,7 & 1,6 & 42,0 & 1,5 & 42,5 & 1,5 & 29,7 & 1,0 & 30,0 & 1,0 \\
\hline $\mathrm{Zr}$ & 445 & 25 & 243 & 14 & 334 & 19 & 334 & 19 & 290 & 16 & 304 & 17 & 339 & 19 & 340 & 19 \\
\hline $\mathrm{Nb}$ & 54,8 & 1,7 & 24,33 & 0,74 & 32,4 & 1,0 & 31,9 & 1,0 & 28,00 & 0,85 & 27,67 & 0,84 & 49,2 & 1,5 & 49,5 & 1,5 \\
\hline Cs & 1,85 & 0,06 & 20,34 & 0,63 & 1,67 & 0,05 & 1,72 & 0,05 & 0,87 & 0,03 & 0,88 & 0,03 & 1,05 & 0,03 & 1,01 & 0,03 \\
\hline $\mathrm{Ba}$ & 1353 & 20 & 547,6 & 7,9 & 628,7 & 9,1 & 612,2 & 8,9 & 537,9 & 7,8 & 541,4 & 7,8 & 1011 & 15 & 1007 & 15 \\
\hline La & 95,1 & 2,8 & 37,0 & 1,1 & 49,5 & 1,5 & 47,7 & 1,4 & 41,2 & 1,2 & 42,0 & 1,2 & 71,3 & 2,1 & 71,4 & 2,1 \\
\hline $\mathrm{Ce}$ & 192 & 7,0 & 82,0 & 3,0 & 106 & 3,9 & 103 & 3,8 & 91,0 & 3,3 & 92,9 & 3,4 & 148 & 5,4 & 147 & 5,4 \\
\hline $\mathrm{Pr}$ & 22,13 & 0,47 & 10,66 & 0,23 & 13,48 & 0,29 & 13,08 & 0,28 & 11,87 & 0,25 & 12,18 & 0,26 & 17,68 & 0,38 & 17,73 & 0,38 \\
\hline $\mathrm{Nd}$ & 82,1 & 2,2 & 45,4 & 1,2 & 56,0 & 1,5 & 54,6 & 1,5 & 50,9 & 1,4 & 52,1 & 1,4 & 68,2 & 1,9 & 68,5 & 1,9 \\
\hline $\mathrm{Sm}$ & 13,64 & 0,35 & 9,59 & 0,24 & 11,79 & 0,30 & 11,44 & 0,29 & 10,99 & 0,28 & 11,28 & 0,29 & 11,95 & 0,30 & 12,09 & 0,31 \\
\hline Eu & 3,53 & 0,09 & 3,00 & 0,08 & 3,31 & 0,09 & 3,24 & 0,09 & 3,28 & 0,09 & 3,26 & 0,09 & 3,34 & 0,09 & 3,34 & 0,09 \\
\hline Gd & 11,98 & 0,43 & 8,42 & 0,30 & 10,14 & 0,36 & 9,76 & 0,35 & 9,26 & 0,33 & 9,38 & 0,33 & 10,07 & 0,36 & 10,20 & 0,36 \\
\hline Tb & 1,48 & 0,08 & 1,27 & 0,07 & 1,60 & 0,09 & 1,55 & 0,08 & 1,49 & 0,08 & 1,51 & 0,08 & 1,29 & 0,07 & 1,32 & 0,07 \\
\hline Dy & 7,37 & 0,23 & 6,81 & 0,21 & 8,78 & 0,28 & 8,52 & 0,27 & 8,14 & 0,26 & 8,22 & 0,26 & 6,43 & 0,20 & 6,52 & 0,20 \\
\hline Ho & 1,30 & 0,03 & 1,31 & 0,03 & 1,75 & 0,04 & 1,70 & 0,04 & 1,62 & 0,04 & 1,62 & 0,04 & 1,15 & 0,03 & 1,15 & 0,03 \\
\hline Er & 3,45 & 0,24 & 3,29 & 0,23 & 4,47 & 0,31 & 4,34 & 0,30 & 4,06 & 0,28 & 4,08 & 0,29 & 2,97 & 0,21 & 2,99 & 0,21 \\
\hline $\mathrm{Tm}$ & 0,45 & 0,01 & 0,46 & 0,01 & 0,64 & 0,02 & 0,62 & 0,02 & 0,57 & 0,02 & 0,58 & 0,02 & 0,38 & 0,01 & 0,38 & 0,01 \\
\hline $\mathrm{Yb}$ & 2,71 & 0,14 & 2,69 & 0,14 & 3,81 & 0,20 & 3,70 & 0,20 & 3,37 & 0,18 & 3,40 & 0,18 & 2,26 & 0,12 & 2,28 & 0,12 \\
\hline Lu & 0,41 & 0,02 & 0,40 & 0,02 & 0,57 & 0,03 & 0,56 & 0,03 & 0,50 & 0,02 & 0,51 & 0,02 & 0,34 & 0,02 & 0,34 & 0,02 \\
\hline $\mathrm{Hf}$ & 10,77 & 0,37 & 6,24 & 0,22 & 8,63 & 0,30 & 8,55 & 0,30 & 7,57 & 0,26 & 7,85 & 0,27 & 8,38 & 0,29 & 8,26 & 0,29 \\
\hline $\mathrm{Pb}$ & 16,0 & 1,0 & 5,94 & 0,38 & 9,07 & 0,57 & 8,91 & 0,56 & 6,31 & 0,40 & 6,52 & 0,41 & 10,70 & 0,68 & 11,13 & 0,71 \\
\hline Th & 13,41 & 0,34 & 4,00 & 0,10 & 6,19 & 0,16 & 6,00 & 0,15 & 4,55 & 0,12 & 4,54 & 0,12 & 9,26 & 0,24 & 9,58 & 0,25 \\
\hline U & 2,95 & 0,09 & 0,91 & 0,03 & 1,41 & 0,04 & 1,38 & 0,04 & 0,98 & 0,03 & 1,03 & 0,03 & 1,84 & 0,05 & 1,85 & 0,05 \\
\hline
\end{tabular}

Branco do laboratório: $0,01 \mu \mathrm{g} / \mathrm{g}$ para todos os elementos analisados, exceto $\mathrm{Pb}(<0,02 \mu \mathrm{g} / \mathrm{g}), \mathrm{Zr}(<0,03 \mu \mathrm{g} / \mathrm{g}), \mathrm{Nd}(<0,08 \mu \mathrm{g} / \mathrm{g})$ e Ba $(<0,5 \mu \mathrm{g} / \mathrm{g})$ $\sigma=1$ desvio padrão; $\bar{x}=$ media das determinações 
Tabela 4.4. (cont.): Resultado das análises por ICP-MS obtidas no Laboratório de Química e ICP do Instituto de Geociências da USP.

\begin{tabular}{|c|c|c|c|c|c|c|c|c|c|c|c|c|c|c|c|c|}
\hline Amostra & RJ-7 & 27 & RJ-7 & & RJ-7 & 35 & RJ-7 & 44 & RJ-7 & 48 & RJ-7 & 51 & SSA & 56 & SSA & 62 \\
\hline $\mathbf{R b}$ & 55,1 & 1,9 & 57,9 & 2,0 & 47,5 & 1,6 & 107,5 & 3,7 & 58,3 & 2,0 & 53,2 & 1,8 & 122,7 & 4,2 & 116,6 & 4,0 \\
\hline $\mathbf{Y}$ & 45,0 & 1,6 & 41,4 & 1,4 & 39,6 & 1,4 & 34,3 & 1,2 & 46,5 & 1,6 & 45,7 & 1,6 & 54,3 & 1,9 & 47,3 & 1,7 \\
\hline $\mathrm{Zr}$ & 340 & 19 & 338 & 19 & 287 & 16 & 450 & 25 & 351 & 20 & 334 & 19 & 564 & 31 & 523 & 29 \\
\hline Nb & 33,9 & 1,0 & 35,6 & 1,1 & 39,1 & 1,2 & 62,2 & 1,9 & 32,0 & 1,0 & 31,7 & 1,0 & 56,4 & 1,7 & 58,8 & 1,8 \\
\hline La & 52,0 & 1,5 & 50,8 & 1,5 & 51,5 & 1,5 & 90,1 & 2,7 & 53,2 & 1,6 & 47,1 & 1,4 & 85,9 & 2,5 & 96,3 & 2,8 \\
\hline $\mathrm{Ce}$ & 114 & 4,2 & 112 & 4,1 & 112 & 4,1 & 182 & 6,6 & 114 & 4,2 & 103 & 3,8 & 178 & 6,5 & 213 & 7,8 \\
\hline $\mathrm{Pr}$ & 14,89 & 0,32 & 14,47 & 0,31 & 14,51 & 0,31 & 21,42 & 0,46 & 14,40 & 0,31 & 13,30 & 0,29 & 21,88 & 0,47 & 24,05 & 0,52 \\
\hline Nd & 62,8 & 1,7 & 61,2 & 1,7 & 61,7 & 1,7 & 80,2 & 2,2 & 59,6 & 1,6 & 55,9 & 1,5 & 85,5 & 2,3 & 93,7 & 2,5 \\
\hline Sm & 12,99 & 0,33 & 12,37 & 0,32 & 12,35 & 0,31 & 13,30 & 0,34 & 12,23 & 0,31 & 11,65 & 0,30 & 16,12 & 0,41 & 16,79 & 0,43 \\
\hline Dy & 8,89 & 0,28 & 8,17 & 0,26 & 7,98 & 0,25 & 7,35 & 0,23 & 9,01 & 0,28 & 8,77 & 0,28 & 10,52 & 0,33 & 9,63 & 0,30 \\
\hline Ho & 1,73 & 0,04 & 1,56 & 0,04 & 1,49 & 0,04 & 1,29 & 0,03 & 1,78 & 0,04 & 1,73 & 0,04 & 2,00 & 0,05 & 1,80 & 0,04 \\
\hline Er & 4,40 & 0,31 & 3,93 & 0,28 & 3,72 & 0,26 & 3,42 & 0,24 & 4,53 & 0,32 & 4,44 & 0,31 & 5,20 & 0,36 & 4,44 & 0,31 \\
\hline $\mathrm{Tm}$ & 0,60 & 0,02 & 0,53 & 0,01 & 0,49 & 0,01 & 0,45 & 0,01 & 0,64 & 0,02 & 0,63 & 0,02 & 0,72 & 0,02 & 0,61 & 0,02 \\
\hline $\mathbf{Y b}$ & 3,59 & 0,19 & 3,14 & 0,17 & 2,93 & 0,16 & 2,70 & 0,14 & 3,88 & 0,21 & 3,83 & 0,20 & 4,31 & 0,23 & 3,54 & 0,19 \\
\hline Lu & 0,54 & 0,03 & 0,47 & 0,02 & 0,44 & 0,02 & 0,41 & 0,02 & 0,58 & 0,03 & 0,57 & 0,03 & 0,64 & 0,03 & 0,52 & 0,03 \\
\hline $\mathrm{Hf}$ & 8,64 & 0,30 & 8,47 & 0,29 & 7,25 & 0,25 & 10,47 & 0,36 & 8,95 & 0,31 & 8,46 & 0,29 & 13,92 & 0,48 & 12,06 & 0,42 \\
\hline $\mathbf{P b}$ & 8,65 & 0,55 & 7,57 & 0,48 & 7,49 & 0,47 & 14,05 & 0,89 & 9,48 & 0,60 & 8,72 & 0,55 & 16,6 & 1,0 & 14,98 & 0,95 \\
\hline Th & 6,18 & 0,16 & 5,76 & 0,15 & 4,98 & 0,13 & 12,7 & 0,32 & 7,10 & 0,18 & 5,83 & 0,15 & 12,30 & 0,31 & 13,14 & 0,34 \\
\hline $\mathbf{U}$ & 1,41 & 0,04 & 1,32 & 0,04 & 1,12 & 0,03 & 2,68 & 0,08 & 1,48 & 0,04 & 1,39 & 0,04 & 2,88 & 0,08 & 2,87 & 0,08 \\
\hline
\end{tabular}

Branco do laboratório: 0,01mg/g para todos os elementos analisados, exceto $\mathrm{Pb}(<0,02 \mu \mathrm{g} / \mathrm{g}), \mathrm{Zr}(<0,03 \mu \mathrm{g} / \mathrm{g}), \mathrm{Nd}(<0,08 \mu \mathrm{g} / \mathrm{g})$ e Ba $(<0,5 \mu \mathrm{g} / \mathrm{g})$ 
Tabela 4.5.: Valores de precisão (\%) e exatidão (\%) inferidos para os dados de ICP-MS calculados através das análises do basalto BR (CRPG).

\begin{tabular}{|c|c|c|c|c|c|c|c|c|c|c|c|c|c|}
\hline Elemento & $\mathbf{R b}$ & $\mathrm{Sr}$ & $\mathbf{Y}$ & $\mathrm{Zr}$ & $\mathrm{Nb}$ & Cs & $\mathrm{Ba}$ & La & $\mathrm{Ce}$ & $\mathrm{Pr}$ & Nd & Sm & Eu \\
\hline Precisão (\%) & 3,5 & 3,5 & 3,5 & 5,6 & 3,0 & 3,1 & 1,4 & 2,9 & 3,6 & 2,1 & 2,7 & 2,6 & 2,7 \\
\hline \multirow[t]{2}{*}{ Exatidão (\%) } & 1,7 & 1,4 & 5,9 & 2,4 & 7,8 & 5,1 & 1,2 & 0,6 & 1,1 & 0,6 & 1,0 & 3,1 & 3,9 \\
\hline & Gd & Tb & Dy & Ho & $\mathrm{Er}$ & $\mathrm{Tm}$ & $\mathrm{Yb}$ & Lu & Hf & $\mathrm{Pb}$ & Th & $U$ & \\
\hline Precisão (\%) & 3,6 & 5,4 & 3,1 & 2,4 & 7,0 & 2,7 & 5,3 & 4,8 & 3,5 & 6,3 & 2,6 & 2,9 & \\
\hline Exatidão (\%) & 5,3 & 1,1 & 1,8 & 2,1 & 1,4 & 4,9 & 4,3 & 0,4 & 0,3 & 11 & 4,3 & 1,7 & \\
\hline
\end{tabular}

\subsection{Comparação entre resultados obtidos por AAN e ICP-MS}

Para realizar a comparação entre os resultados obtidos pelas técnicas de AAN e ICP-MS foram utilizadas duas metodologias: a) a comparação de métodos pela diferença de resultados (Nalimov, 1963); b) ajuste linear calculado a partir do gráfico dos dados da AAN versus dados de ICP-MS (Origin Pro 7.0). Além disso, comparou-se os dados de ICP-MS com aqueles determinados por fluorescência de raios $\mathrm{X}$, a saber, $\mathrm{Sr}, \mathrm{Zr}, \mathrm{Nb}$ e $\mathrm{Y}$, a fim de verificar a necessidade do uso de correções.

\subsubsection{Método das diferenças entre os resultados}

0 método das diferenças entre os resultados é basicamente um teste bicaudal que leva em consideração as diferenças entre medidas obtidas a partir de duas metodologias distintas $\left(d_{i}\right)$ (Nalimov, 1963). Para um grande número de medidas decorre que a somatória dessas diferenças tende a zero $(\bar{d}=0)$. Temse, portanto:

$$
\begin{gathered}
s_{d}^{2}=\frac{\sum d_{i}^{2}-\left(\sum d_{i}\right)^{2} / n}{n-1} \\
t_{\text {exp }}=\frac{|\bar{d}| \sqrt{n}}{s_{d}}
\end{gathered}
$$


com $\bar{d}=\frac{\sum_{1}^{n} d_{i}}{n}$, sendo $\mathrm{s}_{\mathrm{d}}$ a variância das diferenças e texp um fator calculado que será comparado com um fator tabelado ( $\mathrm{t}_{\mathrm{tab}}$ ) para um determinado nível de confiança. Se $t_{\exp }<t_{t a b}$, nestas condições, os valores são iguais estatisticamente. Este teste possui n-1 graus de liberdade e não leva em consideração as variâncias das médias comparadas.

Para o conjunto de dados obtidos a partir da AAN e de ICP-MS foram calculados texp para cada um dos 14 elementos investigados pelas duas técnicas e comparados com tab para 15 graus de liberdade (16 amostras). A Tabela 4.6 mostra o resultado desses cálculos para cada elemento. Como pode ser observado, os valores de $t_{\exp }$ estão abaixo do valor limite de 2,1 para um nível de confiança de 95\%, com exceção do elemento $\mathrm{Nd}\left(\mathrm{t}_{\exp }=2,3\right)$ e do $\mathrm{Lu}\left(\mathrm{t}_{\exp }=3,1\right)$. Isso indica que as metodologias fornecem resultados equivalentes neste nível de confiança, a não ser para os dois elementos citados.

Tabela 4.6.: Parâmetros calculados para determinação do texp para cada elemento investigado nesse estudo, para $\mathrm{n}=16$.

\begin{tabular}{|c|c|c|c|c|c|c|c|c|c|c|c|c|c|c|}
\hline Elemento & $\mathbf{U}$ & Th & $\mathrm{Ba}$ & $\mathbf{R b}$ & Cs & Hf & La & $\mathrm{Ce}$ & Nd & Sm & $\mathrm{Eu}$ & Tb & $\mathbf{Y b}$ & Lu \\
\hline$\sum d_{i}$ & 2,1 & 0,074 & 241,1 & 19,6 & 1,2 & $-1,2$ & $-18,7$ & $-24,9$ & 67,4 & $-0,66$ & 0,57 & $-0,57$ & 0,79 & $-0,34$ \\
\hline$\left(\sum d_{i}\right)^{2}$ & 4,3 & 0,005 & 58143 & 384 & 1,6 & 1,3 & 351 & 621 & 4543 & 0,43 & 0,33 & 0,32 & 0,63 & 0,11 \\
\hline$\sum\left(d_{i}{ }^{2}\right)$ & 3,2 & 0,66 & 20225 & 254 & 0,66 & 1 & 246 & 330 & 1114 & 8,1 & 0,58 & 0,33 & 0,65 & 0,018 \\
\hline $\bar{d}$ & 0,13 & 0,005 & 15 & 1,2 & 0,078 & 0,07 & 1,2 & 1,6 & 4,2 & 0,041 & 0,036 & 0,036 & 0,049 & 0,021 \\
\hline$s_{d}$ & 0,44 & 0,21 & 33 & 3,9 & 0,19 & 0,3 & 3,9 & 4,4 & 7,4 & 0,73 & 0,19 & 0,14 & 0,20 & 0,027 \\
\hline$t_{\text {exp }}$ & 1,2 & 0,088 & 1,8 & 1,3 & 1,6 & 1,1 & 1,2 & 1,4 & 2,3 & 0,23 & 0,74 & 0,98 & 0,98 & 3,1 \\
\hline$t_{t a b ; 0,1}$ & 1,8 & 1,8 & 1,8 & 1,8 & 1,8 & 1,8 & 1,8 & 1,8 & 1,8 & 1,8 & 1,8 & 1,8 & 1,8 & 1,8 \\
\hline
\end{tabular}

\subsubsection{Ajuste linear}

O segundo método utilizado para testar a compatibilidade dos resultados foi o ajuste de reta calculado pelo software Origin Pro 7.0, onde foram plotadas as concentrações elementares obtidas pela AAN em função dos valores obtidos por ICP-MS, e depois calculados os coeficientes angular e linear da reta 
que melhor se ajusta aos pontos (menor somatória de resíduos). A equação da reta que melhor ajusta aos pontos é descrita da seguinte maneira:

$$
Y(X)=A+B * X
$$

onde A é o coeficiente linear e B é o coeficiente angular. Espera-se que a reta ajustada passe pela origem $(A=0)$ e que os valores encontrados pelas diferentes metodologias sejam o mais próximos possível entre si $(X=Y)$, sendo, portanto, $B$ =1. A Tabela 4.7 mostra os coeficientes calculados para os elementos estudados, e as Figuras 4.1 e 4.2 apresentam os gráficos com os ajustes realizados.

Tabela 4.7.: Coeficientes angular (B) e linear (A) e os respectivos erros associados ao ajuste realizado pelo software Origin Pro 7.0, segundo a Equação $(X): Y(X)=A+B^{*} X$.

\begin{tabular}{|c|c|c|c|c|c|c|c|}
\hline Elemento & Coeficiente & Ajuste & $1 \sigma$ & Elemento & Coeficiente & Ajuste & $1 \sigma$ \\
\hline \multirow{2}{*}{$\mathbf{U}$} & A & 0,26 & 0,05 & \multirow{2}{*}{$\mathrm{Ce}$} & A & $-6,17$ & 3,50 \\
\hline & B & 0,83 & 0,03 & & B & 1,06 & 0,03 \\
\hline \multirow{2}{*}{ Th } & A & 0,12 & 0,13 & \multirow{2}{*}{ Nd } & A & 6,1 & 9,3 \\
\hline & B & 0,98 & 0,02 & & B & 0,85 & 0,13 \\
\hline \multirow{2}{*}{$\mathrm{Ba}$} & A & -34 & 27 & \multirow{2}{*}{ Sm } & A & $-3,27$ & 0,75 \\
\hline & B & 1,02 & 0,03 & & B & 1,25 & 0,06 \\
\hline \multirow{2}{*}{$\mathbf{R b}$} & A & 1,15 & 2,78 & \multirow{2}{*}{ Eu } & A & 0,70 & 0,32 \\
\hline & B & 0,97 & 0,03 & & B & 0,79 & 0,09 \\
\hline \multirow{2}{*}{ Cs } & A & $-0,11$ & 0,06 & \multirow{2}{*}{ Tb } & A & 0,57 & 0,21 \\
\hline & B & 1,01 & 0,01 & & B & 0,64 & 0,14 \\
\hline \multirow{2}{*}{ Hf } & A & 0,32 & 0,32 & \multirow{2}{*}{ Yb } & A & 0,11 & 0,30 \\
\hline & B & 0,97 & 0,03 & & B & 0,95 & 0,09 \\
\hline \multirow{2}{*}{ La } & A & $-5,8$ & 3,0 & \multirow{2}{*}{ Lu } & A & 0,07 & 0,03 \\
\hline & B & 1,12 & 0,05 & & B & 0,90 & 0,07 \\
\hline
\end{tabular}

É importante destacar que os dados foram submetidos ao teste $U$ antes de serem utilizados no ajuste gráfico (comparação entre AAN e ICP-MS). Dessa forma foi possível identificar e remover aqueles incompatíveis dentro de 2 sigma, sendo retirados um dado de $\mathrm{U}$ e $\mathrm{Rb}$ (resultando em 15 amostras) e dois dados de Cs, La e Sm (14 amostras plotadas). Assim, é possível observar que os 
ajustes ressaltam a compatibilidade da maioria dos dados, sendo os coeficientes A e B calculados equivalentes a 0 e 1 , respectivamente, dentro de $2 \sigma$. Há três exceções, U e Sm, com coeficientes linear (A) e angular (B) incompatíveis, e Tb, com A no limite (diferença de até 0,06 ) e B incompatível, e outros três que ficaram no limite La (B), Eu (A e B) e Lu (A).
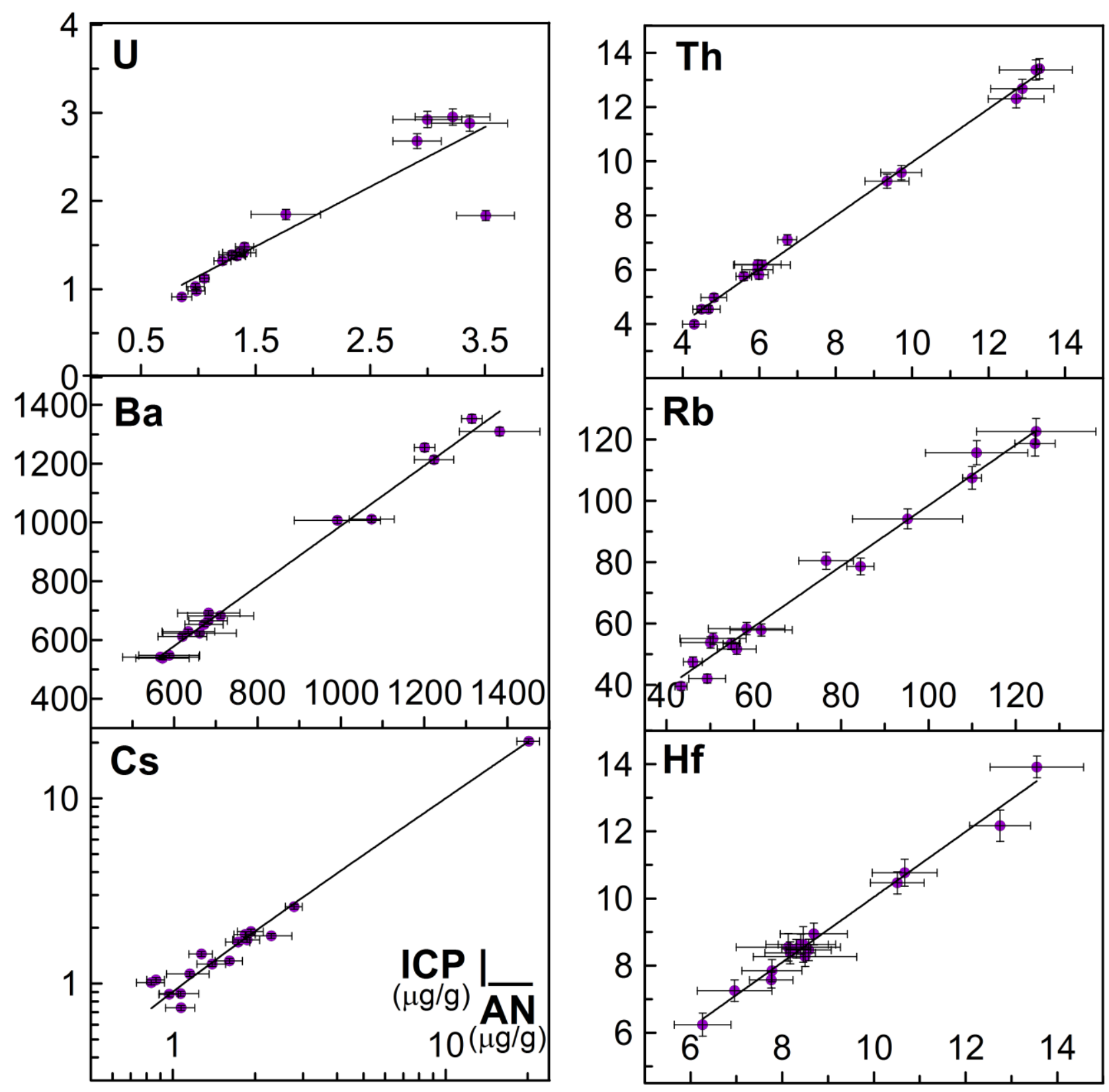

Figura 4.1.: Ajuste linear aplicado nos dados da AAN em função dos dados de ICP-MS para elementos traço. 

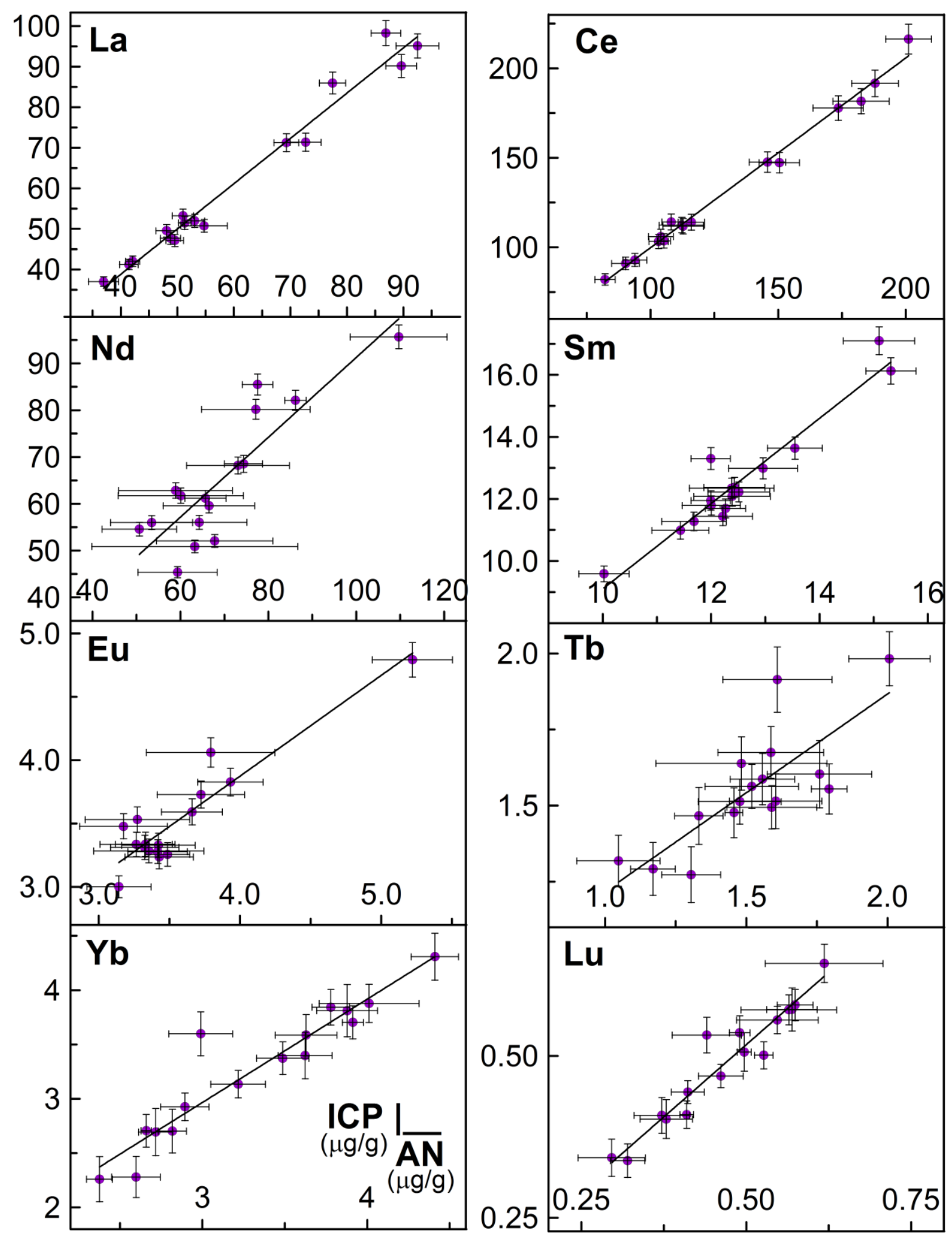

Figura 4.2.: Ajuste linear aplicado nos dados da AAN em função dos dados de ICP-MS para elementos terras raras. 


\subsubsection{Dados de fluorescência de raios X}

Com a finalidade de comparar os dados obtidos através da técnica da fluorescência de raios X com os de ICP-MS, devido à grande diferença entre as precisões dos métodos, foram construídos gráficos semelhantes aos da seção anterior, como mostra a Figura 4.3.
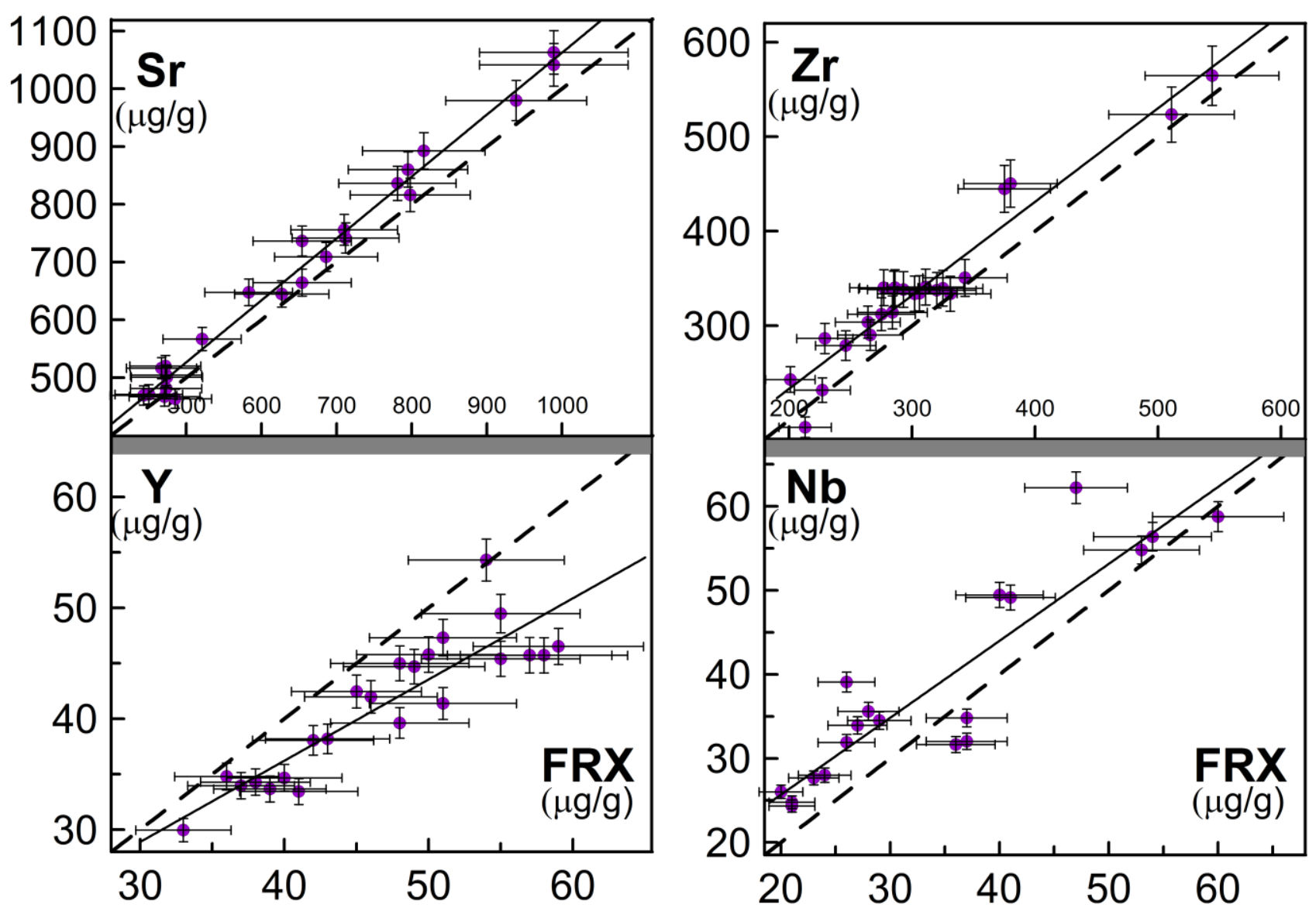

Figura 4.3: Comparação entre os dados de FRX e os dados de ICP-MS. A curva tracejada indica a reta $\mathrm{Y}(\mathrm{X})=\mathrm{X}$.

Como pode ser observado na Figura 4.3 há uma tendência dos dados concentrarem-se acima da curva ( $\mathrm{Zr}, \mathrm{Sr}$ e $\mathrm{Nb}$ ) ou abaixo (Y). Isso indica uma diferença sistemática entre as duas metodologias. Em especial, no caso do Y havia uma desconfiança de que os dados de FRX obtidos nas análises realizadas na Universidade de Trieste, Itália (Marques, 2001) não fossem válidos (possivelmente por problemas na calibração do equipamento). Através desta 
comparação foi possível confirmar esta suposição e estabelecer um fator de correção que foi aplicado aos dados de $\mathrm{Y}$ obtidos por fluorescência de raios X.

Assim sendo, utilizando a Equação $(\mathrm{X})$, calculou-se os coeficientes $\mathrm{A}=$ $7,0 \pm 3,8$ e $B=0,73 \pm 0,08$ através do ajuste linear dos pontos a uma reta e foram utilizados estes coeficientes para corrigir as concentrações de Y.

\subsubsection{Comentários Gerais}

Tendo em vista as comparações realizadas entre as diferente técnicas usadas na determinação dos elementos investigados, pode-se concluir que os valores são compatíveis. Desse modo, optou-se por usar nos modelos petrogenéticos desenvolvidos os valores obtidos pela AAN, uma vez que houve maior enfoque nesta metodologia durante o estudo. Além disso, a grande quantidade de dados disponível na literatura obtidos por meio da AAN permite que comparações sejam realizadas sem a preocupação de misturar dados obtidos de formas diferentes.

0 grande problema que este tipo de procedimento pode acarretar é a aparição ou camuflagem de feições oriundas de diferenças sistemáticas existentes apenas pela diferença de técnicas, como visto anteriormente (e.g.:

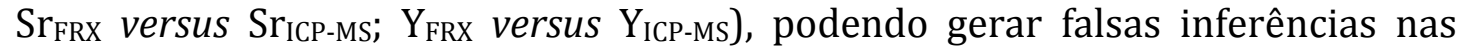
interpretações. Por estes motivos, optou-se por fazer uso dos dados de ativação com nêutrons. Semelhantemente, no caso dos elementos $\mathrm{Sr}$, $\mathrm{Nb}$ e $\mathrm{Zr}$ serão utilizados estes valores obtidos por fluorescência de raios X, pelos mesmos motivos, sendo apenas usado o Y obtido por ICP-MS, no caso das amostras analisadas por esta técnica, e a correção discutida na seção anterior para as amostras em que não houve determinação por ICP-MS. 


\section{Discussão}

Com os dados obtidos foi possível estudar alguns aspectos da origem e evolução dos diques subalcalinos da Serra do Mar. Cabe destacar que, juntamente com os corpos investigados, estão também representados os dados referentes a diques que ocorrem na Ilha de São Sebastião e área continental adjacente (Marques, 2001; Vicentini, 2013), incluindo alguns de caráter mais primitivo, os quais são importantes no estudo da gênese dos litotipos mais diferenciados dessa região, que é o objeto do presente estudo. A tabela completa com as análises químicas (base anidra) e isotópicas usadas na construção dos diagramas e figuras deste trabalho encontra-se no Apêndice B.

\subsection{Análise Química}

\subsubsection{Classificação e Nomenclatura}

Com os dados dos óxidos maiores e menores foi possível classificar e dar a nomenclatura química dos diques estudados (Figura 5.1), com base no diagrama TAS (Total Álcali versus Ślica), proposta pela Subcomissão de Sistemática de Rochas Ígneas (Le Bas et al., 1986). De acordo com esse diagrama, rochas com conteúdo de $\mathrm{SiO}_{2}$ entre $52 \%$ e $63 \%$ são consideradas intermediárias, entretanto, para melhor agrupar as rochas analisadas neste estudo, considerouse como intermediárias aquelas que possuem conteúdo de $\mathrm{SiO}_{2}$ entre $54 \%$ e $63 \%$ (e $\mathrm{MgO}<3 \%$ ). Assim, a maioria das rochas se enquadra no grupo das intermediárias, sendo 3 basaltos traqui-andesíticos e 9 traqui-andesitos, ocorrendo, subordinadamente, litotipos básicos (2 basaltos e 4 basaltos andesíticos) e ácidos (2 traqui-dacitos). A natureza subalcalina dessas rochas é também evidenciada nesse diagrama, já que todas elas situam-se abaixo da linha divisória entre os campos alcalino e subalcalino proposta por Irvine \& Baragar (1971). Porém, é possível perceber que elas se encontram bem próximas à linha, conferindo-lhes uma leve tendência alcalina. 


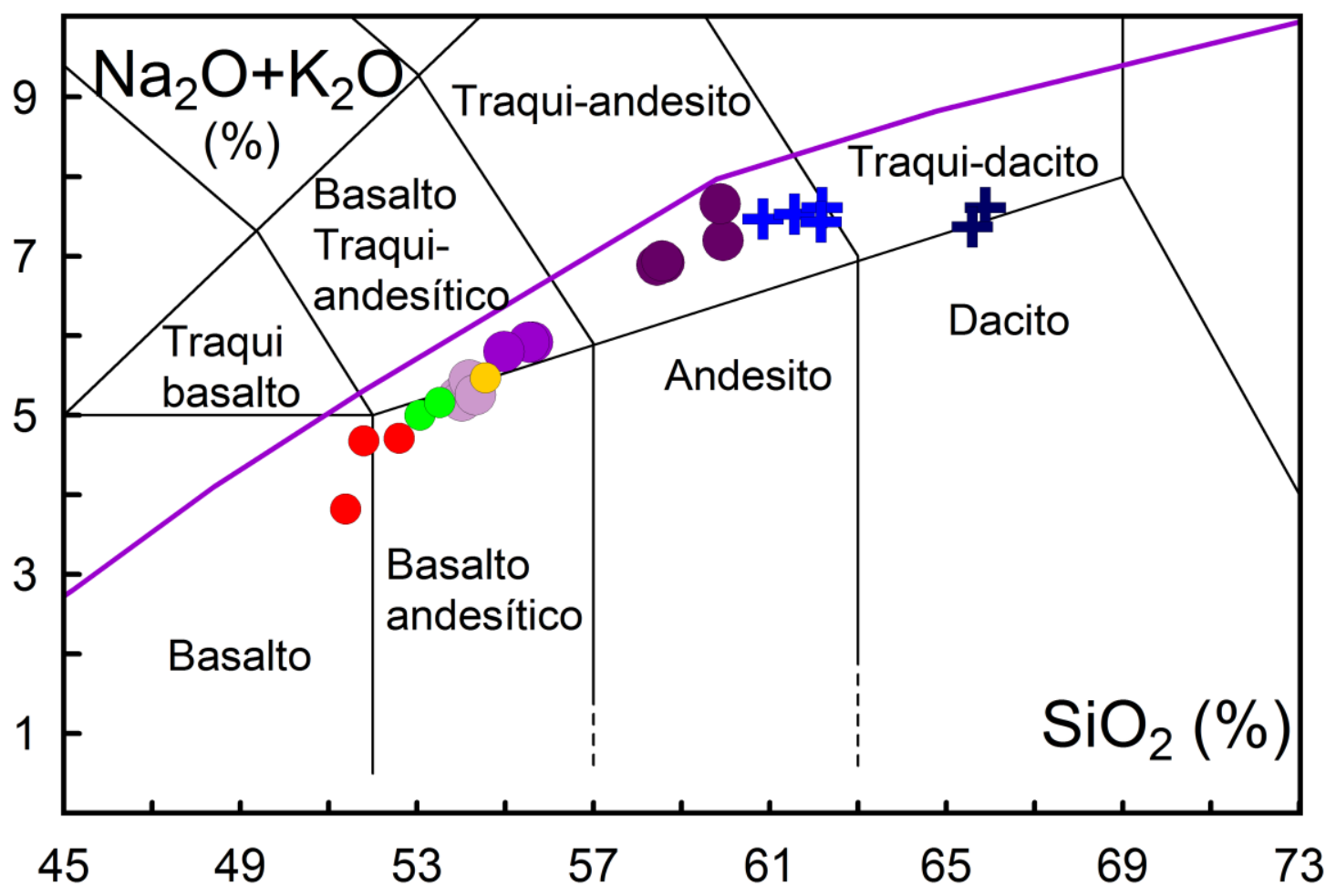

Figura 5.1.: Nomenclatura dos diques segundo classificação proposta por Le Bas et al. (1986). Legenda: círculos e cruzes cheias = presente estudo. Cores: vermelho = tipo Urubici; verde = tipo Pitanga; amarelo = tipo misto (que não possui equivalente extrusivo na PMP; Marques, 2001); roxo e azul = rochas mais diferenciadas. Linha roxa: linha divisória entre os campos alcalino e subalcalino proposta por Irvine \& Baragar (1971).

A nomenclatura baseada no esquema proposto por De La Roche et al. (1980) está substancialmente de acordo com a TAS, como pode ser observado na Figura 5.2 (Diagrama R1vsR2), sendo que os diques considerados são majoritariamente lati-andesitos (LTA) e dacitos (DAC), ocorrendo de modo subordinado andesi-basaltos toleíticos (ABT) e riodacitos (RC). Optou-se neste trabalho pela nomenclatura de De La Roche (1980), principalmente por levar em consideração praticamente todos os óxidos maiores e menores, permitindo uma melhor divisão das litologias (Rollinson, 1993). 


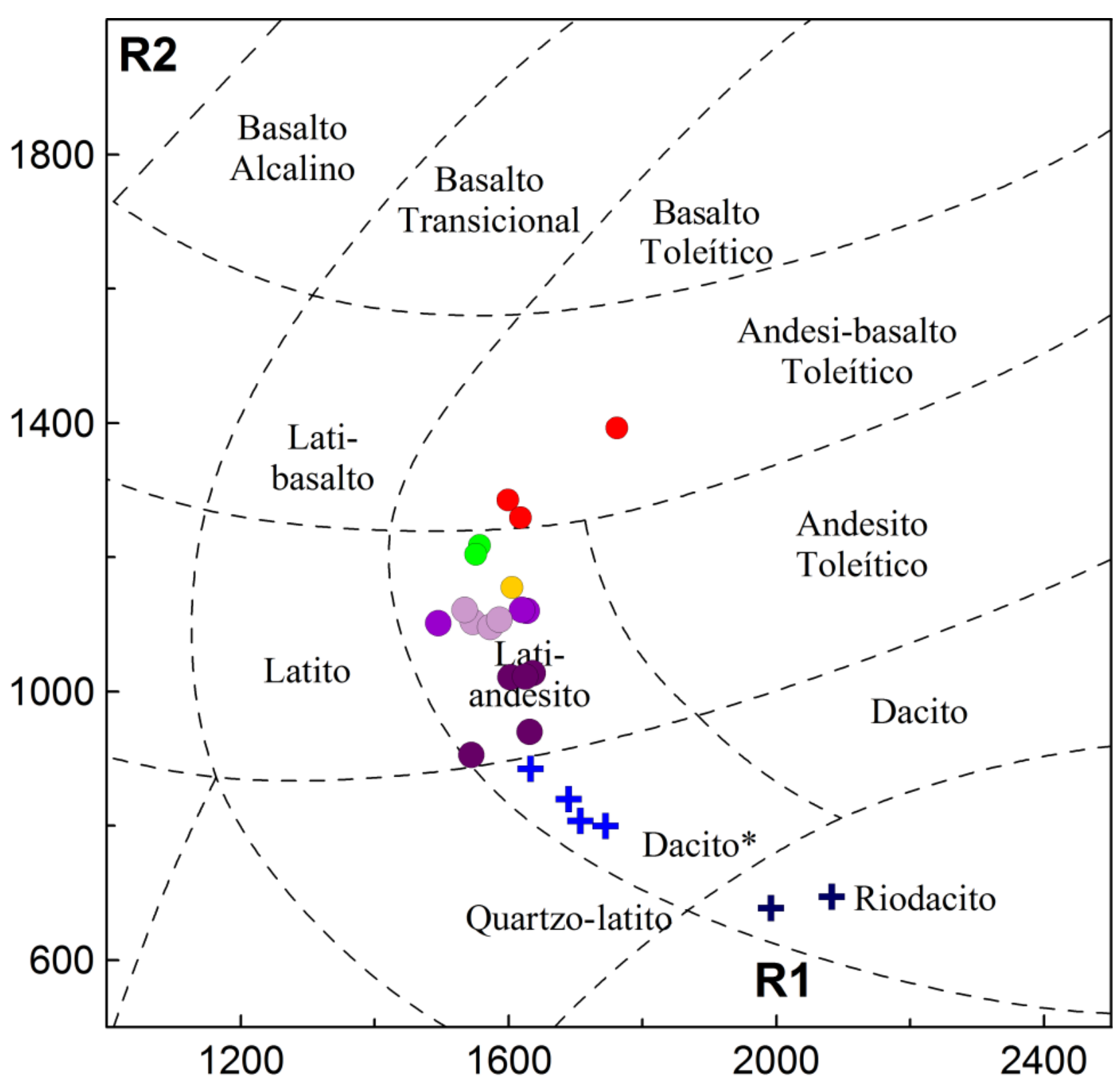

Figura 5.2.: Nomenclatura dos diques segundo classificação proposta por De La Roche et al. (1980). Legenda: círculos e cruzes cheias = presente estudo. Cores: vermelho = tipo Urubici; verde = tipo Pitanga; amarelo = tipo misto (que não possui equivalente extrusivo na PMP; Marques, 2001); roxo e azul = rochas mais diferenciadas. 


\subsubsection{Definição dos magmas-tipo para os diques básicos}

Para verificar se os diques básicos analisados possuem similaridade geoquímica com os basaltos da PMP, foi usado o diagrama proposto por Peate et al. (1992), que diferencia os derrames basálticos com $\mathrm{SiO}_{2}<55 \%$ e $\mathrm{MgO}>3 \%$ por meio da razão Ti/Y e das concentrações de $\mathrm{Sr}$ e de $\mathrm{Fe}_{2} \mathrm{O}_{3}$ total $\left(\mathrm{Fe}_{2} \mathrm{O}_{3 \mathrm{t}}\right)$, conforme mostrado na Figura 5.3.
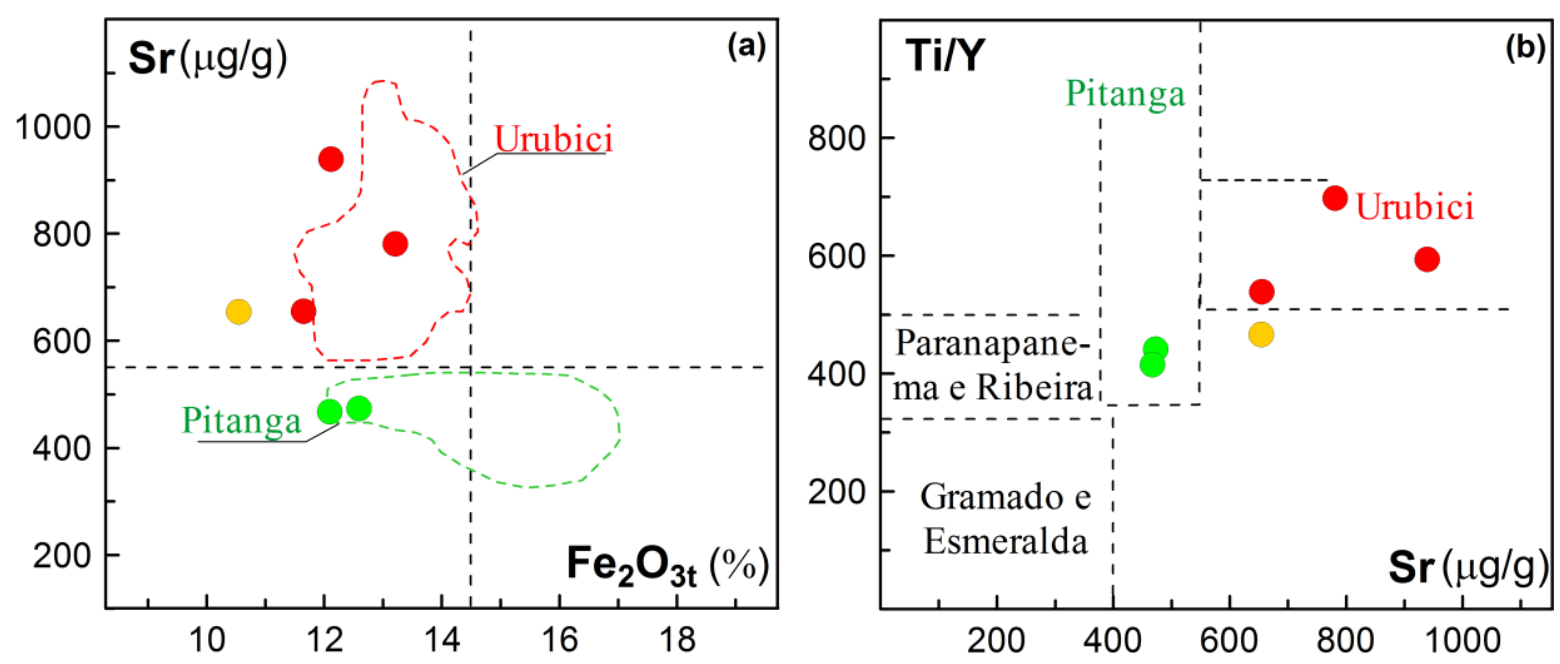

Figura 5.3.: Nomenclatura das rochas básicas estudadas (Peate et al., 1992). Legenda: círculos cheios = presente estudo; Cores: vermelho = tipo Urubici; verde $=$ tipo Pitanga; amarelo $=$ tipo misto (que não possui equivalente extrusivo na PMP; Marques, 2001).

É possível identificar na Figura $5.3(\mathrm{a}, \mathrm{b})$ a presença de três grupos distintos nos diques básicos analisados. 0 primeiro semelhante aos basaltos Pitanga da PMP ( $\mathrm{Sr}<550 \mu \mathrm{g} / \mathrm{g})$, outro semelhante aos Urubici $(\mathrm{Ti} / \mathrm{Y}>500 ; \mathrm{Sr}>$ $550 \mu \mathrm{g} / \mathrm{g}$ ) e um terceiro grupo que apresenta características mistas, ou seja, concentrações relativamente baixas de $\mathrm{Fe}_{2} \mathrm{O}_{3 \mathrm{t}}, \mathrm{Ti} / \mathrm{Y}<500$ e $\mathrm{Sr}>550 \mu \mathrm{g} / \mathrm{g}$. Este resultado está em concordância com os dados obtidos por Marques (2001), que mostrou a existência de um grupo de diques com características geoquímicas não encontradas nos derrames da PMP. Dessa forma, os diques básicos foram provavelmente originados em fontes mantélicas composicionalmente distintas, a exemplo do que ocorre nos derrames da PMP (e.g.: Peate et al., 1999; Marques et al., 1999; Rocha-Júnior et al., 2013). 


\subsubsection{Diagramas de variação de óxidos maiores e menores}

Os diagramas de variação de óxidos maiores e menores, em função de MgO, considerado como índice de diferenciação magmática (Figura 5.4), mostram de modo geral enriquecimento de $\mathrm{SiO}_{2}, \mathrm{Na}_{2} \mathrm{O}$ e $\mathrm{K}_{2} \mathrm{O}$ e empobrecimento de $\mathrm{TiO}_{2}, \mathrm{FeO}_{\mathrm{t}}$ e CaO, com o aumento do grau de evolução. Entretanto, não há uma tendência evolutiva nítida, com dispersão significativa de praticamente todos os elementos, principalmente de $\mathrm{Al}_{2} \mathrm{O}_{3}$ e $\mathrm{P}_{2} \mathrm{O}_{5}$, a qual pode ser causada pelo acúmulo de plagioclásio e apatita em alguns dos diques. 0 comportamento geoquímico destes óxidos sugere que a diferenciação não ocorreu por um processo petrogenético simples, como cristalização fracionada, a partir de um único magma parental e em sistema fechado. Nesses diagramas, a título de ilustração e para facilitar a interpretação dos resultados, estão também representados os dados de Piccirillo et al. (1987) e Marques (2001) para os diques do ESM, assim como as análises realizadas por Marques (1988) e Garland et al. (1995) para as rochas vulcânicas ácidas Chapecó-Ourinhos, que apresentam semelhanças com os diques mais evoluídos, conforme será discutido mais adiante.

Nos diagramas de $\mathrm{SiO}_{2}, \mathrm{TiO}_{2}, \mathrm{FeO}_{\mathrm{t}}, \mathrm{K}_{2} \mathrm{O}$ e $\mathrm{CaO}$ parece haver duas famílias distintas que evoluíram diferentemente (Grupos 1 e 2). Um aspecto que chama a atenção nestes diagramas é que um conjunto de quatro lati-andesitos mais diferenciados (LTA-1: $\mathrm{SiO}_{2}$ entre 54\% e 55\%; $\mathrm{MgO}<3 \%$ ) encontra-se sistematicamente associado ao conjunto dos basaltos do tipo Pitanga, sugerindo um caminho evolutivo para essas rochas (Grupo 1). Porém, não é possível inferir uma relação dos LTA-1 com os dacitos e riodacitos. 0s demais lati-andesitos pertencem ao Grupo 2 e foram separados em dois subgrupos: LTA-2a, composto por três amostras que apresentam características geoquímicas distintas dos demais (RJ-7527: $\mathrm{SiO}_{2} \sim 55 \%$ e $\mathrm{MgO}$ 2,5\%; RJ-7525 e RJ-7526: $\mathrm{SiO}_{2} \sim 55,5 \%$ e $\mathrm{MgO} 4 \%)$; e LTA-2b, composto por cinco rochas mais evoluídas $\left(\mathrm{SiO}_{2}\right.$ entre $58 \%$ e 60\%; $\mathrm{MgO}$ entre 3\% e 4\%), cuja diferenciação por cristalização fracionada controlada por clinopiroxênio, plagioclásio e titanomagnetita, poderia a princípio gerar os diques mais evoluídos (dacitos e riodacitos) desse grupo. 

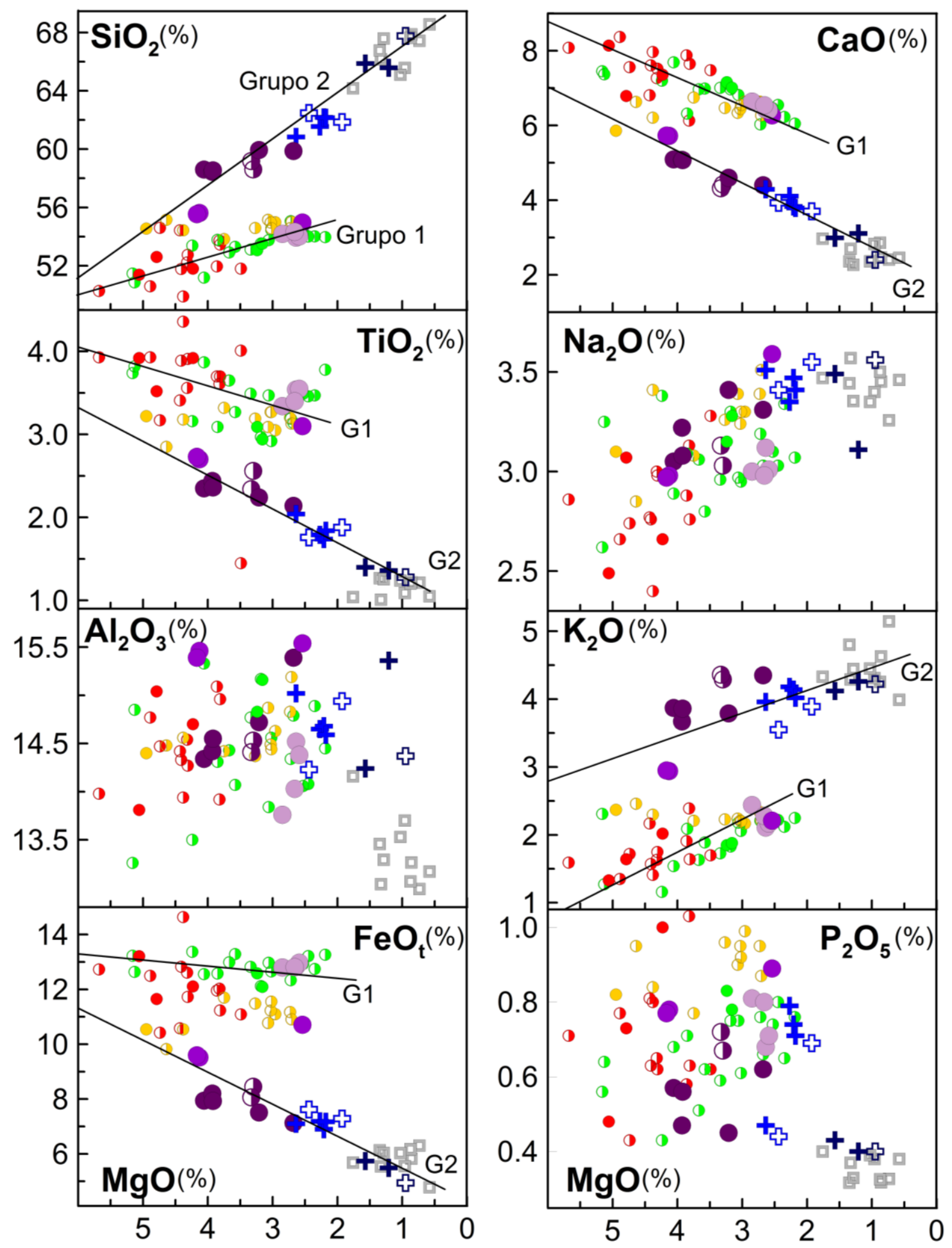

Figura 5.4.: Diagramas de variação dos óxidos maiores em função de $\mathrm{MgO}$. Legenda: círculos e cruzes cheias = presente estudo; círculos meio cheios e cruzes vazias $=$ Marques $(2001) ;$ quadrados $=$ Chapecó-Ourinhos. Cores: vermelho $=$ tipo Urubici; verde = tipo Pitanga; amarelo = tipo misto; roxo claro $=\mathrm{LTA}-1 ;$ roxo = LTA-2a; roxo escuro = LTA-2b; azul = DAC; azul escuro = RC. 


\subsubsection{Diagramas de variação de elementos traço}

Foram construídos diagramas que mostram a variação dos elementos em função de $\mathrm{Zr}$ (Figuras 5.5 e 5.6), que é um dos elementos mais incompatíveis do grupo analisado e que pode também servir como índice de evolução magmática. Diagramas de elementos incompatíveis são muito úteis para obter informações importantes sobre a origem das rochas ígneas, inclusive as características geoquímicas das fontes que sofreram fusão, como também sobre o processo de diferenciação magmática. Nos casos de suítes de rochas distintas os diagramas de elementos fortemente incompatíveis (coeficientes de partição D $<0.1$ ), tendem a se alinhar em retas que passam pela origem, mas que apresentam diferentes coeficientes angulares (Treuil et al., 1976; Wilson, 2007; Rollinson, 1993).

De maneira geral e conforme esperado, estes gráficos mostram um enriquecimento dos traços incompatíveis nas rochas mais evoluídas. 0 comportamento geoquímico desses elementos reforça a possibilidade de ocorrência de dois caminhos distintos de evolução magmática, conforme observado no comportamento dos óxidos dos elementos maiores e menores. Um dos caminhos evolutivos (Grupo 1) contempla os diques básicos composicionalmente semelhantes aos derrames Pitanga e inclui os LTA-1 como os membros mais diferenciados desta família. 0 outro (Grupo 2) abrange os demais LTA (LTA-2a e LTA-2b) juntamente com os dacitos (DAC) e riodacitos (RC). Este último grupo é caracterizado por apresentar um enriquecimento significativo de elementos terras raras (ETR) leves, Ta, Th, U, Ba, Rb e Sr (Figuras 5.5 e 5.6$)$.

É interessante notar o comportamento dos ETR nas rochas dos dois grupos. Em relação aos LTA do Grupo 1, os do Grupo 2 são enriquecidos em La, Ce e $\mathrm{Nd}$, e empobrecidos em $\mathrm{Tb}, \mathrm{Yb}, \mathrm{Lu}$, sendo que as concentrações de $\mathrm{Sm}$ e Eu são similares. Isto mostra que os ETR leves sofreram um fracionamento significativo em relação aos ETR pesados na diferenciação magmática. 0 elemento Y possui comportamento similar aos ETR pesados. Verifica-se também que as concentrações de $\mathrm{La}, \mathrm{Ce}, \mathrm{Nd}, \mathrm{Ta}, \mathrm{Nb}$, Th e Ba nos DAC e RC são similares às dos LTA-2b, ocorrendo também um aumento de Tb, Lu e Y comparando esses mesmos litotipos. 

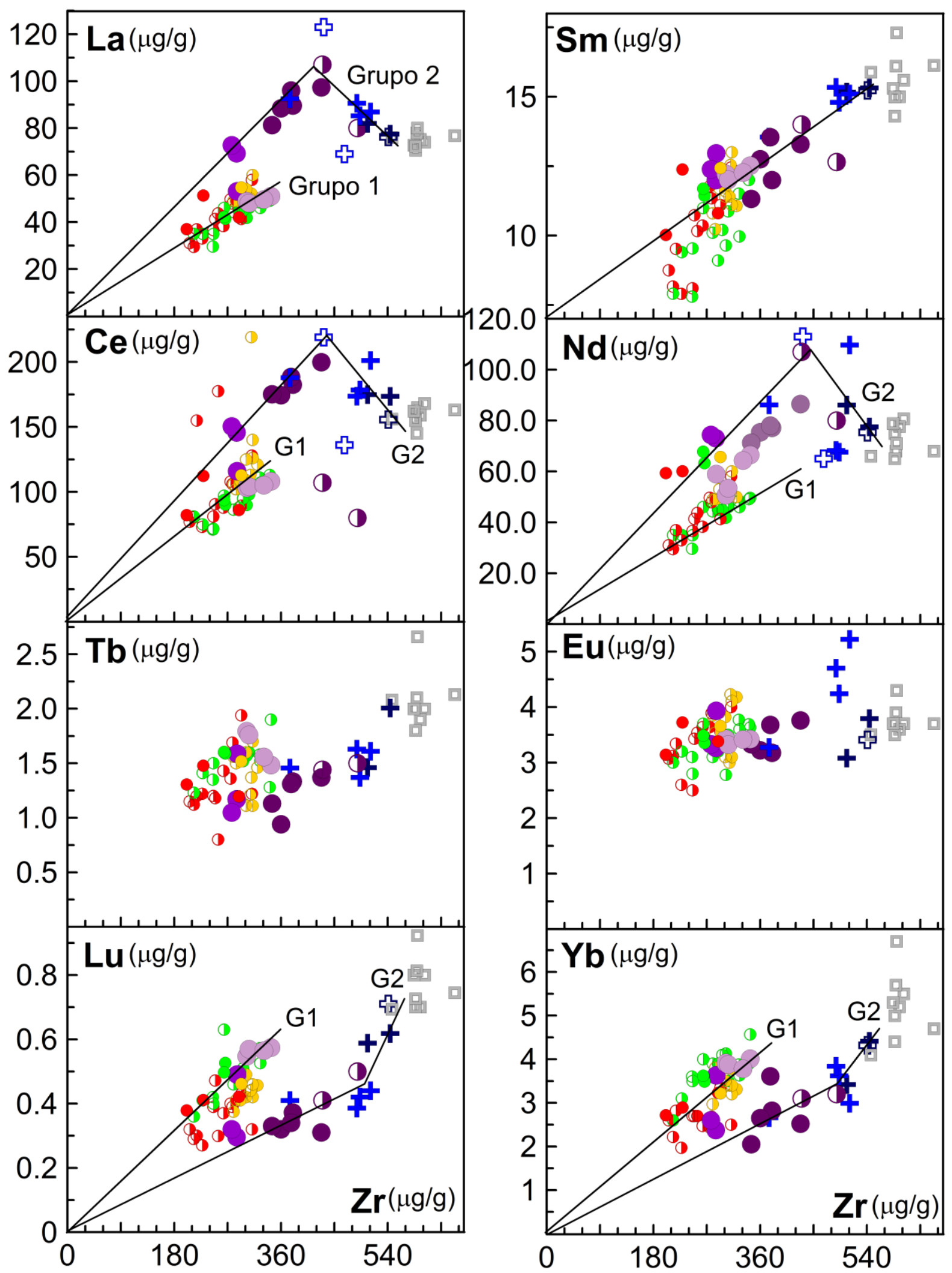

Figura 5.5.: Diagramas de variação de ETR em função do $\operatorname{Zr}$ (fortemente incompatível). Legenda: círculos e cruzes cheias = presente estudo; círculos meio cheios e cruzes vazias = Marques (2001); quadrados $=$ Chapecó-Ourinhos. Cores: vermelho = tipo Urubici; verde = tipo Pitanga; amarelo = tipo misto; roxo claro = LTA-1; roxo = LTA-2a; roxo escuro = LTA $-2 b ;$ azul = DAC; azul escuro = RC. Linhas pretas: representam as possíveis trajetórias de diferenciação magmática dos grupos 1 e 2 . 

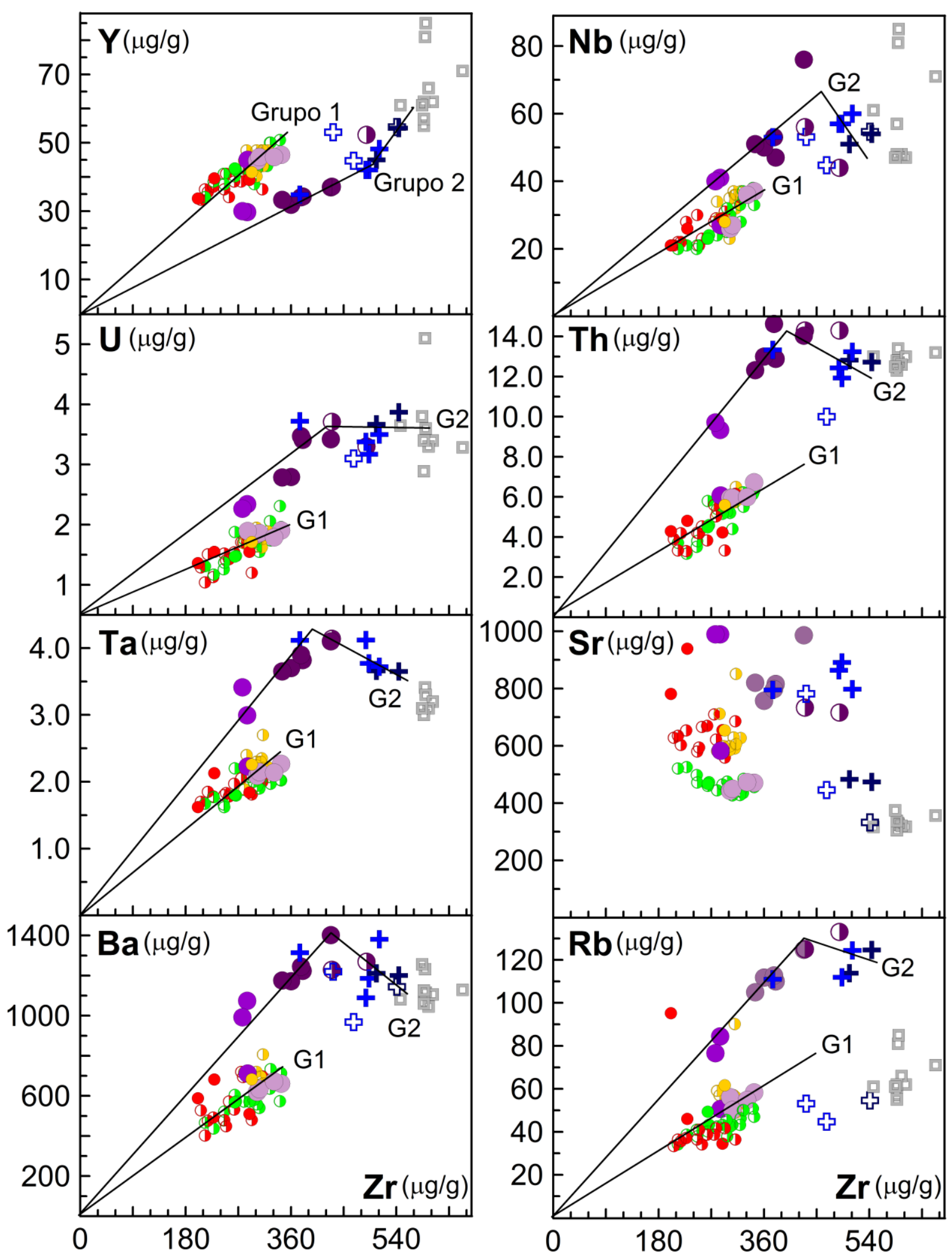

Figura 5.6.: Diagramas de variação de elementos traço em função do Zr. Legenda: círculos e cruzes cheias = presente estudo; círculos meio cheios e cruzes vazias = Marques (2001); quadrados = Chapecó-Ourinhos. Cores: vermelho = tipo Urubici; verde = tipo Pitanga; amarelo = tipo misto (Marques, 2001); roxo claro = LTA-1; roxo $=$ LTA $-2 \mathrm{a}$; roxo escuro $=\mathrm{LTA}-2 \mathrm{~b} ;$ azul $=\mathrm{DAC}$; azul escuro = RC. Linhas pretas: representam as possíveis trajetórias de diferenciação magmática dos grupos $1 \mathrm{e}$ 2. 
Assim como na Figura 5.4, é possível ver que o comportamento geoquímico dos diques mais evoluídos (DAC e RC) assemelha-se com aquele das vulcânicas do tipo Chapecó-Ourinhos (Figuras 5.5 e 5.6). Cabe ainda mencionar que os DAC e RC apresentam variação bastante significativa nas concentrações de $\mathrm{Rb}$ e de $\mathrm{Sr}$, sendo que somente aqueles que possuem baixas concentrações desses dois elementos são similares com tais vulcânicas ácidas.

\subsubsection{Padrões de abundância de elementos terras raras}

Os padrões de abundância de ETR dos litotipos básicos (Grupo 1) estão apresentados na Figura 5.7. O lati-andesito do tipo misto mostra um fracionamento ligeiramente diferente dos demais tipos (Pitanga e Urubici) encontrados no ESM, sendo mais enriquecido em ETR leves e mais empobrecido em ETR pesados em relação à média dos diques tipo Pitanga do ESM. Nota-se, porém, um maior enriquecimento em ETR pesados do que a média dos diques Urubici do enxame. Comparando-se com os derrames da PMP, nota-se um enriquecimento em ETR leves, sendo que os ETR pesados apresentam concentrações muito semelhantes (Tabela 5.1).

Os ABT do tipo Urubici se mostraram muito semelhantes aos diques do ESM do mesmo tipo, assim como aos derrames da PMP. Para estes três conjuntos, o teor de $\mathrm{MgO}$ está entre 4\% e 5\% mostrando, portanto, que a comparação foi feita considerando-se rochas com o mesmo grau de evolução magmática (Figura 5.7). Em relação aos LTA do tipo Pitanga, observa-se que estas rochas apresentam o mesmo comportamento dos demais diques do mesmo tipo do ESM. Comparando-se com os derrames da PMP, o padrão de ETR é similar, porém mais enriquecido em todos os elementos da família. Isto reflete o grau de evolução das rochas, uma vez que os diques contêm $\mathrm{MgO} 3,2 \%$ enquanto os derrames são mais primitivos, apresentando MgO entre 4\% e 5\%. Vale ressaltar que os valores de $\mathrm{Nd}$ indicam uma anomalia positiva nos padrões de abundância (tipo Pitanga e tipo Urubici), relacionada a um erro analítico, já que a determinação desse elemento por ativação neutrônica, puramente instrumental, pode apresentar problemas, conforme discutido no capítulo 4 (seção 4.1.5). 
Tabela 5.1.: Valor médio e desvio padrão das razões entre elementos menores e traço calculadas para as rochas estudadas.

\begin{tabular}{|c|c|c|c|c|c|c|c|c|}
\hline \multirow{3}{*}{$\begin{array}{l}\text { LTA tipo } \\
\text { misto }\end{array}$} & & ${ }^{[1]}(\mathrm{La} / \mathrm{Lu})_{\mathrm{n}}$ & ${ }^{[1]}(\mathrm{La} / \mathrm{Yb})_{\mathrm{n}}$ & ${ }^{[1]}(\mathrm{La} / \mathrm{Sm})_{\mathrm{n}}$ & ${ }^{[1]}(\mathrm{Sm} / \mathrm{Yb})_{\mathrm{n}}$ & $\mathrm{Eu} / \mathrm{Eu}^{*}$ & ${ }^{[2]}(\mathrm{Rb} / \mathrm{Ba})_{\mathrm{n}}$ & $\mathrm{Ti} / \mathrm{Y}$ \\
\hline & $\bar{x}$ & 12,1 & 10 & 2,7 & 3,7 & 1,05 & 1,07 & 415 \\
\hline & $1 \sigma$ & 0,5 & 1 & 0,1 & 0,4 & 0,10 & 0,31 & 35 \\
\hline \multirow{2}{*}{$\begin{array}{l}\text { LTA tipo } \\
\text { Pitanga }\end{array}$} & $\bar{x}$ & 8,8 & 8,1 & 2,5 & 3,2 & 1,00 & 0,89 & 505 \\
\hline & $1 \sigma$ & 0,9 & 0,8 & 0,2 & 0,3 & 0,09 & 0,10 & 95 \\
\hline \multirow{2}{*}{$\begin{array}{l}\text { ABT tipo } \\
\text { Urubici }\end{array}$} & $\bar{x}$ & 12 & 11 & 2,5 & 4,3 & 1,05 & 0,96 & 598 \\
\hline & $1 \sigma$ & 3 & 2 & 0,2 & 0,6 & 0,07 & 0,46 & 69 \\
\hline \multirow{2}{*}{ LTA-1 } & $\bar{x}$ & 9,1 & 8,6 & 2,52 & 3,4 & 0,86 & 0,93 & 454 \\
\hline & $1 \sigma$ & 0,2 & 0,2 & 0,02 & 0,1 & 0,02 & 0,06 & 20 \\
\hline \multirow{2}{*}{ LTA-2a } & $\bar{x}$ & 24,0 & 19 & 3,64 & 5,3 & 0,91 & 0,86 & 545,3 \\
\hline & $1 \sigma$ & 0,5 & 1 & 0,04 & 0,2 & 0,01 & 0,01 & 0,4 \\
\hline \multirow{2}{*}{ LTA-2b } & $\bar{x}$ & 28 & 23 & 4,5 & 5,1 & 0,91 & 1,00 & 407 \\
\hline & $1 \sigma$ & 3 & 4 & 0,1 & 0,8 & 0,05 & 0,03 & 41 \\
\hline \multirow{2}{*}{ DAC } & $\bar{x}$ & 22 & 19 & 3,8 & 5,0 & 0,97 & 1,12 & 256 \\
\hline & $1 \sigma$ & 2 & 4 & 0,3 & 0,6 & 0,14 & 0,27 & 49 \\
\hline \multirow{2}{*}{$\mathrm{RD}$} & $\bar{x}$ & 13 & 13 & 3,2 & 4,1 & 0,73 & 1,09 & 159 \\
\hline & $1 \sigma$ & 2 & 2 & 0,1 & 0,6 & 0,05 & 0,08 & 20 \\
\hline
\end{tabular}

$\sigma=1$ desvio padrão; $\bar{x}=$ media das determinações

[1] = valores normalizados pelo condrito de McDonough \& Sun (1995);

[2] = valores normalizados pelo manto primitivo de McDonough \& Sun (1995).

Os cálculos incluem outros dados do ESM (Marques (2001) e Marques, dados inéditos). ABT tipo misto: $\mathrm{N}=4$; ABT tipo Pitanga: $N=6$; $A B T$ tipo Urubici: $N=13$; $L T A-1$ = rochas diferenciadas semelhantes às do tipo Pitanga $(\mathrm{N}=4) ; \mathrm{LTA}-2 \mathrm{a}=$ não apresentam semelhanças com as demais $(\mathrm{N}=2)$; $\mathrm{LTA}-2 \mathrm{~b}=$ rochas mais diferenciadas; $\mathrm{DAC}$ : $\mathbf{N}=4 ; \mathbf{R C}: \mathbf{N}=3$.

Do grupo dos litotipos mais diferenciados (Figura 5.8), os LTA-1 mostram um comportamento bastante similar à média dos diques tipo Pitanga do ESM, com leve enriquecimento nos ETR leves e pesados. Comparado aos derrames Pitanga da PMP os LTA-1 exibem semelhanças no padrão de ETR, sendo, porém, mais enriquecidos, uma vez que são mais diferenciados (Mg0 2,5\%). Além disso, é possível notar que duas amostras apresentam leve anomalia negativa de $\mathrm{Eu}$, semelhante àquela apresentada pela média das ácidas do tipo Chapecó-Ourinhos, embora apresentem maior empobrecimento nos ETR comparativamente a essas vulcânicas. 


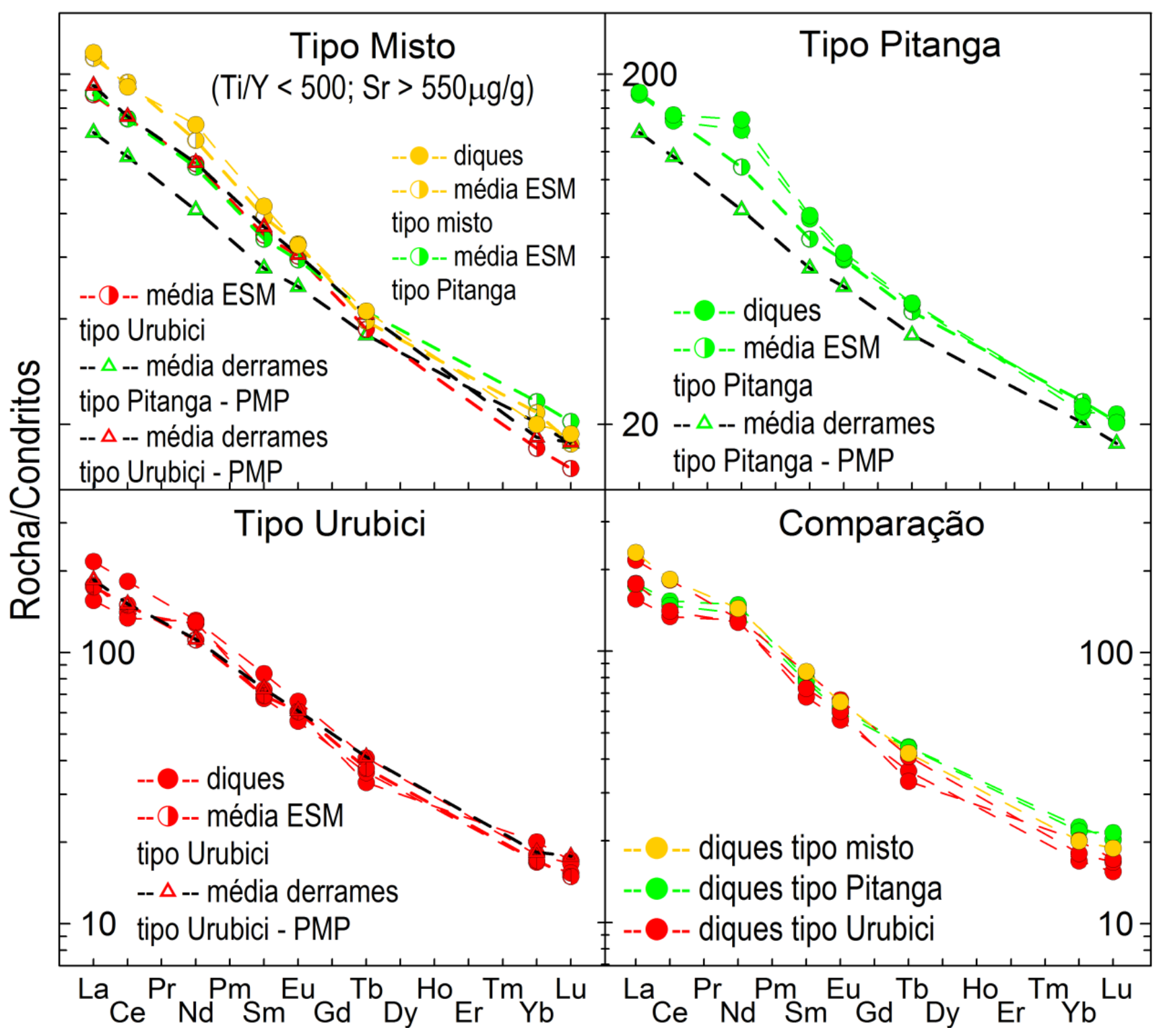

Figura 5.7.: Diagramas das concentrações de elementos terras raras normalizadas em relação aos condritos (McDonough \& Sun, 1995) para os litotipos básicos. Legenda: círculos cheios = presente estudo; círculos meio cheios = média ESM (Marques, 2001); triângulos vazios = média dos derrames Pitanga e Urubici da PMP (Mantovani et al., 1985a; Marques et al., 1989; Peate et al., 1999). Cores: vermelho = tipo Urubici; verde = tipo Pitanga; amarelo = tipo misto; preto = derrames da PMP.

Os LTA-2a, por sua vez, exibem um comportamento muito próximo às ácidas do tipo Chapecó-Ourinhos especialmente nos ETR leves, sem expressivas anomalias de Eu. Já os LTA-2b são mais enriquecidos em ETR leves do que a média do tipo Chapecó-Ourinhos, entretanto, os dois grupos apresentaram um 
forte empobrecimento em ETR pesados comparativamente às ácidas. Os termos mais evoluídos do conjunto, os DAC e RC, se mostraram mais semelhantes às vulcânicas ácidas Chapecó-Ourinhos, mas com menor fracionamento de ETR pesados para os RC.

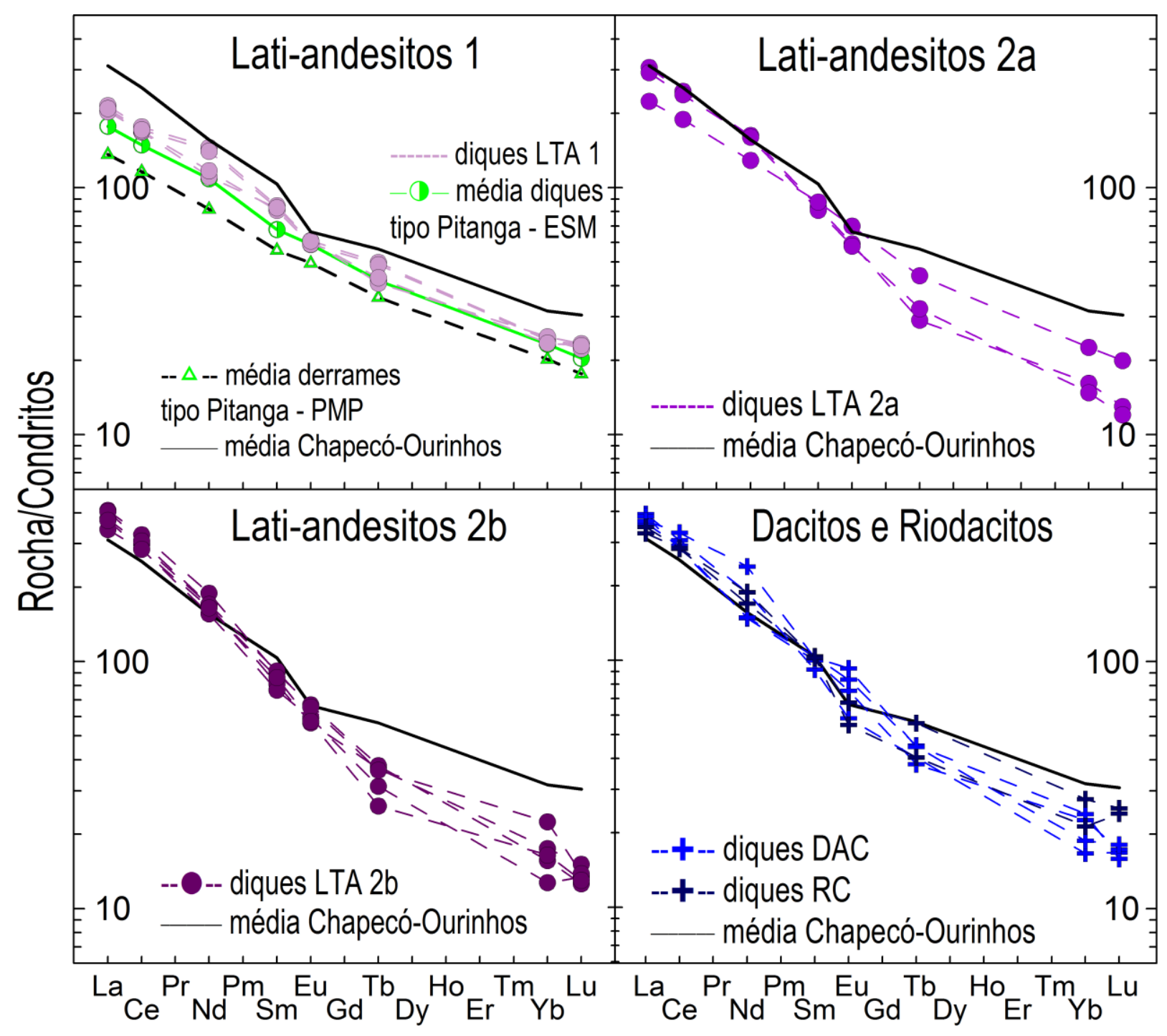

Figura 5.8.: Diagramas das concentrações de elementos terras raras normalizadas em relação aos condritos (McDonough \& Sun, 1995) para os litotipos diferenciados. Legenda: círculos e cruzes cheias = presente estudo; círculos meio cheios = média ESM (Marques, 2001); triângulos vazios = média dos derrames Pitanga da PMP (Mantovani et al., 1985a; Marques et al., 1989). Cores: verde $=$ tipo Pitanga; roxo claro $=$ LTA- 1 ; roxo $=$ LTA-2a; roxo escuro = LTA-2b; azul = DAC; azul escuro = RC; linha preta = média das vulcânicas ácidas tipo Chapecó-Ourinhos. 
Para o grupo diferenciado, as maiores razões $(\mathrm{La} / \mathrm{Yb})_{\mathrm{n}}$ são observadas nos LTA-2b $(23 \pm 4 ; N=5)$, seguido dos LTA-2a $(19 \pm 1 ; N=3)$, sendo os menores valores pertencentes ao grupo de LTA-1 $(8,6 \pm 0,2 ; \mathrm{N}=4)$. Nos dacitos esses valores são menores $(19 \pm 4 ; \mathrm{N}=4)$ do que os dos $\mathrm{LTA}-2 \mathrm{~b}$ e nos riodacitos os valores decrescem mais $(13 \pm 2 ; \mathrm{N}=3)$. Os padrões de ETR também apresentam anomalias leves a moderadas de $\mathrm{Eu}\left(0,67<\mathrm{Eu} / \mathrm{Eu}^{*}<1,13\right)$, que podem ser tanto negativas, refletindo o fracionamento de plagioclásio, como positivas, resultantes do acúmulo deste mineral em algumas das rochas (Tabela 5.1). A amostra RJ7527 (LTA-2a) não foi incluída nos cálculos para o subgrupo LTA-2a por apresentar características distintas às demais, como já citado, sendo exibidas à parte: $(\mathrm{La} / \mathrm{Lu})_{\mathrm{n}}=11 ;(\mathrm{La} / \mathrm{Yb})_{\mathrm{n}}=9,9 ;(\mathrm{La} / \mathrm{Sm})_{\mathrm{n}}=2,6 ;(\mathrm{Sm} / \mathrm{Yb})_{\mathrm{n}}=3,9 ; \mathrm{Eu} / \mathrm{Eu}^{*}=0,96$.

\subsubsection{Padrões de abundância multielementares}

As Figuras 5.9 e 5.10 mostram diagramas multielementares, normalizados em relação ao manto primordial (McDonough \& Sun, 1995), para os diques básicos e diferenciados, respectivamente. Assim como no padrão de ETR, é possível perceber que o padrão de abundância multielementar dos diques básicos é muito semelhante às médias dos respectivos tipos já encontrados no ESM. Da mesma forma, nos diques do tipo Pitanga investigados foram observadas diferenças sistemáticas em relação aos derrames Pitanga da PMP, com exceção dos elementos $\mathrm{Nb}$ e $\mathrm{Sr}$, que parecem apresentar anomalias negativas similares, bem como de $\mathrm{Zr}$ e $\mathrm{Ti}$, cujos comportamentos parecem ligeiramente distintos (leves anomalias negativas nos diques).

No caso dos diques tipo Urubici, são observados padrões de abundância muito semelhantes, com exceção do alto teor de Rb em uma amostra (B-1111), porém, concentrações assim altas são também são observadas em outros diques do ESM (Marques, 2001). Da mesma forma como no tipo Pitanga, o comportamento do Zr parece divergir levemente nos diques, apresentando leves anomalias negativas em comparação com os derrames. 


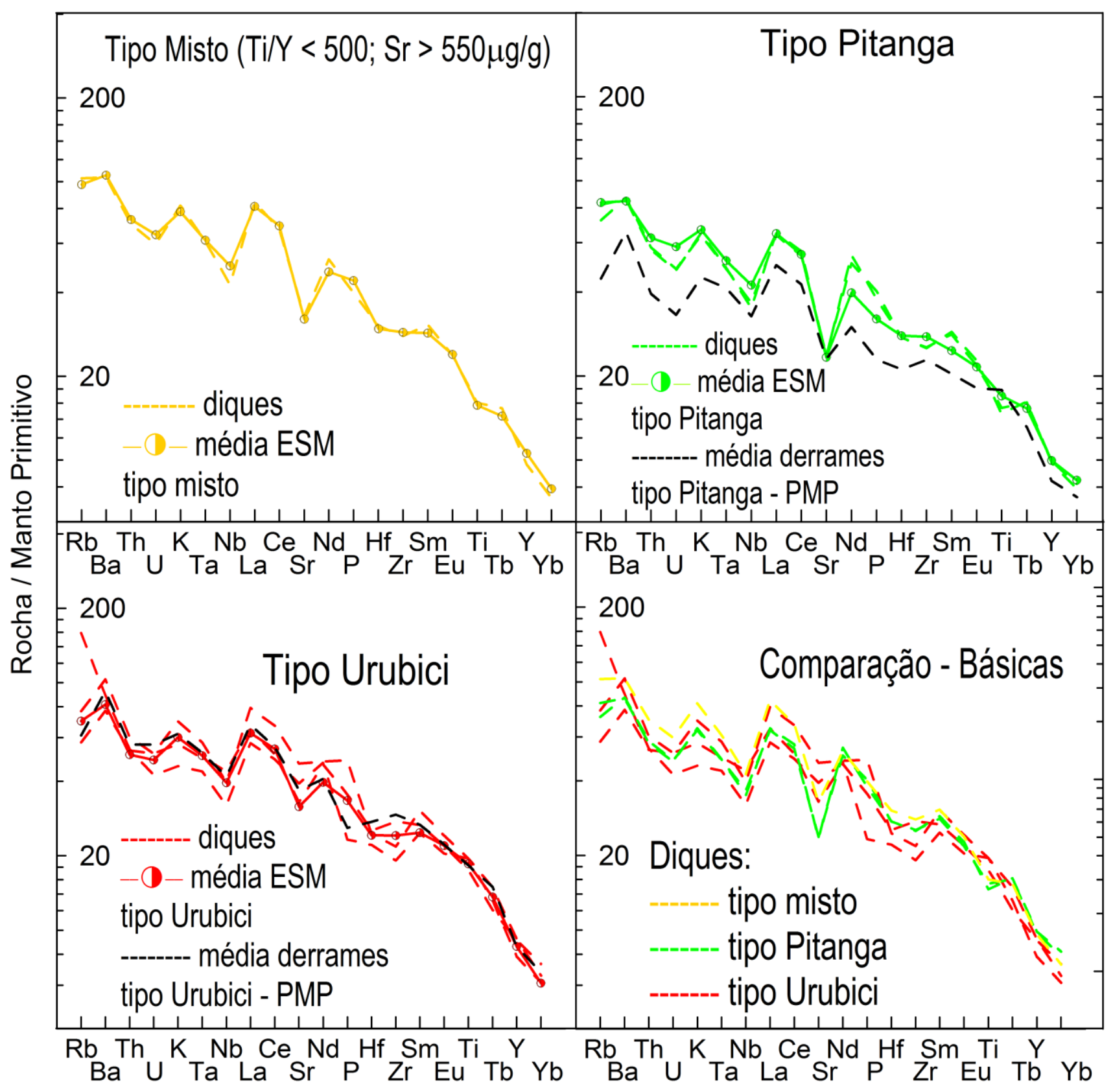

Figura 5.9.: Diagramas multielementares normalizados em relação ao manto primitivo (McDonough \& Sun, 1995) para os litotipos básicos. Legenda: círculos meio cheios = média ESM (Marques, 2001). Cores: vermelho = tipo Urubici; verde = tipo Pitanga; amarelo = tipo misto; preto = derrames da PMP (Mantovani et al., 1985a; Marques et al., 1989; Peate et al., 1999).

Para as rochas mais diferenciadas do estudo, de forma geral, são observadas acentuadas anomalias negativas de $\mathrm{Sr}, \mathrm{P}$ e $\mathrm{Ti}$ nos diagramas multielementares (Figura 5.10), sendo que quando comparados aos das 
vulcânicas Chapecó-Ourinhos, observa-se um empobrecimento significativo de ETR pesados e Y. As razões $(\mathrm{Rb} / \mathrm{Ba})_{\mathrm{PM}}$, que são indicadoras de processos de contaminação crustal, variam de 0,9 a 1,5, sendo semelhantes às dessas rochas vulcânicas ácidas.

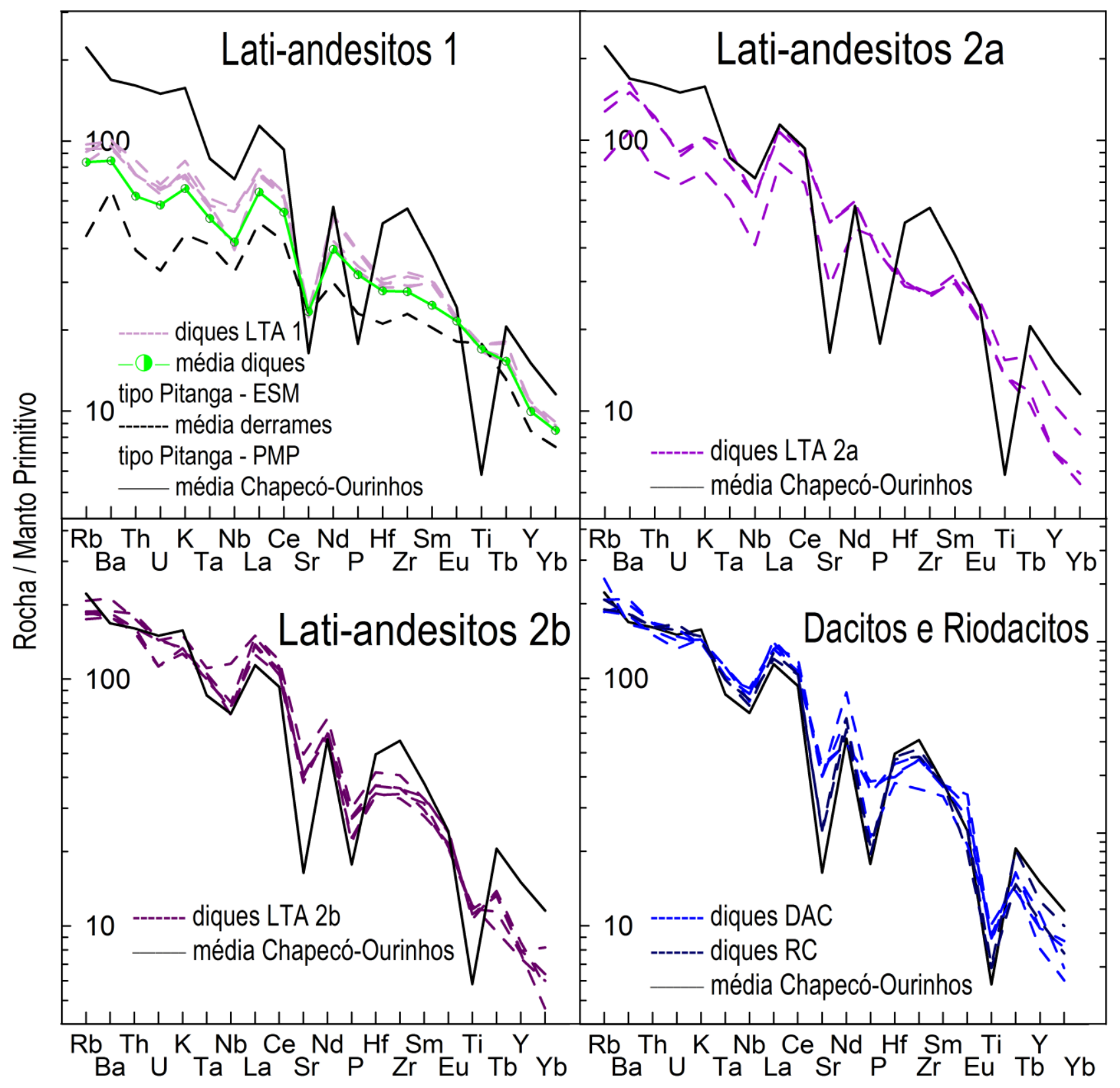

Figura 5.10.: Diagramas multielementares normalizados em relação ao manto primitivo (McDonough \& Sun, 1995) para os litotipos diferenciados. Legenda: círculos meio cheios = média ESM (tipo Pitanga - Marques, 2001). Cores: verde = tipo Pitanga; roxo claro $=\mathrm{LTA}-1$; roxo $=\mathrm{LTA}-2 \mathrm{a}$; roxo escuro $=\mathrm{LTA}-2 \mathrm{~b}$; azul = DAC; azul escuro = RC; preto = derrames da PMP (Mantovani et al., 1985a; Marques et al., 1989). 
Para o grupo dos litotipos mais diferenciados, são observados padrões de abundância intermediários para os LTA-1, sendo mais enriquecidos que os derrames Pitanga e ligeiramente mais enriquecidos do que os diques do ESM, com exceção do Sr e Ti. Quando comparados com as ácidas Ourinhos da PMP são notadas diferenças apenas nas concentrações de P, Hf e Zr. No caso dos LTA-2a, o comportamento é mais próximo das rochas Chapecó-Ourinhos, divergindo apenas nos três elementos anteriormente citados. Observa-se também um leve enriquecimento em Th, U, K, ETR pesados e empobrecimento em Sr e Ti. No caso dos LTA-2b, DAC e RC o comportamento é muito similar às vulcânicas ácidas, sendo praticamente idêntico no caso dos RC.

Os valores das razões $(\mathrm{Rb} / \mathrm{Ba})_{\mathrm{n}}$, normalizadas em relação ao manto primordial, incluindo-se outros dados do ESM (Marques, 2001) encontram-se na Tabela 5.1. Conforme mencionado anteriormente, amostra RJ-7527 (LTA-2a) não foi incluída nos cálculos para o subgrupo LTA-2a por apresentar características distintas às demais, como já citado, sendo exibidas a parte: $(\mathrm{Rb} / \mathrm{Ba})_{\mathrm{n}}=0,8$; Ti/Y=413. A Figura 5.11 mostra a comparação de todas as amostras estudadas nos diagramas de ETR e multielementares.

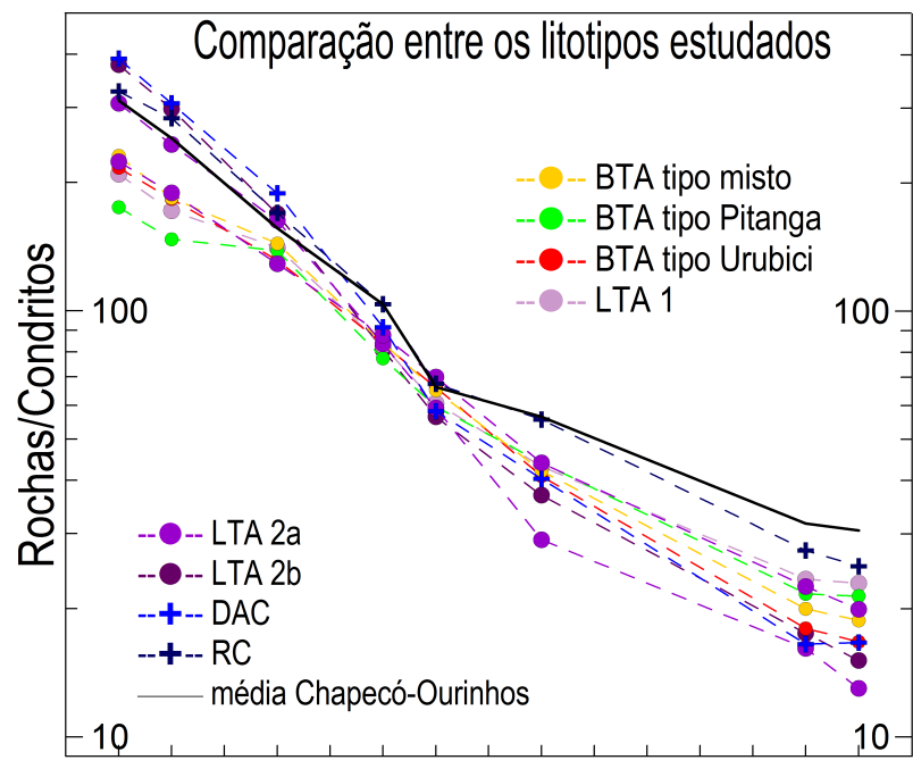

La Ce Pr Nd Pm Sm Eu Gd Tb Dy Ho Er Tm Yb Lu

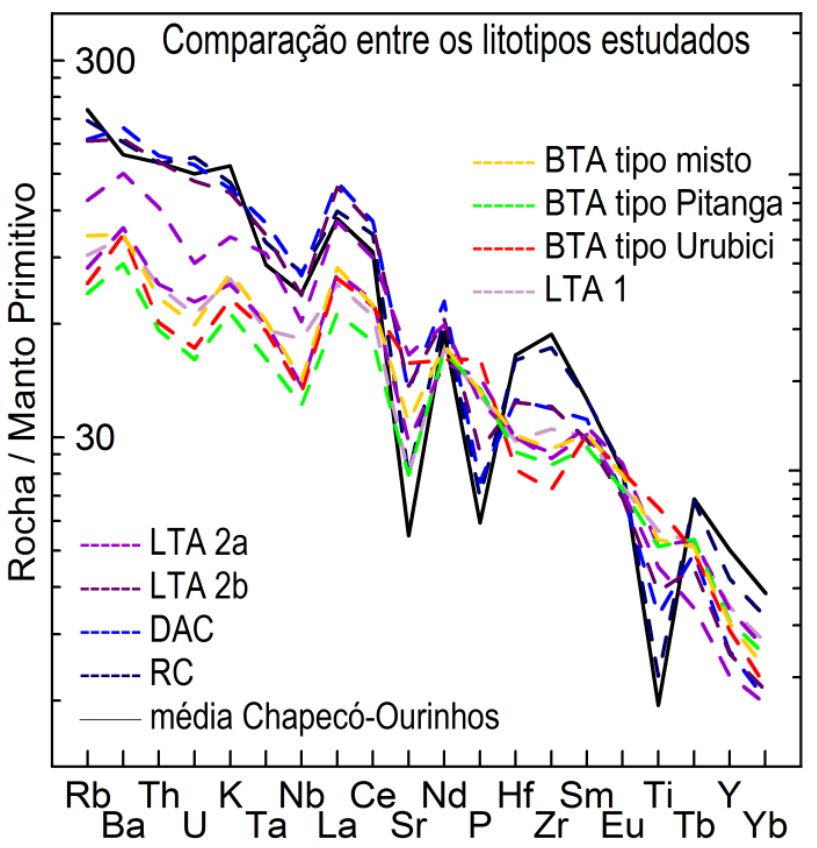

Figura 5.11.: Diagramas de elementos terras raras normalizados em relação aos condritos e diagramas multielementares normalizados em relação ao manto primitivo (McDonough \& Sun, 1995), comparando todos os litotipos estudados. Legenda indicada na figura. 


\subsection{Isótopos radiogênicos}

Dentre as rochas mais evoluídas do conjunto estudado, foram escolhidas para as análises isotópicas de $\mathrm{Sr}, \mathrm{Nd}$ e $\mathrm{Pb}$ : um lati-andesito do grupo LTA-1 (RJ7517), um lati-andesito do grupo LTA-2b (RJ-7544), dois dacitos (B-1097 e SSA62) e um riodacito (SSA-57), cujos resultados encontram-se na Tabela 5.2. As comparações desses resultados com outros do conjunto, somados a dados da literatura estão dispostas nas seções seguintes.

Tabela 5.2.: Valores medidos das razões isotópicas de $\mathrm{Sr}, \mathrm{Nd}$ e $\mathrm{Pb}$ para cinco amostras representativas dos diques diferenciados do ESM.

\begin{tabular}{|c|c|c|c|c|c|}
\hline Amostra & RJ-7517 & RJ-7544 & B-1097 & SSA-62 & SSA-56 \\
\hline Subgrupo & LTA-1 & LTA-2b & DAC & DAC & $\mathrm{RC}$ \\
\hline${ }^{87} \mathrm{Sr} /{ }^{86} \mathrm{Sr}_{\mathrm{m}}$ & 0,706910 & 0,708164 & 0,708660 & 0,708024 & 0,708332 \\
\hline $2 \sigma$ & 0,000041 & 0,000045 & 0,000030 & 0,000028 & 0,000050 \\
\hline${ }^{143} \mathrm{Nd} /{ }^{144} \mathrm{Nd}$ & 0,512362 & 0,512189 & 0,512156 & 0,512288 & 0,512323 \\
\hline $2 \sigma$ & 0,000006 & 0,000004 & 0,000009 & 0,000003 & 0,000004 \\
\hline${ }^{206} \mathrm{~Pb} /{ }^{204} \mathrm{~Pb}_{\mathrm{m}}$ & 18,361 & 18,160 & 18,287 & 18,359 & 18,383 \\
\hline $2 \sigma$ & 0,006 & 0,004 & 0,006 & 0,008 & 0,005 \\
\hline${ }^{207} \mathrm{~Pb} /{ }^{204} \mathrm{~Pb}_{\mathrm{m}}$ & 15,578 & 15,550 & 15,576 & 15,571 & 15,586 \\
\hline $2 \sigma$ & 0,006 & 0,004 & 0,005 & 0,007 & 0,004 \\
\hline${ }^{208} \mathrm{~Pb} / 204 \mathrm{~Pb} \mathrm{~m}$ & 38,569 & 38,573 & 38,673 & 38,627 & 38,620 \\
\hline $2 \sigma$ & 0,014 & 0,009 & 0,015 & 0,015 & 0,012 \\
\hline
\end{tabular}

\subsubsection{Isótopos de $\mathrm{Sr}$ e $\mathrm{Nd}$}

As razões isotópicas iniciais $\left({ }^{87} \mathrm{Sr} /{ }^{86} \mathrm{Sr}\right)_{\mathrm{i}}$, corrigidas para $130 \mathrm{Ma}$, dos diques investigados não apresentam muita variação, situando-se entre 0,70628 e 0, 70788 (média $=0,7071 \pm 0,0006$ ), sendo significativamente mais radiogênicas do que os derrames Pitanga e Urubici da PMP, os quais são caracterizados por apresentarem razões $\left({ }^{87} \mathrm{Sr} /{ }^{86} \mathrm{Sr}\right)_{\mathrm{i}}<0,7060$. Os resultados obtidos mostram, que exceto por uma amostra, as razões isotópicas de Sr são mais radiogênicas do que aquelas dos diques do ESM anteriormente estudadas (Marques et al., 2012; Carvas, 2014), cuja grande maioria apresenta $\left({ }^{87} \mathrm{Sr} /{ }^{86} \mathrm{Sr}\right)_{\mathrm{i}}>0,7060$ (Figura 5.12). 
Cabe destacar que, para os derrames da PMP, razões isotópicas de $\mathrm{Sr}$ acima de 0,7060 são resultantes de processos de contaminação crustal, que afetaram principalmente os derrames basálticos de baixo Ti e as vulcânicas ácidas do tipo Palmas que ocorrem na parte sul da PMP.

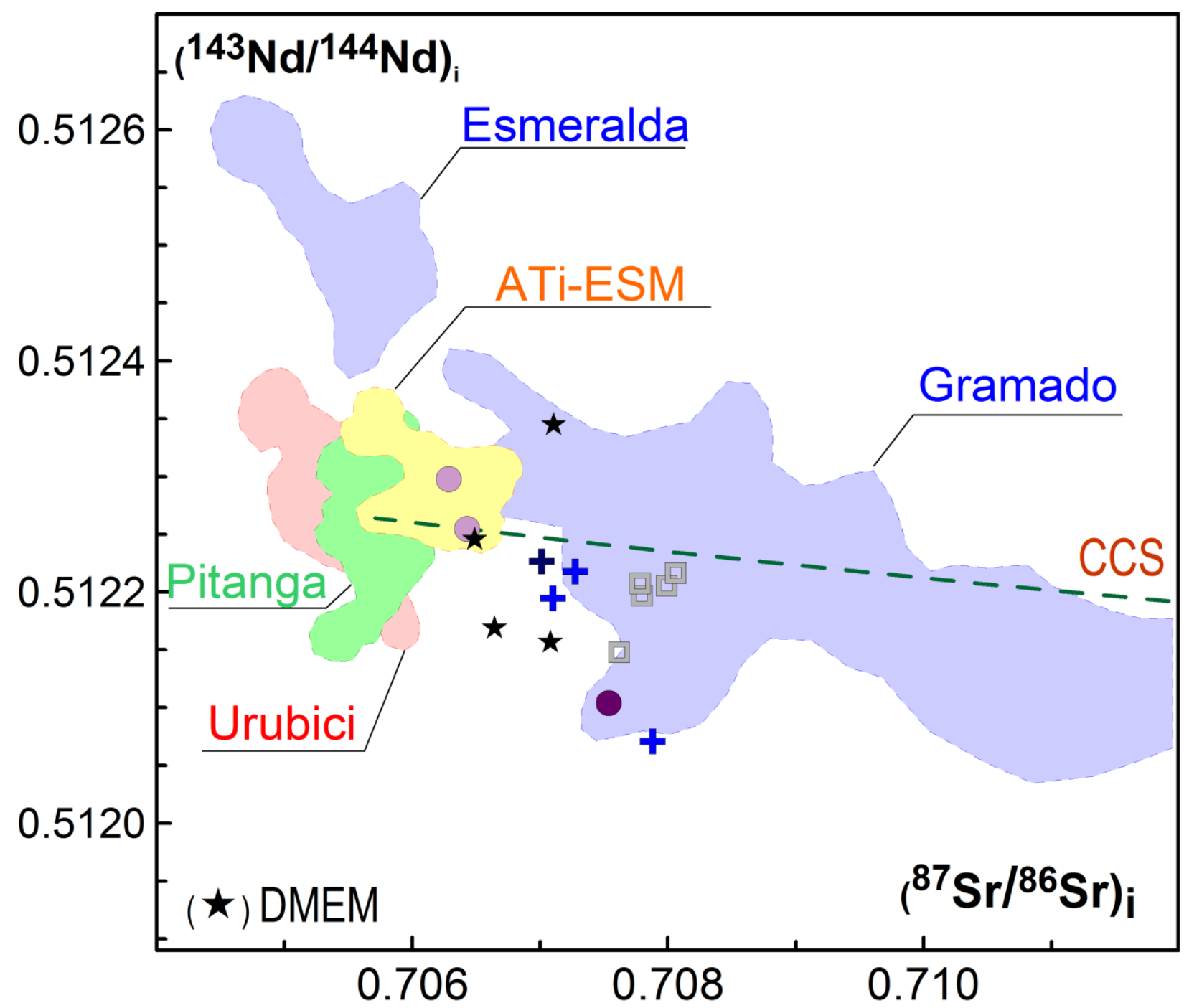

Figura 5.12.: Diagrama das razões isotópicas iniciais de $\mathrm{Sr}$ e $\mathrm{Nd}$ para as rochas intermediárias do ESM. Legenda: círculos e cruzes cheias = presente estudo; quadrado = Chapecó-Ourinhos; estrelas = diques mesozoicos do Espinhaço Meridional (Marques et al., 2015). Cores: roxo claro = LTA-1; roxo escuro = LTA2b; azul = DAC; azul escuro = RC. Campos: vermelho = derrames Urubici (PMP); verde = derrames Pitanga; amarelo = diques ESM (Bellieni et al. (1990); Marques, 2001 e dados inéditos; Carvas, 2014); azul = derrames Esmeralda e Gramado. Linha tracejada verde = linha de mistura de basaltos do tipo Pitanga com crosta continental superior (CCS; Rudinick \& Gao, 2003). 
As razões isotópicas iniciais $\left({ }^{143} \mathrm{Nd} /{ }^{144} \mathrm{Nd}\right)_{\mathrm{i}}$ variam de 0,51207 a 0,51225 (média = 0,51219 $\pm 0,00009$ ), sendo que os valores são semelhantes aos dos derrames basálticos Pitanga e Urubici, com exceção de um lati-andesito e de um dacito que apresentam valores um pouco mais baixos, conforme pode ser observado na Figura 5.12. Apenas dois lati-andesitos estão no campo dos diques anteriormente analisados do ESM (Bellieni et al. (1990); Marques et al., 2012 e dados inéditos; Carvas, 2014), sendo que os demais apresentam valores mais baixos.

\subsubsection{Isótopos de $\mathrm{Pb}$}

As razões isotópicas iniciais, corrigidas para $130 \mathrm{Ma}$, de $\left({ }^{206} \mathrm{~Pb} /{ }^{204} \mathrm{~Pb}\right)_{\mathrm{i}}$ variam de 17,893 a 18,167 (média $=18,08 \pm 0,10)$, as de $\left({ }^{207} \mathrm{~Pb} /{ }^{204} \mathrm{~Pb}\right.$ ) i situam-se no intervalo de 15,537 a 15,573 (média $=15,56 \pm 0,01$ ), enquanto as de $\left({ }^{208} \mathrm{~Pb} /{ }^{204} \mathrm{~Pb}\right)_{\text {i }}$ possuem média $38,25 \pm 0,06(38,163-38,319)$, as quais são bem mais radiogênicas do que aquelas observadas para os derrames Pitanga e Urubici da PMP, como pode ser observado nos diagramas da Figuras 5.13 e 5.14. Nota-se, no entanto, que as razões isotópicas de $\mathrm{Pb}$ são muito semelhantes àquelas dos diques do ESM (Marques et al., 2012; Carvas, 2014), sendo que dois dacitos, um riodacito e um lati-andesito (LTA-1) apresentam as composições radiogênicas do grupo, enquanto um lati-andesito do outro grupo (LTA-2) possui as menores razões isotópicas de $\mathrm{Pb}$. 

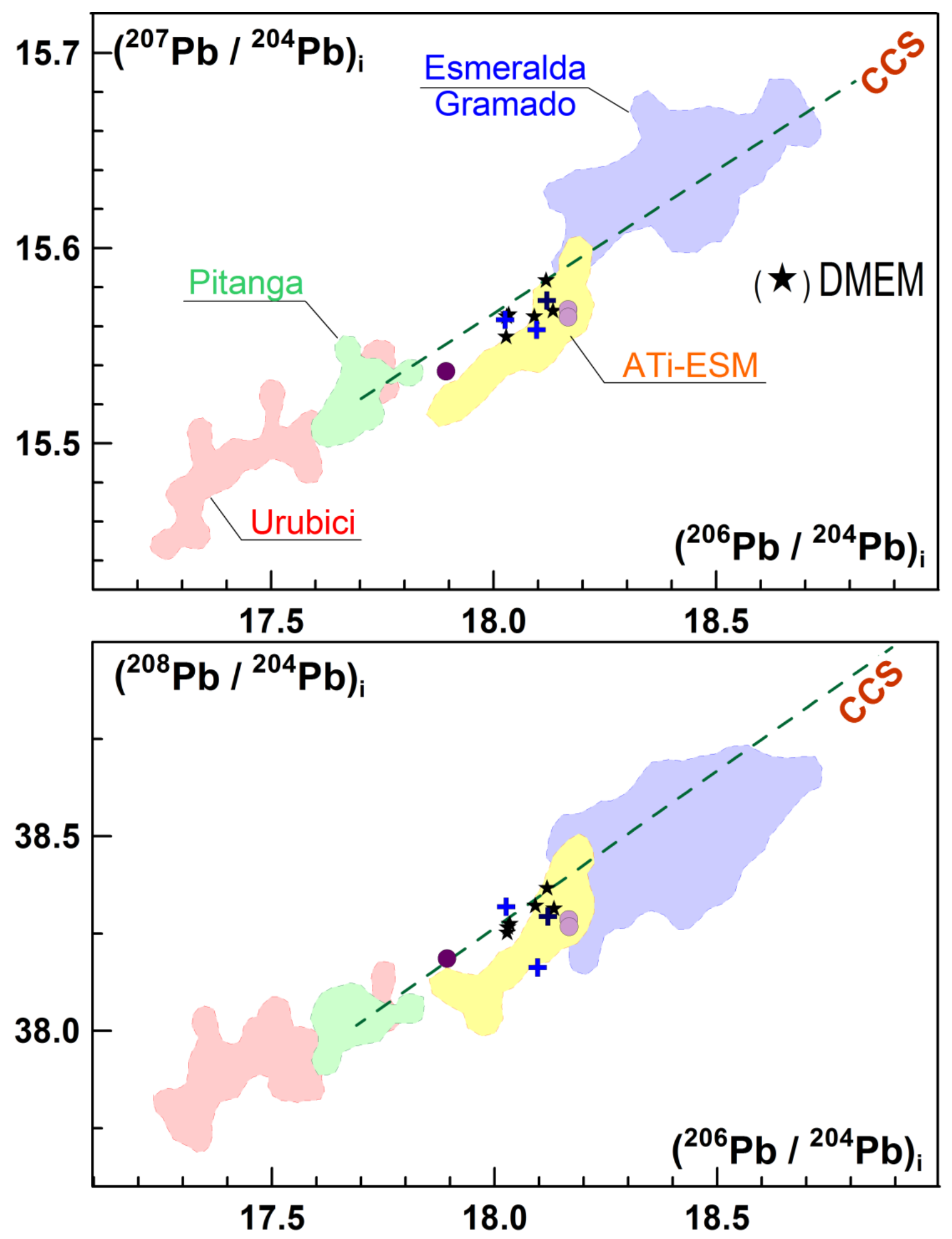

Figura 5.13.: Diagramas de ${ }^{207} \mathrm{~Pb} /{ }^{204} \mathrm{~Pb}$ vs. ${ }^{206} \mathrm{~Pb} /{ }^{204} \mathrm{~Pb}$ e de ${ }^{208} \mathrm{~Pb} /{ }^{204} \mathrm{~Pb}$ vs. ${ }^{206} \mathrm{~Pb} /{ }^{204} \mathrm{~Pb}$ para as rochas intermediárias do ESM. Legenda: círculos e cruzes cheias = presente estudo; quadrado = Chapecó-Ourinhos; estrelas $=$ diques mesozoicos do Espinhaço Meridional (Marques et al., 2015). Cores: roxo claro = LTA-1; roxo escuro = LTA-2b; azul = DAC; azul escuro $=$ RC. Campos: vermelho $=$ derrames Urubici; verde = derrames Pitanga; amarelo = diques ESM (Bellieni et al. (1990); Marques, 2001 e dados inéditos; Carvas, 2014); azul = derrames Esmeralda e Gramado. Linha tracejada verde = linha de mistura de basaltos do tipo Pitanga com crosta continental superior (CCS; Rudinick \& Gao, 2003). 

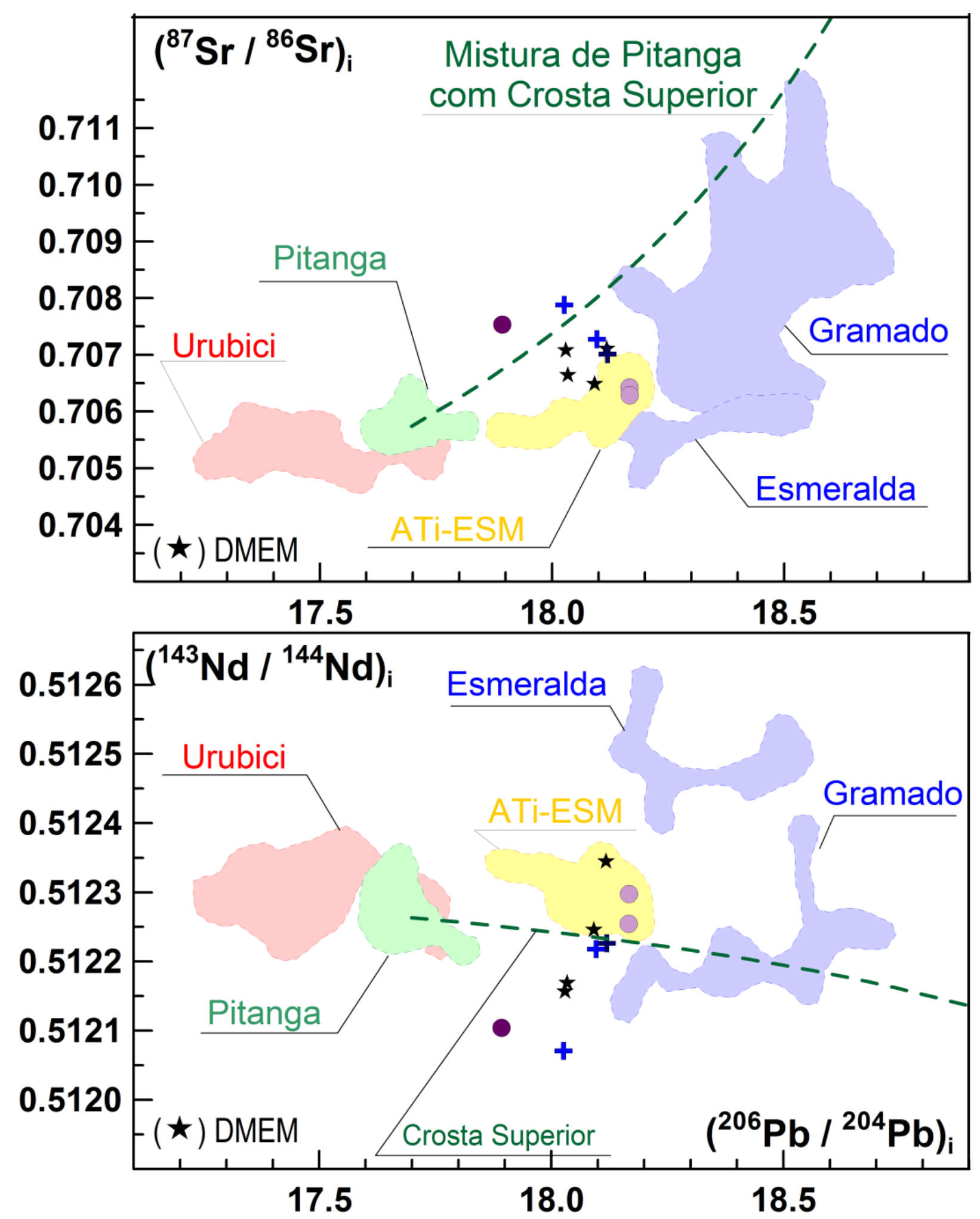

Figura 5.14.: Diagramas de ${ }^{87} \mathrm{Sr} /{ }^{86} \mathrm{Sr} v$ vs. ${ }^{206} \mathrm{~Pb} /{ }^{204} \mathrm{~Pb}$ e de ${ }^{143} \mathrm{Nd} /{ }^{144} \mathrm{Nd}$ vs. ${ }^{206} \mathrm{~Pb} /{ }^{204} \mathrm{~Pb}$ para as rochas intermediárias do ESM. Legenda: círculos e cruzes cheias = presente estudo; quadrado = Chapecó-Ourinhos; estrelas = diques mesozoicos do Espinhaço Meridional (Marques et al., 2015). Cores: roxo claro $=$ LTA-1; roxo escuro = LTA-2b; azul = DAC; azul escuro $=$ RC. Campos: vermelho $=$ derrames Urubici; verde $=$ derrames Pitanga; amarelo $=$ diques ESM (Bellieni et al. (1990); Marques, 2001 e dados inéditos; Carvas, 2014); azul = derrames Esmeralda e Gramado. Linha tracejada verde = linha de mistura de basaltos do tipo Pitanga com crosta continental superior (CCS; Rudinick \& Gao, 2003). 


\subsection{Aspectos da petrogênese}

Conforme mencionado anteriormente, com base no comportamento dos elementos maiores, menores e traços, há a indicação da ocorrência de dois grupos que evoluíram de maneiras distintas. Um deles (Grupo 1) parece estar relacionado à diferenciação das rochas Pitanga do ESM, enquanto o outro conjunto (Grupo 2) é mais enriquecido em $\mathrm{SiO}_{2}, \mathrm{Na}_{2} \mathrm{O}, \mathrm{K}_{2} \mathrm{O}$, ETR leves, $\mathrm{U}, \mathrm{Th}, \mathrm{Nb}$, $\mathrm{Ta}, \mathrm{Ba}, \mathrm{Rb}$ e $\mathrm{Sr}$, como pode ser observado nas figuras 5.4 a 5.6.

No caso do Grupo 2, foram efetuados testes com balanço de massa (Stormer \& Nicholls, 1978) com os óxidos, para verificar a possibilidade de evolução por processo de cristalização fracionada a partir de basaltos Pitanga, como também partindo-se das rochas mais primitivas do tipo Pitanga do próprio ESM, as quais geralmente possuem razões isotópicas de $\left({ }^{87} \mathrm{Sr} /{ }^{86} \mathrm{Sr}\right)_{\mathrm{i}}>0,7060$. Entretanto, devido principalmente às lacunas composicionais, observadas, sobretudo, no $\mathrm{SiO}_{2}$ (56-58\%) e $\mathrm{K}_{2} \mathrm{O}$ (3,0-3,8\%), os resultados não foram satisfatórios, indicando uma gênese mais complexa para esses diques, conforme também apontado por Bellieni et al. (1990). Quando este tipo de processo petrogenético ocorre, espera-se encontrar litotipos apresentando variações composicionais gradativas, com a presença de todos os termos de evolução entre o magma primitivo e o mais diferenciado.

Os diagramas de razões de elementos fortemente incompatíveis em função do elemento de maior incompatibilidade (Figura 5.15), também reforçam que as rochas ácidas não foram originadas por cristalização fracionada em sistema fechado, pois os dados não se ajustam a uma reta paralela ao eixo das abcissas, conforme esperado para esse processo petrogenético (Treuil, et al., 1976).

Observa-se na Figura 5.16 que ocorre uma variação significativa nas concentrações de elementos traço em função das razões isotópicas iniciais de Sr, mostrando que parte das características geoquímicas dos diques mais diferenciados poderia ser resultante de assimilação crustal. Conforme mencionado anteriormente, de modo geral, esses diques são composicionalmente semelhantes às rochas vulcânicas ácidas do tipo ChapecóOurinhos, que sofreram contaminação pela crosta continental, cuja origem está 
relacionada à refusão de material basáltico do tipo Pitanga, que ficou aprisionado na interface crosta-manto por ocasião da efusão das lavas basálticas. Dessa forma, o mesmo tipo de processo pode ter ocorrido na geração dos diques mais evoluídos (DAC e RC).
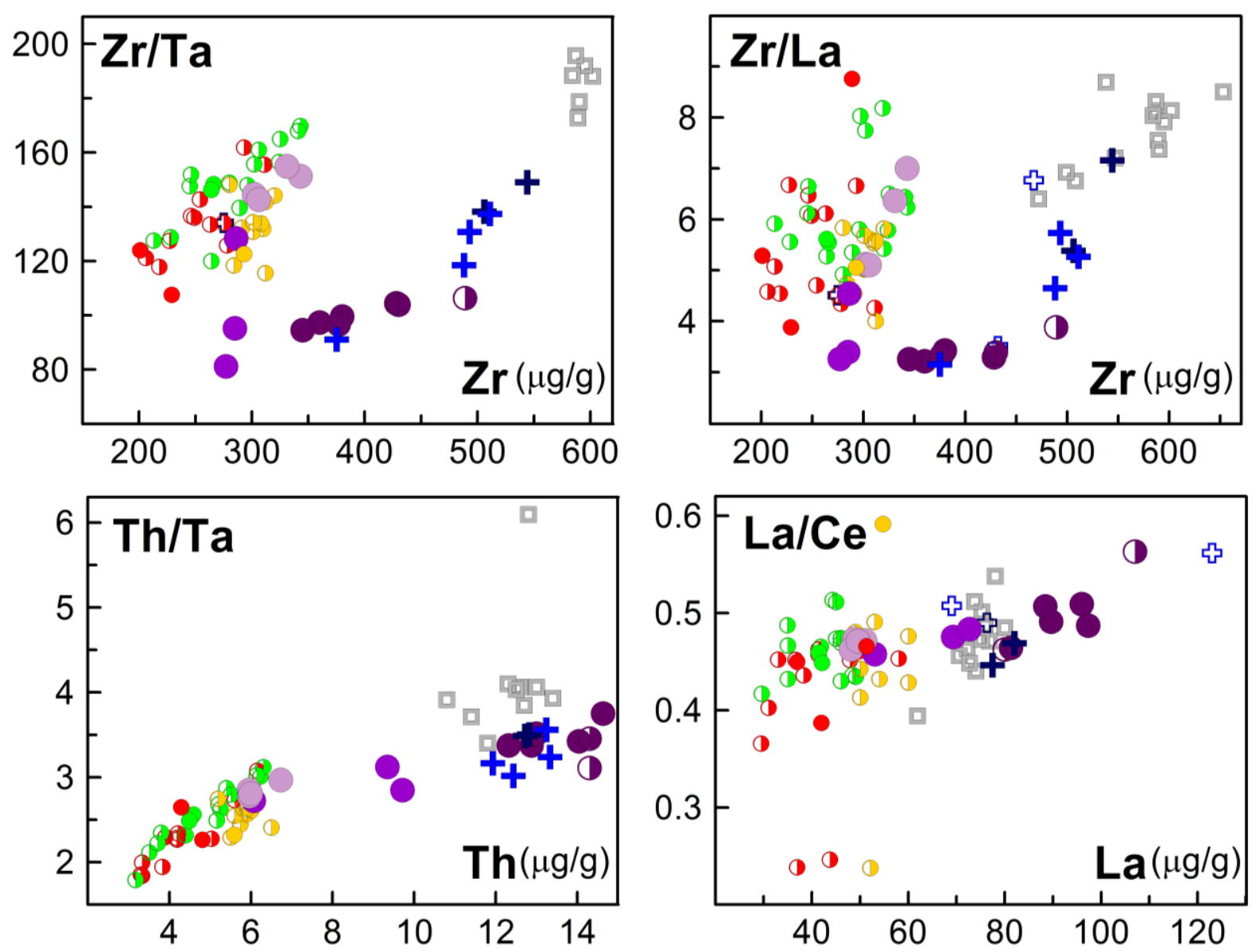

Figura 5.15.: Diagramas de razões entre elementos fortemente incompatíveis em função do elemento de maior incompatibilidade. Legenda: círculos e cruzes cheias = presente estudo; círculos meio cheios e cruzes vazias = Marques (2001); quadrados = Chapecó-Ourinhos. Cores: vermelho = tipo Urubici; verde = tipo Pitanga; amarelo = tipo misto (Marques, 2001); roxo claro = LTA-1; roxo $=\mathrm{LTA}-2 \mathrm{a}$; roxo escuro = LTA $-2 \mathrm{~b}$; azul = DAC; azul escuro $=\mathrm{RC}$.

$\mathrm{O}$ uso conjunto das razões isotópicas de $\mathrm{Sr}, \mathrm{Nd}$ e $\mathrm{Pb}$ pode servir para investigar tanto as características do material que sofreu refusão para gerar os diques ácidos, como também para testar de modo mais aprofundado a possibilidade de contaminação crustal. 

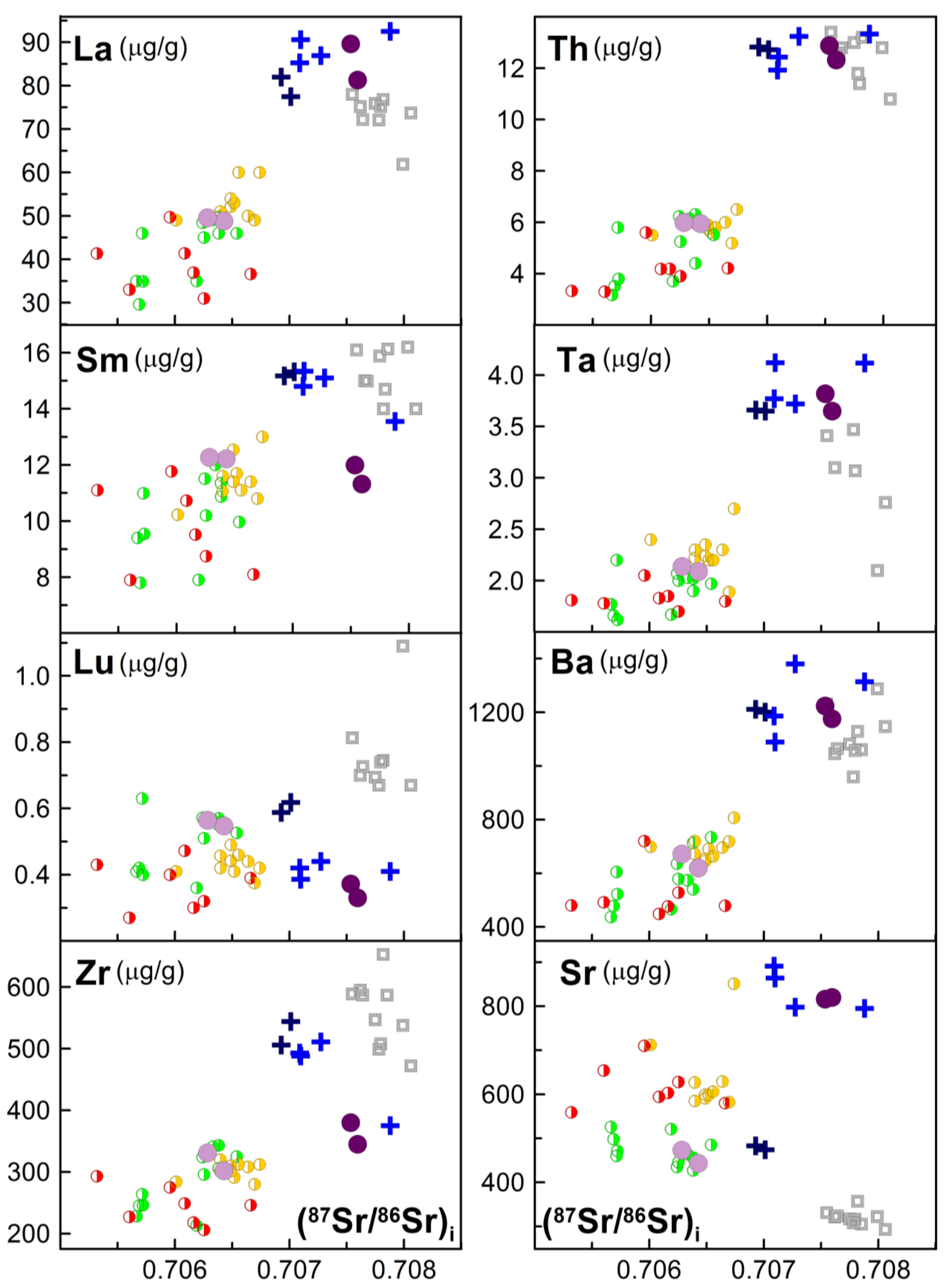

Figura 5.16.: Diagramas de variação de elementos traço em função da razão isotópica inicial de ${ }^{86} \mathrm{Sr} /{ }^{87} \mathrm{Sr}_{1}$. Legenda: círculos e cruzes cheias = presente estudo; círculos meio cheios e cruzes vazias = Marques (2001); quadrados = Chapecó-Ourinhos. Cores: vermelho = tipo Urubici; verde = tipo Pitanga; amarelo = tipo misto (Marques, 2001); roxo claro $=\mathrm{LTA}-1$; roxo $=\mathrm{LTA}-2 \mathrm{a}$; roxo escuro $=\mathrm{LTA}-2 \mathrm{~b} ;$ azul $=\mathrm{DAC}$; azul escuro $=\mathrm{RC}$. 
Em diagramas das razões isotópicas de $\mathrm{Sr}$ e $\mathrm{Nd}$, o comportamento esperado para processos de mistura entre dois componentes é o de uma hipérbole (Faure \& Mensing, 2005). Assim, havendo um processo de contaminação crustal, os dados deveriam se alinhar a uma curva hiperbólica. Esse comportamento é observado na Figura 5.12 na evolução dos basaltos de baixo Ti do tipo Esmeralda, para os do tipo Gramado, até chegar às rochas ácidas do tipo Palmas da PMP, cuja diferenciação é explicada por um processo de cristalização fracionada com assimilação de crosta continental (Garland et al., 1995). É possível observar nas Figuras 5.12 e 5.14 que não existe essa tendência de evolução nos diques investigados, uma vez que as razões isotópicas dos LTA e DAC estão misturadas entre si no diagrama e não acompanham a hipérbole de mistura entre basaltos Pitanga e a crosta continental superior. No diagrama da Figura 5.12 estão também mostradas as razões isotópicas iniciais (corrigidas para $133 \mathrm{Ma}$ ) de Sr e $\mathrm{Nd}$ de cinco rochas vulcânicas ácidas do tipo ChapecóOurinhos (Garland et al., 1995; Freitas, 2009), que se distinguem dos diques investigados, por apresentarem composições isotópicas mais radiogênicas de $\mathrm{Sr}$, situando-se já no campo dos basaltos de baixo titânio do tipo Gramado, que notadamente passaram por processos de contaminação crustal. Nota-se que a grande maioria das vulcânicas Chapecó-Ourinhos localiza-se bem próxima à linha de mistura entre os basaltos Pitanga e a crosta continental superior, diferindo do comportamento dos diques diferenciados.

Cabe ainda destacar que os diques aqui investigados, como também os demais do ESM, apresentam razões isotópicas iniciais de $\mathrm{Sr}$ e $\mathrm{Nd}$ muito semelhantes àquelas dos diques mesozoicos de natureza básica e com alto titânio (tipo Urubici), que ocorrem no Espinhaço Meridional (Cráton do São Francisco), cuja origem está relacionada à fusão de manto litosférico subcontinental metassomatizado, por agentes piroxeníticos e carbonatíticos, relacionados a antigos processos de subducção (Marques et al., 2015). Dessa forma, a fonte mantélica que originou os diques básicos do ESM poderia ser sido afetada por processos similares, que causaram um aumento significativo nas razões isotópicas de $\mathrm{Sr}$ (agentes carbonatíticos) e $\mathrm{Pb}$ (piroxeníticos). Esta interpretação é também corroborada nos diagramas das figuras 5.13 e 5.16, que mostram a grande similaridade dos diques básicos do ESM com os do Espinhaço Meridional. 
As razões isotópicas de $\mathrm{Pb}$ das amostras analisadas estão situadas no campo dos diques básicos do ESM (Marques et al., 2012; Carvas, 2014), sendo significativamente distintos dos derrames Pitanga, não se ajustando também à reta de mistura entre este componente e a crosta continental (Figura 5.13). Da maneira semelhante ao que ocorre com os diques do Espinhaço Meridional, a composição radiogênica de $\mathrm{Pb}$ dos diques do ESM pode ser explicada pelo envolvimento de um componente piroxenítico, caracterizado por composição isotópica de $\mathrm{Pb}$ bastante radiogênica (Rocha-Júnior et al., 2013; Marques et al., 2015).

Como verificado no comportamento das razões isotópicas iniciais de Sr e Nd (Figura 5.12), observa-se novamente nos diagramas da Figura 5.15 que as composições isotópicas dos diques diferenciados não estão sobre o campo delimitado pelos básicos do ESM, sugerindo uma maior heterogeneidade na fonte (material que ficou aprisionado na interface crosta-manto) que originou essas rochas. Não se pode, porém, descartar completamente a ocorrência de um processo de contaminação crustal, cujas características devem ser distintas daquelas da crosta continental superior pela falta de ajuste das composições isotópicas de $\mathrm{Sr}, \mathrm{Nd}$ e $\mathrm{Pb}$ dos diques às hipérboles de mistura. 


\section{6. $\quad$ Considerações finais}

Os principais resultados obtidos neste trabalho encontram-se apresentados a seguir:

1) Embora os diques subalcalinos do ESM sejam principalmente básicos, na Ilha de São Sebastião e costa continental adjacente ocorrem corpos diferenciados, os quais são quimicamente representados por lati-andesitos, dacitos e riodacitos, e que apresentam uma leve tendência alcalina. A caracterização geoquímica e isotópica ( $\mathrm{Sr}, \mathrm{Nd}$ e $\mathrm{Pb}$ ) desses diques mais evoluídos, constitui o principal objetivo do presente estudo, permitindo também discutir alguns aspectos relacionados à sua gênese.

2) A caracterização geoquímica foi principalmente baseada na determinação de elementos traço, tais como terras raras (La, Ce, Nd, Sm, Eu, Tb, $\mathrm{Yb}$ e $\mathrm{Lu}$ ), Th, Ta, U, Ba, Hf, Ba, Rb, Co e Sc, determinados pela técnica de ativação com nêutrons térmicos e epitérmicos (AAN), seguida de espectrometria gama de alta resolução. Os resultados obtidos foram estatisticamente tratados, sendo que a qualidade das determinações foi analisada tomando-se como base as determinações desses elementos realizadas no material de referência BRP-1 (basalto do tipo Pitanga da Província Magmática do Paraná). Dentre os critérios estatísticos empregados destacou-se o critério U como o mais adequado para este tipo de análise. A precisão de até $12 \%$ e a exatidão de até $4 \%$ obtidas pelo método empregado se mostraram apropriadas para as análises petrogenéticas.

3) A comparação da técnica de AAN com a técnica de espectrometria de massa com fonte de plasma induzido (ICP-MS) mostrou que os dados são estatisticamente iguais para a grande maioria dos elementos. Já para os dados de Y obtidos por fluorescência de raios X foi necessário aplicar uma correção, uma vez na comparação com os resultados de ICP-MS observa-se uma diferença sistemática. Uma vez aplicada esta correção, os dados se mostram compatíveis e satisfatórios para as análises petrogenéticas realizadas.

4) Os dados de óxidos (maiores e menores) e elementos traço nos diques analisados, juntamente com dados já existentes na literatura, permitem verificar a existência de duas linhas evolutivas distintas, compondo dois grupos. 
Um deles, denominado Grupo 1, possui conteúdo de $\mathrm{SiO}_{2}$ inferior a 55\%, sendo mais empobrecido em elementos fortemente incompatíveis (La, Ce, Th, U, Ta e $\mathrm{Nb}$ ), cuja gênese parece ser associada aos basaltos do tipo Pitanga, dominantes no norte da Província Magmática do Paraná (PMP). Enquanto, o Grupo 2, que compreende os litotipos mais diferenciados do conjunto, destaca-se pelo enriquecimento significativo destes mesmos elementos, além de $\mathrm{Na}_{2} \mathrm{O}$ e $\mathrm{K}_{2} \mathrm{O}$, que lhes confere uma leve tendência alcalina.

5) Os padrões de ETR mostram que os litotipos básicos (Grupo 1) são bastante semelhantes aos dos diques do ESM. Em relação aos derrames da PMP, observa-se que os diques do tipo Urubici exibem o mesmo comportamento dos diques análogos. Por outro lado, os diques Pitanga são mais enriquecidos do que os derrames do mesmo tipo, provavelmente por serem relativamente mais evoluídos, contaminados e/ou gerados em fontes mantélicas com características distintas (conforme indicado pelos dados isotópicos). Os LTA-1 apresentam comportamento similar às básicas do Grupo 1 , sendo considerados os membros mais evoluídos do grupo. Já o Grupo 2 exibe um comportamento bastante similar às ácidas do tipo Chapecó-Ourinhos, sendo mais empobrecidas em ETR pesados. As anomalias de $\mathrm{Eu} / \mathrm{Eu}^{*}$ variam de leves a moderadas $(0,67$ - 1,13), refletindo tanto o fracionamento de plagioclásio, no caso das anomalias negativas, como o acúmulo deste mineral, no caso das positivas, em alguns litotipos.

6) Os diagramas multielementares reforçam as semelhanças entre os diques básicos estudados e os já encontrados no ESM, com expressivas anomalias negativas em $\mathrm{Nb}$ e $\mathrm{Sr}$ e leves em Zr. Da mesma forma, as rochas diferenciadas possuem grande semelhança com as ácidas do tipo OurinhosChapecó, caracterizadas pelas expressivas anomalias negativas de $\mathrm{Sr}, \mathrm{P}$ e $\mathrm{Ti}$, e leves anomalias de $\mathrm{Nb}$, diferindo apenas no empobrecimento relativo de ETR pesadas e Y, o qual pode estar relacionado à presença de granada residual durante o processo de fusão parcial. Este empobrecimento fica mais evidente nos LTA do que nos termos mais evoluídos (RC). No geral, as razões (Rb/Ba)n, normalizadas em relação ao manto primordial, que são indicadores dos processos de contaminação crustal, mostram que e os litotipos básicos apresentam pouca contaminação $(\sim 1,0)$ e que os diques mais diferenciados são sistematicamente mais contaminados, com os DAC e RC com valores > 1 . 
7) Do ponto de vista isotópico, as amostras estudadas são significativamente mais radiogênicas $\left({ }^{87} \mathrm{Sr} /{ }^{86} \mathrm{Sr}_{\mathrm{i}}>0,7060\right)$ do que os derrames Pitanga e Urubici da PMP. Para a maioria dos diques as razões isotópicas iniciais $\left({ }^{143} \mathrm{Nd} /{ }^{144} \mathrm{Nd}\right)_{\mathrm{i}}$ têm valores semelhantes aos derrames com alto titânio da PMP, enquanto as razões isotópicas iniciais de $\mathrm{Pb}$ dos litotipos analisados são bem mais radiogênicos.

8) A evolução do Grupo 2 por processo de cristalização fracionada não consegue explicar o comportamento geoquímico observado nos elementos investigados, principalmente devido à lacuna composicional observada para $\mathrm{SiO}_{2}$ e $\mathrm{K}_{2} \mathrm{O}$. Devido à forte semelhança encontrada entre as rochas mais diferenciadas deste grupo com as ácidas do tipo Chapecó-Ourinhos, sugere-se que a origem dos diques estudados tenha ocorrido por meio de processos semelhantes, ou seja, por refusão de material basáltico que ficou aprisionado na interface crostamanto, com composição ligeiramente diferente do magma-tipo Pitanga. Esta hipótese é também reforçada pelo fato de as razões isotópicas iniciais de $\mathrm{Sr}, \mathrm{Nd}$ e $\mathrm{Pb}$ possuírem um comportamento semelhante às encontradas para diques que ocorrem no Espinhaço Meridional (borda do Craton do São Francisco). A possível interpretação para a origem desses diques envolve fusão de manto litosférico subcontinental metassomatizado, sendo que parte dos magmas gerados nesse processo ficou aprisionada na interface crosta-manto. A refusão desse material gerou os diques diferenciados. Assim, os mecanismos de metassomatismo, associados a antigos processos de subducção, poderiam estar ligados à gênese dessas rochas, cuja colocação ocorreu em zonas de suturas associadas a antigas zonas de subducção.

Por fim, cabe ressaltar a importância que este trabalho tem por trazer novas informações a respeito dos diques do enxame da Serra do Mar, principalmente para isótopos de $\mathrm{Pb}$, já que não há grande quantidade de dados publicados sobre os diques mais diferenciados do enxame. Concomitantemente aos dados isotópicos, o estudo dos elementos traço foi muito útil na identificação de processos de origem e evolução dessas rochas, mostrando-se uma importante ferramenta nesse tipo de análise. 


\section{Referências Bibliográficas}

Alfassi, Z.B. (1990). Activation Analysis. Vol. I, CRC Press Inc., Florida.

Almeida, F.F.M. (1986). Distribuição regional e relações tectônicas do magmatismo pós-paleozóico no Brasil. Rev. Bras. Geoc., 16(4): 325-349.

Almeida, J.; Dios, F.; Mohriak, W.U.; Valeriano, C.D.M.; Heilbron, M.; Eirado, L.G.; Tomazzoli, E. (2013). Pre-rift tectonic scenario of the Eo-Cretaceous Gondwana break-up along SE Brazil-SW Africa: insights from tholeiitic mafic dyke swarms. Geological Society, London, Special Publications, 369(1): 11-40.

Amaral, G.; Cordani, U.G.; Kawashita, K.; Reynolds, J.H. (1966). Potassium-argon dates of basaltic rocks from southern Brazil. Geochimica et Cosmochimica Acta, 80: 159-189.

Babinski, M.; Van Schmus, W.R.; Chemale Jr., F. (1999). Pb-Pb dating and Pb isotope geochemistry of Neoproterozoic carbonate rocks from the São Francisco basin, Brazil: implications for the mobility of Pb isotopes during tectonism and metamorphism. Chemical Geology, 160: 175-199.

Bellieni, B.; Comin-Chiaramonti, P.; Marques, L.S.; Melfi, A.J., Nardy, A.J.R.; Piccirillo, E.M.; Roisenberg, A. (1984). High- and $\mathrm{Low}_{-} \mathrm{TiO}_{2}$ flood basalts from the Paraná plateau (Brazil): petrology and geochemical aspects bearing on their mantle origin. N. Jb. Miner. Abh., 150: 273-306.

Bellieni, G.; Comin-Chiaramonti, P.; Marques, L.S.; Melfi, A.J; Nardy, A.J.R.; Papatrechas, C.; Piccirillo, E.M.; Roisenberg, A.; Stolfa, D. (1986). Petrogenetic aspects of acid and basaltic lavas from the Paraná plateau (Brazil): mineralogical and petrochemical relationships. J. Petrol., 27: 915-944.

Bellieni, G.; Montes-Lauar, C. R.; De Min, A.; Piccirillo, E. M.; Cavazzini, G.; Melfi A. J.; Pacca, I. G. (1990). Early and late Cretaceous magmatism from São Sebastião Island (SE - Brazil): Geochemistry and Petrology. Geochim. Brasil., 4(1): 59-83.

Bennio, L.; Brotzu, P.; D'Antonio, M.; Feraud, G.; Gomes, C. B.; Marzoli, A.; Melluso, L.; Morbidelli, L.; Morra, V.; Rapaille, C.; Ruberti, E. (2003). The tholeiitic dyke swarm of the Arraial do Cabo peninsula (SE Brazil): ${ }^{39} \mathrm{Ar} /{ }^{40} \mathrm{Ar}$ ages, 
petrogenesis, and regional significance. Journal of South American Earth Sciences, 16(2): 163-176.

Bryan, S.E. \& Ernst, R.E. (2008). Proposed Revision to Large Igneous Province Classification. http://www.mantleplumes.org/LIPClass2.html.

Carvas, K.Z. (2014). Determinação de razões isotópicas de $\mathrm{Sr}$, Nd e Pb de diques do Cretáceo Inferior do Enxame da Serra do Mar (SP-RJ). Monografia para obtenção de título de bacharel em Geofísica, Instituto de Astronomia, Geofísica e Ciências Atmosféricas, USP, São Paulo, Brasil, pp. 39.

Carvas, K.Z.; Marques, L.S.; Babinski, M. (2014). Desenvolvimento de um protocolo para preparação de amostras para determinação das concentrações $e$ razões isotópicas de chumbo. 47ํㅡ Congresso Brasileiro de Geologia, Salvador, Brasil, 21-26 de setembro, Anais do congresso.

Coffin, M.F. \& Eldholm, O. (1994). Large igneous provinces: crustal structure, dimensions, and external consequences. Reviews of Geophysics, 32 (1): 136.

Comin-Chiaramonti, P.; Bellieni, G.; Piccirillo, E.M.; Melfi, A.J. (1988). Classification and petrography of continental stratoid volcanics and related intrusives from the Paraná Basin (Brazil). In: "The Mesozoic flood volcanism of the Paraná Basin: petrogenetic and geophysical aspects”. Piccirillo E. M. \& Melfi A. J. (eds.), IAG, University of São Paulo, Brazil, 47$72 \mathrm{p}$.

Cordani, U. G.; Sartori P.L.P.; Kawashita, K. (1980). Geoquímica dos isótopos de estrôncio e a evolução da atividade vulcânica na Bacia do Paraná (sul do Brasil) durante o Cretáceo. An. Acad. brasil. Ciênc., 52: 811-818.

Cordani, U. G. (1984). Estudo preliminar de integração do Pré-Cambriano com os eventos tectônicos das bacias sedimentares brasileiras (No. 15). Petrobrás, Centro de Pesquisas e Desenvolvimento Leopoldo A. Miguez de Mello, Setor de Informação Técnica e Propriedade Industrial. (Republicação em 2009).

Cordani, U.G. Civetta, L., Mantovani, M.S.M., Petrini, R., Kawashita, K., Hawkesworth, C.J., Taylor, P., Longinelli, A., Cavazzini, G.; Piccirillo, E.M. (1988). Isotope geochemistry of flood basalts from the Paraná basin (Brazil). In: "The Mesozoic flood volcanism of the Paraná basin: 
petrogenetic and geophysical aspects”. Piccirillo E. M. \& Melfi A. J (eds). IAG, University of São Paulo, Brazil, 157-178.

Corval, A. (2009). Petrogênese e Contexto Geodinâmico das Suítes Basálticas Toleíticas (de alto-TiO 2 e baixo-TiO 2 ) do Cretáceo Inferior da Porção Centro-oriental do Enxame de Diques da Serra do Mar. Tese de Doutorado, Universidade Estadual do Rio de Janeiro, Rio de Janeiro, Brasil. 189p.

Cotta, A.J.B; Enzweiler, J.; Nardy, A.J.R. (2008). Certificado de Análise do Material de Referência BRP-1 (Basalto Ribeirão Preto). Geochim. Brasil, 22(2): 113-118.

Coutinho, J.M.V. (2008). Enxame de diques da junção tríplice do Paraná, Brasil meridional. Geologia USP. Série Científica, 8(2): 28-52.

Damasceno, E.C. (1966). Estudo preliminar dos diques de rochas básicas e ultrabásicas da região de Ubatuba, Estado de São Paulo. Anais da Academia Brasileira de Ciências, 38(2): 293-304.

De La Roche, H.; Leterrier, J.; Grandclaude, P.; Marchal, M. (1980). A classification of volcanic and plutonic rocks using R1:R2-diagram and major - element analysis - its relationships with current nomenclature. Chem. Geol., 29: 183-210.

De Paolo, D.J. (1981). Trace element and isotopic effects of combined wallrock assimilation and fractional crystallization. Earth and Planetary Science Letters, 53: 189-202.

Deckart, K.; Féraud, G.; Marques, L.S.; Bertrand, H. (1998). New time constraints on dyke swarms related to the Paraná-Etendeka magmatic province, and subsequent South Atlantic opening, southeastern Brazil. Journal of Volcanology and Geothermal Research, 80(1-2): 67-83.

Dutra, T. (2006). Petrogênese dos basaltos de baixo-TiO 2 do Enxame de Diques da Serra do Mar na Região dos Lagos, RJ. Dissertação de Mestrado, Universidade Estadual do Rio de Janeiro, Rio de Janeiro, Brasil.

Ernesto, M.; Raposo, M.I.B.; Marques, L.S.; Renne, P.R.; Diogo, L.A.; De Min, A. (1999). Paleomagnetism, geochemistry and ${ }^{40} \mathrm{Ar} /{ }^{39} \mathrm{Ar}$ dating of the Northeastern Paraná Magmatic Province: tectonic implications. Journal of Geodynamics, 28(4): 321-340. 
Ernst, R. \& Bleeker, W. (2010). Large igneous provinces (LIPs), giant dyke swarms, and mantle plumes: Significance for breakup events within Canada and adjacent regions from 2.5 Ga to the present. Canadian Journal of Earth Sciences, 47(5): 695-739.

Faure, G. \& Mensing, T. (2005). Principles of Isotope Geology. $3^{\text {rd }}$ ed., John Wiley \& Son, Inc., New Jersey, E.U.A. pp. 345-362.

Figueiredo, A.M.G.; Marques, L.S. (1989). Determination of Rare Earths and Other Trace Elements in the Brazilian Geological Standards BB-1 and GB-1 by Neutron Activation Analysis. Geochimica Brasiliensis, 3 (1): 1-8.

Florisbal, L.M.; Heaman, L.M.; Janasi, V. A.; Bitencourt, M.F. (2014). Tectonic significance of the Florianópolis Dyke Swarm, Paraná-Etendeka Magmatic Province: A reappraisal based on precise U-Pb dating. J. Volc. Geoth. Res., 289: $140-150$.

Frank, H. T.; Gomes, M.E.B.; Formoso, M. L. L. (2009). Review of the areal extent and the volume of the Serra Geral Formation - Paraná Basin, South. Pesquisas em Geociências, 36(1): 49-57.

Freitas, R.O. (1947). Geologia e petrologia da Ilha de São Sebastião. Bol. Fac. Fil. Ciênc. Letras USP, 85: 1-244.

Freitas, V.A. (2009). A geração de magmas ácidos na Província Magmática do Paraná, Região de Piraju - Ourinhos (SP): uma contribuição da geoquímica isotópica e de elementos traço em rochas e minerais. Dissertação de Mestrado, Instituto de Geociências - IGc, Universidade de São Paulo, 193 p.

Garda, G.M. (1995). Os diques básicos e ultrabásicos da região costeira entre as cidades de São Sebastião e Ubatuba, estado de São Paulo. Tese de Doutorado, Instituto de Geociências da USP, São Paulo, 156p.

Garda, G.M. \& Schorscher, J.H.D. (1996). Os diques costeiros básicos e ultrabásicos adjacentes ao canal de São Sebastião (litoral norte do Estado de São Paulo). Rev. IG São Paulo, 17(1/2): 7-31.

Garland F.; Hawkesworth C.J.; Mantovani M.S.M. (1995). Description and petrogenesis of the Paraná rhyolites, Southern Brazil. J. Petrol., 36(5): 1193-1227. 
Garland F.; Turner, S.; Hawkesworth, C. (1996). Shifts in the source of the Paraná basalts through time. Lithos, 37: 223-243.

Gomes, C.B.; Ruberti, E.; Comin-Chiaramonti, P.; Azzone, R.G. (2011). Alkaline magmatism in the Ponta Grossa Arch, SE Brazil: a review. Journal of South American Earth Science, 32: 152-168.

Govindaraju, K. (1994). Compilation of working values and sample description for 383 geostandars. Geostand. Newsl., 18(special issue): 1-158.

Guedes, E.; Heilbron, M.; Vasconcelos, P.M.; Valeriano, C.M.; Almeida, J.C.H.; Teixeira, W.; Thomaz Filho, A. (2005). $K-A r$ and ${ }^{40} \mathrm{Ar} /{ }^{39} \mathrm{Ar}$ ages of dikes emplaced in the onshore basement of the Santos Basin, Resende area, SE Brazil: implications for the South Atlantic opening and Tertiary reactivation. J. S. Am. Ear Sci., 18: 371-382p.

Guedes, E. (2007). O enxame de diques da Serra do Mar na região entre Resende ea Baía da Ilha Grande, RJ. Tese de doutorado. Universidade do Estado do Rio de Janeiro. Faculdade de Geologia.

Halls, H.C. (1982). The importance and potential of mafic dyke swarms in studies of geodynamic processes. Geoscience Canada, 9(3): 145-154.

Handbook of Nuclear Chemistry, Vol. 1, Basics of Nuclear Science, Vértes, A.; Nagy, S.; Klencsár, Z. (Eds), Kluwer Academic Publishers, 2003.

International Atomic Energy Agency - IAEA (1990). Practical aspects of operating a neutron activation analysis laboratory. Vienna. (IAEA - TECDOC 564).

Irvine, T.N. \& Baragar, W.R.A. (1971). A guide to the chemical classification of the common volcanic rocks. Canadian Journal of Earth Sciences, 8: 523-548.

Janasi, V.A.; Freitas, V.A.; Heaman, L.H. (2011). The onset of flood basalt volcanism, Northern Paraná Basin, Brazil: A precise U-Pb baddeleyite/zircon age for a Chapecó-type dacite. Earth. Plan. Sci. Letters 302: 147-153.

Kawashita, K. (1972). O método $\mathrm{Rb}-\mathrm{Sr}$ em rochas sedimentares. Tese de Doutorado, Instituto de Geociências, Universidade de São Paulo.

Le Bas, M.J.; Le Maitre, R.W.; Streckeisen, A.; Zannetin, B. (1986). A chemical classification of volcanic rocks based on total alkali-silica diagram. J. Petrol., 27: 745-750.

Luchetti, A.C.F.; Nardy, A.J.R.; Machado, F.B.; Madeira, J.E.O.; Arnosio, J.M. (2014). New insights on the occurrence of peperites and sedimentary deposits 
within the silicic volcanic sequences of the Paraná Magmatic Province, Brazil. Solid Earth, 5(1):121-130.

Machado, F.B.; Rocha-Júnior, E.R.V.; Marques, L.S.; Nardy, A.R. (2015). Volcanological aspects of the northwest region of Paraná continental flood basalts (Brazil). Solid Earth, 6: 227-241.

Mantovani, M.S.M.; Marques, L.S.; Sousa, M.A. de; Atalla, L.T.; Civetta, L.; Inoccenti I, F. (1985a). Trace element and strontium isotope constraints on the origin and evolution of the Paraná Continental flood basalts of Santa Catarina State (Southern Brazil). J. Petrol., 26: 187-209.

Mantovani, M.S.M.; Cordani, U.G.; Roisenberg, A. (1985b). Geoquímica Isotópica em vulcânicas ácidas da Bacia do Paraná e implicações genéticas associadas. Rev. Bras. Geoc., 15: 61-65.

Marques, L.S. (1983). Estudo do comportamento geoquímico de alguns elementos traços determinados em rochas vulcânicas da Bacia do Paraná. Dissertação de Mestrado, Instituto Astronômico e Geofísico (IAG) - USP, $172 \mathrm{p}$.

Marques, L.S. (1988). Caracterização geoquímica das rochas vulcânicas da Bacia do Paraná: implicações petrogenéticas. Tese de Doutorado, Instituto de Astronomia, Geofísica e Ciências Atmosféricas, Universidade de São Paulo, 175p.

Marques, L.S., Piccirilo, E.M., Melfi, A.J., Comin-Chiaramonti, P., and Bellieni, G. (1989). Distribuição de terras raras e outros elementos traços em basaltos da Bacia do Paraná, Geochim. Brasil., 3: 33-50.

Marques, L.S.; Dupré, B.; Piccirillo, E.M. (1999). Mantle source compositions of the Paraná Magmatic Province (southern Brazil): evidence from trace element and $\mathrm{Sr}-\mathrm{Nd}-\mathrm{Pb}$ isotope geochemistry. Journal of Geodynamics, 28(4-5): 439-458.

Marques, L.S. (2001). Geoquímica de diques toleíticos da costa sul-sudeste do Brasil: contribuição ao conhecimento da Província Magmática do Paraná. Tese de Livre Docência, Departamento de Geofísica, IAG-USP, 86p.

Marques, L.S., Piccirillo, E.M., Bellieni, G., Figueiredo, A.M.G., Min, A. (2003). Caracterização geoquímica dos diques mesozóicos de natureza toleítica da 
costa sudeste do Brasil. In: IX Congresso Brasileiro de Geoquímica, Belém. Livro de Resumos Expandidos, 652-654p.

Marques, L.S. \& Ernesto, M. (2004). O magmatismo toleítico da Bacia do Paraná. In: "Geologia do Continente Sul-Americano: evolução da obra de Fernando Flávio Marques de Almeida". Mantesso Neto, V., Bartorelli, A., Carneiro, C.R., Brito Neves, B.B. (eds.), Beca Produções Culturais, São Paulo, 245$263 p$.

Marques, L.S.; De Min, A.; Babinski, M.; Figueiredo, A.M.G.; Andrade, L.L.; Vicentini, C.M.; Piccirillo, E.M. (2012). Genesis of the early Cretaceous tholeiites from Serra do Mar Dyke Swarm (Brazil): trace element and strontium, neodymium and lead isotopic constraints. South American Symposium on Isotope Geology, Medelin, Colombia, Anais, CD-ROM.

Marques, L.S.; Rocha-Júnior, E.R.V.; Babinski, M.; Carvas, K.; Petronilho; De Min, A. (2015). Lead isotope constraints on the mantle sources involved in the genesis of Mesozoic high-Ti tholeiite dykes (Urubici type) from the São Francisco Craton (Southern Espinhaço, Brazil).Brazilian Journal of Geology, em publicação.

Marzoli, A.; Melluso, L.; Morra, V.; Renne, P.R.; Sgrosso, I.; D'Antonio, M.; Duarte Morais, L.; Morais, E.A.A.; Ricci, G. (1999). Geochronology and petrology of Cretaceous basaltic magmatism in the Kwanza basin (western Angola), and relationships with the Parana-Etendeka continental flood basalt province. Journal of Geodynamics 28(4-5): 341-356.

McDonough, W.F. \& Sun, S.-S. (1995). Composition of the Earth. Chemical Geology, 120: 223-253.

Melfi, A.J. (1967). Potassium-argon dates for core samples of basaltic rocks from Southern Brazil. Geochi. Cosmochim. Acta, 31: 1079-1089.

Milani, E.J. (1992). Intraplate Tectonics and the Evolution of the Paraná Basin. In: Inversion Tectonics of the Cape Fold Belt, Karoo and Cretaceous Basin of Southern Africa". Wite \& Ransorne (Coord.), 101-108p.

Milani, E.J.; Melo, J.H.G.; Souza P.A.; Fernandes, L.A.; França, A.B., (2007). Bacia do Paraná. Boletim de Geociências da Petrobrás, 15(2): 265-287. 
Montes-Lauar, C.R.; Pacca, I.G.; Melfi, A.J.; Kawashita, K. (1995). Late Cretaceous alkaline complexes, southeastern Brazil: paleomagnetism and geochronology. Earth. Planet. Sci. Letters, 134: 425-440.

Nalimov, V.V. (1963). The application of mathematical statistics to chemical analysis. Williams, M. (trad.), Pergamon Press, 294p.

Nardy A.J.R. (1996). Geologia e petrologia do vulcanismo mesozoico da região central da Bacia do Paraná. Tese de Doutorado, Instituto de Geociências e Ciências Exatas, Universidade Estadual Paulista, 316p.

Nardy, A.J.R.; Oliveira, M.A.F. de; Betancourt, R.H.S.; Verdugo, D.R.H.; Machado, F.B. (2001). Geologia e estratigrafia da Formação Serra Geral. Geociências, 21(2): 15-32.

Nardy, A. J. R.; Oliveira, M. A. F.; Machado, F. B. (2002). Geologia e estratigrafia da Formação Serra Geral. Geociências, 21: 13-30.

Nardy, A.J.R.; Machado, F.B.; Oliveira, M.A.F. (2008). As rochas vulcânicas mesozoicas ácidas da Bacia do Paraná: litoestratigrafia e considerações geoquímico-estratigráficas. Rev. Bras. de Geoc., 38(1): 178-195.

Peate, D.W.; Hawkesworth, C.J.; Mantovani, M.S.M. (1992). Chemical stratigraphy of the Paraná lavas, South America: classification of magma types and their spatial distribution. Bulletin of Volcanology, 55: 119-139.

Peate, D.W. \& Hawkesworth, C.J. (1996). Lithospheric to asthenospheric transition in low-Ti flood basalts from southern Paraná, Brazil. Chemical Geology, $127,1-24$.

Peate, D.W. (1997). The Paraná-Etendeka Province. In: J Mahoney \& M Coffin (eds), Large Igneous Provinces: Continental, Oceanic, and Planetary Flood Volcanism. AGU Geophysical Monograph, 100: 217-245.

Peate, D.W.; Hawkesworth, C.J.; Mantovani, M.S.M.; Rogers, N.W.; Turner, S.P. (1999). Petrogenesis and stratigraphy of the high-Ti/Y Urubici magma type in the Paraná flood basalt province and implications for the nature of 'Dupal'- type mantle in the South Atlantic region. Journal of Petrology, 40(3): 451-473.

Petrini, R.; Civetta, L.; Piccirillo, E.M.; Bellieni, B.; Comin-Chiaramonti, P.; Marques, L.S.; Melfi, A.J. (1987). Mantle heterogeneity and crustal contamination in the genesis of low-Ti continental flood basalts from the 
Paraná plateau (Brazil): Sr-Nd isotope and geochemical evidence. Journal of Petrology, 28: 701-726.

Piccirillo, E.M.; Raposo, M.I.B.; Melfi, A.J.; Comin-Chiaramonti, P.; Bellieni, B.; Cordani, U.G.; Kawashita, K. (1987). Bimodal fissural volcanlc suites from the Paraná Basin (Brazil): K-Ar age, Sr-tsotopes and geochemtstry. Geochimica Brasiliensis, 1: 53-69.

Piccirillo E. M. \& Melfi A. J. (1988). The Mesozoic flood volcanism of the Paraná Basin: petrogenetic and geophysical aspects. São Paulo, Brazil. IAG, University of São Paulo (ed.). 600p.

Piccirillo, E.M.; Comin-Chiaramonti, P.; Bellieni, B.; Civetta, L.; Marques, L.S.; Melfi, P.; Petrini, R.; Raposo, M.I.B.; Stolfa, D. (1988). Petrogenetic aspects of continental flood basalt-rhyolite suites from the Paraná Basin. In: “The Mesozoic flood volcanism of the Paraná Basin: petrogenetic and geophysical aspects”. Piccirillo E. M. \& Melfi A. J. (eds.), IAG, University of São Paulo, Brazil, 179-205p.

Piccirillo, E.M.; Civetta, L.; Petrini, R.; Longinelli, A.; Bellieni, G.; CominChiaramonti, P.; Marques, L.S.; Melfi, A.J. (1989). Regional variations within the Paraná flood basalts (southern Brazil): Evidence for subcontinental mantle heterogeneity and crustal contamination. Chemical Geology, 75(1-2): 103-122.

Piccirillo, E.M.; Bellieni, G.; Cavazzini, G.; Comin-Chiaramonti, P.; Petrini, R.; Melfi, A.J.; Pinese, J.P.P.; Zantadeschi, P.; De Min, A. (1990). Lower Cretaceous tholeiitic dyke swarms from the Ponta Grossa Arch (southeast Brazil): Petrology, Sr-Nd isotopes and genetic relationships with the Paraná flood volcanics. Chemical Geology, 89(1): 19-48.

Polo, L. (2014). O vulcanismo ácido da Província Magmática Paraná-Etendeka na Região de Gramado Xavier, RS: Estratigrafia, estruturas, petrogênese e modelo eruptivo. Tese de Doutorado, Instituto de Geociências, Universidade de São Paulo, 340 p.

Quintas, M.C.L.; Mantovani, M.S.M. \& Zalán, P.V. (1999). Contribuição ao estudo da evolução mecânica da Bacia do Paraná. Revista Brasileira de Geociências, 29(2): 217-226. 
Raposo, M.I.B. (1987). Evolução magmática e petrológica das rochas vulcânicas ácidas mesozoicas da região de Pirajú- Ourinhos (SP e PR). Dissertação de mestrado, IAG-USP, $159 \mathrm{p}$.

Renne, P.R.; Ernesto, M.; Pacca, I.G.; Col, R.S.; Glen, J.M.; Prevot, M.; Perrin, M. (1992). The age of Paraná flood volcanism, rifting of Gondwanaland and Jurassic-Cretaceous boundary. Science 258: 975-979.

Richards, M.A.; Duncan, R.A.; Courtillot, V.E. (1989). Flood basalts and hot-spot tracks: Plume heads and tails. Science, 246(4926): 103-107.

Rocha-Campos, A.C.; Cordani, U.; Kawashita, K.; Sonoki, H.M.; Sonoki, I.K. (1988). Age of the Paraná flood volcanism. In: "The Mesozoic flood volcanism of the Paraná Basin: petrogenetic and geophysical aspects”. Piccirillo E. M. \& Melfi A. J. (eds.), IAG, University of São Paulo, Brazil, 25-45p.

Rocha-Júnior, E.R.V.; Puchtel, I.S.; Marques, L.S.; Walker, R.J.; Machado, F.B.; Nardy, A.J.R.; Babinski, M.; Figueiredo, A.M.G. (2012). Re-Os isotope and highly siderophile element systematics of the Paraná continental flood basalts (Brazil). Earth and Planetary Science Letters, 337-338: 164-173.

Rocha-Júnior, E.R.V.; Marques L.S.; Babinski, M.; Nardy, A.J.R.; Figueiredo, A.M.G.; Machado, F.B. (2013). Sr-Nd-Pb isotopic constraints on the nature of the mantle sources involved in the genesis of the high-Ti tholeiites from northern Paraná Continental Flood Basalts (Brazil). Journal of South American Earth Sciences, 46: 9-25.

Rollinson, H. (1993). Using geochemical data: evaluation, presentation, interpretation. 1aㅡ edição, Longman Scientific \& Technical, New York, $352 \mathrm{p}$.

Rudinick, R.L. \& Gao, S. (2003). Composition of the Continental Crustal. In: Treatise on Geochemistry. Heinrich D. Holland and Karl K. Turekian (eds), 3: 1-64.

Sato, K.; Tassinari, C.G.C.; Kawashita, K.; Petronillo, L. (1995). O método geocronológico Sm-Nd no IG-USP e suas aplicações. Anais da Academia Brasileira de Ciências, 67: 313-336.

Shibuya, E.K. (1999). Acoplamento laser - espectrômetro de massa de dupla focalização com fonte de plasma induzido (LA-HR-ICPMS): estudos fundamentais e análises quantitativas em amostras sólidas. Dissertação 
de Mestrado, Instituto de Pesquisas Tecnológicas e Nucleares (IPEN), $170 \mathrm{p}$.

Silva, A.T.S.F.; Chiodi Filho, C.; Chiodi, D.K.; Pinto Filho, W.D. (1977). Projeto Santos - Iguape. Volume 1: Geologia convênio DNPM-CPRM, 639p.

Stormer, J.C.; Nicholls, J. (1978). XLFRAC: A program for the interactive testing of magmatic differentiation models. Computer \& Geosciences, 4: 143-159.

Thiede, D.S. \& Vasconcelos, P.M. (2010). Paraná flood basalts: Rapid extrusion hypothesis confirmed by new ${ }^{40} \mathrm{Ar} /{ }^{39} \mathrm{Ar}$ results. Geology, 38: 747-750.

Treuil, M.; Joron, J.L.; Jaffrezic, H. (1976). Trace element geochemistry of magmatic rock series of converging and diverging plate boundaries. Journal of Radioanalytical Chemistry, 38: 351-362.

Turner, S.; Regelous, M.; Kelley, S.; Hawkesworth, C.; Mantovani, M. (1994). Magmatism and continental break-up in the South Atlantic: high precision ${ }^{40} \mathrm{Ar} /{ }^{39} \mathrm{Ar}$ geochronology. Earth and Planetary Science Letters, 121: 333348.

Valente, S.C.; Corval, A.; Duarte, B.P.; Ellam, R.M.; Fallick, A.E.; Meighan, I.G.; Dutra, T. (2007). Tectonic boundaries, crustal weakness zones and plumesubcontinental lithospheric mantle interactions in the Serra do Mar dyke swarm, SE Brazil. Revista Brasileira de Geociências, 37(1): 194-201.

Vicentini, C.M. (2013). Caracterização geoquímica dos diques sub-alcalinos mesozoicos da Serra do Mar. Monografia para obtenção de título de bacharel em Geofísica, Instituto de Astronomia, Geofísica e Ciências Atmosféricas, USP, São Paulo, Brasil, pp. 43.

Vicentini, C.M.; Marques L.S.; Figueiredo, A.M.G. (2013). Determinação de elementos traços em diques mesozoicos da Serra do Mar por meio de ativação com nêutrons. International Nuclear Atlantic Conference, Short Paper, CD-ROM.

Vicentini, C.M.; Marques L.S.; Figueiredo, A.M.G. (2014). Caracterização geoquímica dos diques subalcalinos diferenciados da Serra do Mar: resultados preliminares. 47ํㅡㄹ Congresso Brasileiro de Geologia, Salvador, Brasil, 21-26 de setembro, anais do congresso.

Wilson, M. (2007). Igneous Petrogenesis.. 10ª edição, Springer (ed.), Dordrecht, 13-30p. 
White, R. \& McKenzie, D. (1989). Magmatism at rift zones: the generation of volcanic continental margins and flood basalts. Journal of Geophysical Research, 94(B6): 7685-7729.

Wolf, R.E. (2005). "What is ICP-MS?.. and more importantly, what can it do?". Research Chemist, USGS/CR/CICT.

Zalán, P.V.; Conceição, J.C.; Wolff, S.; Astolfi, M.A.; Vieira, I.S.; Appi, V.T.; Neto, E.V.S.; Cerqueira, J.R.; Zanotto, O.A.; Paumer, M.L.; Marques, A. (1986). Análise da Bacia do Paraná. Relatório Interno, Petrobrás (DEPEXCENPES), 195p. 


\section{APÊNDICES}




\section{Apêndice A}

Tabela i: Valores de $r_{\min }\left(\right.$ ou $r_{\max }$ ) para diferentes níveis de significância usado no teste estatístico " $r$ " (Nalimov, 1963).

\begin{tabular}{|c|c|c|c|c|}
\hline \multirow{2}{*}{$\begin{array}{c}\mathrm{N}^{0} \mathrm{de} \\
\text { graus de } \\
\text { liberdade }\end{array}$} & \multicolumn{4}{|c|}{ Nível de significância } \\
\hline & 0,1 & 0,05 & 0,025 & 0,01 \\
\hline 1 & 1,406 & 1,412 & 1,414 & 1,414 \\
\hline 2 & 1,645 & 1,689 & 1,710 & 1,723 \\
\hline 3 & 1,791 & 1,869 & 1,917 & 1,955 \\
\hline 4 & 1,894 & 1,996 & 2,067 & 1,130 \\
\hline 5 & 1,974 & 2,093 & 2,182 & 2,265 \\
\hline 6 & 2,041 & 2,172 & 2,273 & 2,374 \\
\hline 7 & 2,097 & 2,237 & 2,349 & 2,464 \\
\hline 8 & 2,146 & 2,294 & 2,414 & 2,540 \\
\hline 9 & 2,190 & 2,343 & 2,470 & 2,606 \\
\hline 10 & 2,229 & 2,387 & 2,519 & 2,663 \\
\hline 11 & 2,264 & 2,426 & 2,562 & 2,714 \\
\hline 12 & 2,297 & 2,461 & 2,602 & 2,759 \\
\hline 13 & 2,326 & 2,493 & 2,638 & 2,800 \\
\hline 14 & 2,354 & 2,523 & 2,670 & 2,837 \\
\hline 15 & 2,380 & 2,551 & 2,701 & 2,871 \\
\hline 16 & 2,404 & 2,577 & 2,728 & 2,903 \\
\hline 17 & 2,426 & 2,600 & 2,754 & 2,932 \\
\hline 18 & 2,447 & 2,623 & 2,778 & 2,959 \\
\hline 19 & 2,467 & 2,644 & 2,801 & 2,984 \\
\hline 20 & 2,486 & 2,664 & 2,823 & 3,008 \\
\hline 21 & 2,504 & 2,683 & 2,843 & 3,030 \\
\hline 22 & 2,520 & 2,701 & 2,862 & 3,051 \\
\hline 23 & 2,537 & 2,717 & 2,880 & 3,071 \\
\hline
\end{tabular}




\section{Apêndice B}

Tabela ii: Análises químicas de óxidos maiores (\%), menores (\%) e elementos traço $(\mu \mathrm{g} / \mathrm{g})$, obtidos por meio de fluorescência de raios $\mathrm{X}$, para o conjunto de amostras estudadas do Enxame Serra do Mar.

\begin{tabular}{|c|c|c|c|c|c|c|c|c|c|c|c|c|}
\hline Amostra & $\begin{array}{c}\text { RJ- } \\
7532\end{array}$ & $\begin{array}{c}\text { RJ- } \\
7519\end{array}$ & $\begin{array}{l}\text { RJ- } \\
7520\end{array}$ & $\begin{array}{c}\text { B- } \\
1111\end{array}$ & $\begin{array}{c}\text { RJ- } \\
7535\end{array}$ & $\begin{array}{c}\text { SSA- } \\
64\end{array}$ & $\begin{array}{c}\text { RJ- } \\
7517\end{array}$ & $\begin{array}{c}\text { RJ- } \\
7516\end{array}$ & $\begin{array}{l}\text { RJ- } \\
7548\end{array}$ & $\begin{array}{l}\text { RJ- } \\
7551\end{array}$ & $\begin{array}{l}\text { RJ- } \\
7527\end{array}$ & $\begin{array}{c}\text { RJ- } \\
7525\end{array}$ \\
\hline Litologia & LTA & LTA & LTA & ABT & ABT & ABT & LTA & LTA & LTA & LTA & LTA & LTA \\
\hline $\mathrm{SiO}_{2}$ & 54,55 & 53,07 & 53,52 & 51,38 & 51,80 & 52,60 & 53,94 & 54,02 & 54,19 & 54,33 & 54,97 & 55,62 \\
\hline $\mathrm{TiO}_{2}$ & 3,22 & 3,09 & 2,94 & 3,92 & 3,92 & 3,52 & 3,54 & 3,55 & 3,34 & 3,40 & 3,10 & 2,70 \\
\hline $\mathrm{Al}_{2} \mathrm{O}_{3}$ & 14,40 & 14,83 & 15,16 & 13,81 & 14,70 & 15,04 & 14,52 & 14,38 & 13,76 & 14,03 & 15,54 & 15,46 \\
\hline $\mathrm{FeO}_{\mathrm{t}}$ & 10,54 & 12,59 & 12,09 & 13,21 & 12,11 & 11,65 & 12,83 & 12,97 & 12,80 & 12,81 & 10,71 & 9,52 \\
\hline MnO & 0,19 & 0,19 & 0,18 & 0,18 & 0,20 & 0,16 & 0,19 & 0,18 & 0,17 & 0,17 & 0,18 & 0,15 \\
\hline MgO & 4,95 & 3,24 & 3,16 & 5,06 & 4,23 & 4,79 & 2,64 & 2,59 & 2,85 & 2,66 & 2,54 & 4,13 \\
\hline $\mathrm{CaO}$ & 5,86 & 7,16 & 7,01 & 8,14 & 7,36 & 6,79 & 6,43 & 6,41 & 6,64 & 6,54 & 6,27 & 5,72 \\
\hline $\mathrm{Na}_{2} \mathrm{O}$ & 3,10 & 3,15 & 3,28 & 2,49 & 2,66 & 3,07 & 3,12 & 3,01 & 3,00 & 2,98 & 3,59 & 2,98 \\
\hline $\mathrm{K}_{2} \mathrm{O}$ & 2,37 & 1,85 & 1,88 & 1,33 & 2,02 & 1,64 & 2,11 & 2,17 & 2,44 & 2,28 & 2,21 & 2,94 \\
\hline $\mathrm{P}_{2} \mathrm{O}_{5}$ & 0,82 & 0,83 & 0,78 & 0,48 & 1,00 & 0,73 & 0,68 & 0,71 & 0,81 & 0,80 & 0,89 & 0,78 \\
\hline PF & 2,39 & 1,09 & 1,02 & & 2,06 & 1,87 & 1,47 & 1,54 & 1,85 & 1,46 & 0,86 & 2,51 \\
\hline R1 & 1605 & 1556 & 1551 & 1762 & 1599 & 1618 & 1546 & 1573 & 1534 & 1586 & 1495 & 1627 \\
\hline $\mathrm{R} 2$ & 1155 & 1218 & 1204 & 1393 & 1286 & 1259 & 1104 & 1096 & 1122 & 1107 & 1102 & 1120 \\
\hline $\mathrm{Na}_{2} \mathrm{O}+\mathrm{K}_{2} \mathrm{O}$ & 5,47 & 5,00 & 5,16 & 3,82 & 4,68 & 4,71 & 5,23 & 5,18 & 5,44 & 5,26 & 5,80 & 5,92 \\
\hline $\mathrm{Cr}^{*}$ & 17 & 46 & 41 & 49 & 19 & 21 & 9 & 14 & 13 & 22 & 6 & 14 \\
\hline $\mathrm{N}^{*}{ }^{*}$ & 45 & 42 & 39 & 69 & 47 & 49 & 31 & 32 & 34 & 27 & 7 & 13 \\
\hline $\mathrm{Ba}^{*}$ & 708 & 537 & 536 & 504 & 687 & 575 & 632 & 648 & 686 & 718 & 697 & 1014 \\
\hline $\mathbf{R b}^{*}$ & 51 & 33 & 34 & 77 & 36 & 39 & 40 & 42 & 63 & 58 & 45 & 69 \\
\hline $\mathrm{Sr}^{*}$ & 654 & 473 & 467 & 781 & 939 & 655 & 443 & 450 & 471 & 473 & 583 & 989 \\
\hline $\mathrm{La}^{*}$ & 58 & 48 & 47 & 38 & 59 & 33 & 59 & 60 & 49 & 52 & 63 & 84 \\
\hline $\mathrm{Ce}^{*}$ & 122 & 96 & 97 & 92 & 106 & 94 & 112 & 102 & 110 & 109 & 120 & 152 \\
\hline $\mathrm{Nd}^{*}$ & 68 & 57 & 55 & 59 & 66 & 50 & 63 & 64 & 60 & 55 & 73 & 72 \\
\hline $\mathrm{Zr}^{*}$ & 293 & 266 & 264 & 201 & 229 & 289 & 302 & 306 & 343 & 331 & 286 & 285 \\
\hline$Y^{* *}$ & $41^{* * *}$ & $42^{* * *}$ & $43^{* * *}$ & $34^{* * *}$ & $40^{* * *}$ & 39 & $45^{\star * *}$ & $46^{* * *}$ & $47^{* * *}$ & $46^{* * *}$ & $45^{* * *}$ & $30^{* * *}$ \\
\hline $\mathrm{Nb}^{*}$ & 28 & 24 & 23 & 21 & 26 & 29 & 26 & 27 & 37 & 36 & 27 & 41 \\
\hline
\end{tabular}

* = resultado obtido por análise de fluorescência de raios X;

**= resultado obtido por análise de fluorescência de raios $\mathbf{X}$ após correção;

$* * *=$ resultado obtido por espectrometria de massa com fonte de plasma induzido. 
Tabela ii (CONT.): Análises químicas de óxidos maiores (\%), menores (\%) e elementos traço $(\mu \mathrm{g} / \mathrm{g})$, obtidos por meio de fluorescência de raios $\mathrm{X}$, para o conjunto de amostras estudadas do Enxame Serra do Mar.

\begin{tabular}{|c|c|c|c|c|c|c|c|c|c|c|c|c|}
\hline Amostra & $\begin{array}{l}\text { RJ- } \\
7526\end{array}$ & $\begin{array}{c}\text { RJ- } \\
7544\end{array}$ & $\begin{array}{c}\text { B- } \\
1092\end{array}$ & $\begin{array}{c}\text { RJ- } \\
7542\end{array}$ & $\begin{array}{c}\text { B- } \\
1096\end{array}$ & $\begin{array}{c}\text { RJ- } \\
7543\end{array}$ & $\begin{array}{c}\text { B- } \\
1097\end{array}$ & $\begin{array}{c}\text { SSA- } \\
59\end{array}$ & $\begin{array}{l}\text { SS- } \\
39\end{array}$ & $\begin{array}{c}\text { SSA- } \\
62\end{array}$ & $\begin{array}{c}\text { SSA- } \\
56\end{array}$ & $\begin{array}{c}\text { SSG- } \\
7\end{array}$ \\
\hline Litologia & LTA & LTA & LTA & LTA & LTA & LTA & DAC & DAC & DAC & DAC & $\mathrm{RC}$ & $\mathrm{RC}$ \\
\hline $\mathrm{SiO}_{2}$ & 55,54 & 58,60 & 58,44 & 58,55 & 59,94 & 59,87 & 60,84 & 61,56 & 62,18 & 62,16 & 65,88 & 65,59 \\
\hline $\mathrm{TiO}_{2}$ & 2,73 & 2,35 & 2,44 & 2,36 & 2,24 & 2,14 & 2,04 & 1,79 & 1,74 & 1,84 & 1,40 & 1,36 \\
\hline $\mathrm{Al}_{2} \mathrm{O}_{3}$ & 15,39 & 14,34 & 14,42 & 14,55 & 14,72 & 15,39 & 15,02 & 14,65 & 14,68 & 14,59 & 14,24 & 15,36 \\
\hline $\mathrm{FeO}_{\mathrm{t}}$ & 9,60 & 7,94 & 8,20 & 7,93 & 7,51 & 7,13 & 7,10 & 7,19 & 6,90 & 7,17 & 5,74 & 5,49 \\
\hline MnO & 0,15 & 0,13 & 0,13 & 0,12 & 0,13 & 0,11 & 0,13 & 0,12 & 0,11 & 0,12 & 0,13 & 0,12 \\
\hline MgO & 4,17 & 4,06 & 3,93 & 3,92 & 3,21 & 2,68 & 2,64 & 2,27 & 2,21 & 2,18 & 1,57 & 1,21 \\
\hline $\mathrm{CaO}$ & 5,73 & 5,09 & 5,08 & 5,07 & 4,60 & 4,40 & 4,29 & 4,11 & 3,83 & 3,79 & 2,99 & 3,11 \\
\hline $\mathrm{Na}_{2} \mathrm{O}$ & 2,97 & 3,05 & 3,22 & 3,08 & 3,41 & 3,31 & 3,51 & 3,35 & 3,47 & 3,41 & 3,49 & 3,11 \\
\hline $\mathrm{K}_{2} \mathrm{O}$ & 2,95 & 3,87 & 3,67 & 3,86 & 3,79 & 4,35 & 3,96 & 4,18 & 4,14 & 4,02 & 4,12 & 4,26 \\
\hline $\mathrm{P}_{2} \mathrm{O}_{5}$ & 0,77 & 0,57 & 0,47 & 0,56 & 0,45 & 0,62 & 0,47 & 0,79 & 0,74 & 0,71 & 0,43 & 0,40 \\
\hline PF & 2,53 & 1,83 & & 1,56 & & 1,66 & 1,26 & 0,83 & 1,47 & 1,12 & 0,84 & 1,07 \\
\hline R1 & 1620 & 1636 & 1603 & 1625 & 1631 & 1544 & 1632 & 1690 & 1707 & 1745 & 1992 & 2083 \\
\hline R2 & 1122 & 1027 & 1021 & 1022 & 940 & 906 & 885 & 840 & 807 & 800 & 677 & 694 \\
\hline $\mathrm{Na}_{2} \mathrm{O}+\mathrm{K}_{2} \mathrm{O}$ & 5,92 & 6,92 & 6,89 & 6,94 & 7,20 & 7,66 & 7,47 & 7,53 & 7,61 & 7,43 & 7,61 & 7,37 \\
\hline $\mathrm{Cr}^{*}$ & 10 & 146 & 146 & 146 & 49 & 25 & 25 & 1 & 2 & 1 & 1 & 2 \\
\hline $\mathrm{Ni}^{*}$ & 12 & 72 & 46 & 58 & 24 & 16 & 15 & 9 & 6 & 5 & 3 & 4 \\
\hline $\mathrm{Ba}^{*}$ & 1003 & 1212 & 1192 & 1184 & 1239 & 1303 & 1281 & 1250 & 1281 & 1288 & 1109 & 1186 \\
\hline $\mathbf{R} \mathbf{b}^{*}$ & 67 & 96 & 99 & 97 & 109 & 122 & 116 & 115 & 107 & 112 & 117 & 114 \\
\hline $\mathrm{Sr}^{*}$ & 989 & 816 & 757 & 820 & 798 & 986 & 795 & 891 & 864 & 798 & 474 & 483 \\
\hline La* $^{*}$ & 85 & 111 & 112 & 106 & 113 & 130 & 119 & 86 & 105 & 97 & 76 & 94 \\
\hline $\mathrm{Ce}^{*}$ & 155 & 196 & 191 & 191 & 205 & 216 & 207 & 162 & 175 & 176 & 159 & 156 \\
\hline $\mathrm{Nd}^{*}$ & 74 & 88 & 93 & 86 & 93 & 97 & 97 & 76 & 88 & 85 & 77 & 84 \\
\hline $\mathrm{Zr}^{*}$ & 277 & 380 & 360 & 345 & 377 & 428 & 375 & 493 & 488 & 511 & 544 & 506 \\
\hline$Y^{* *}$ & $30^{* * *}$ & $34^{* * *}$ & 32 & 33 & 34 & 37 & $35^{* * *}$ & 42 & 42 & $48^{* * *}$ & $54^{* * *}$ & 45 \\
\hline $\mathrm{Nb}^{*}$ & 40 & 47 & 50 & 51 & 53 & 76 & 53 & 57 & 57 & 60 & 54 & 51 \\
\hline
\end{tabular}

* = resultado obtido por análise de fluorescência de raios $\mathrm{X}$;

**= resultado obtido por análise de fluorescência de raios $\mathbf{X}$ após correção;

***= resultado obtido por espectrometria de massa com fonte de plasma induzido. 
Tabela iii: Análises químicas de elementos traço $(\mu \mathrm{g} / \mathrm{g})$, obtidos por ativação com nêutrons, e as razões isotópicas iniciais de $\mathrm{Sr}, \mathrm{Nd}$ e $\mathrm{Pb}$, obtidas por espectrometria de massa termoiônica, para o conjunto de amostras estudadas do Enxame Serra do Mar.

\begin{tabular}{|c|c|c|c|c|c|c|c|c|c|c|c|c|}
\hline Amostra & $\begin{array}{c}\text { RJ- } \\
7532\end{array}$ & $\begin{array}{c}\text { RJ- } \\
7519\end{array}$ & $\begin{array}{c}\text { RJ- } \\
7520\end{array}$ & $\begin{array}{c}\text { B- } \\
1111\end{array}$ & $\begin{array}{c}\text { RJ- } \\
7535\end{array}$ & $\begin{array}{c}\text { SSA- } \\
64\end{array}$ & $\begin{array}{c}\text { RJ- } \\
7517\end{array}$ & $\begin{array}{c}\text { RJ- } \\
7516\end{array}$ & $\begin{array}{c}\text { RJ- } \\
7548\end{array}$ & $\begin{array}{c}\text { RJ- } \\
7551\end{array}$ & $\begin{array}{c}\text { RJ- } \\
7527\end{array}$ & $\begin{array}{c}\text { RJ- } \\
7525\end{array}$ \\
\hline La & 54,7 & 41,4 & 42,1 & 36,9 & 51,3 & 42,0 & 48,8 & 48,1 & 51,0 & 49,6 & 53,1 & 69,3 \\
\hline $\mathrm{Ce}$ & 112,8 & 90,2 & 93,8 & 82,1 & 112,3 & 86,0 & 103,1 & 104,0 & 108,1 & 105,2 & 115,9 & 145,8 \\
\hline Nd & 65,7 & 63,3 & 67,8 & 59,4 & 60,1 & & 50,6 & 53,4 & 66,5 & 64,3 & 58,9 & 73,1 \\
\hline Sm & 12,43 & 11,43 & 11,69 & 10,02 & 12,38 & 10,81 & 12,22 & 12,00 & 12,51 & 12,27 & 12,96 & 11,99 \\
\hline Eu & 3,66 & 3,35 & 3,49 & 3,14 & 3,72 & 3,38 & 3,43 & 3,33 & 3,42 & 3,42 & 3,93 & 3,27 \\
\hline Tb & 1,52 & 1,59 & 1,60 & 1,30 & 1,48 & 1,20 & 1,79 & 1,76 & 1,48 & 1,56 & 1,59 & 1,17 \\
\hline $\mathrm{Yb}$ & 3,22 & 3,49 & 3,62 & 2,72 & 2,89 & 3,23 & 3,91 & 3,88 & 4,01 & 3,78 & 3,63 & 2,38 \\
\hline Lu & 0,46 & 0,53 & 0,50 & 0,38 & 0,41 & 0,42 & 0,55 & 0,57 & 0,57 & 0,56 & 0,49 & 0,30 \\
\hline $\mathrm{Ta}$ & 2,26 & 1,79 & 1,81 & 1,62 & 2,13 & 1,84 & 2,09 & 2,15 & 2,27 & 2,14 & 2,23 & 2,99 \\
\hline Th & 5,59 & 4,59 & 4,49 & 4,29 & 4,81 & 4,23 & 5,95 & 5,96 & 6,73 & 5,99 & 6,07 & 9,34 \\
\hline U & 1,21 & 0,98 & 0,97 & 0,86 & 1,05 & 1,05 & 1,34 & 1,36 & 1,40 & 1,29 & 1,39 & 1,84 \\
\hline $\mathrm{Hf}$ & 8,58 & 7,76 & 7,77 & 6,26 & 6,96 & 7,16 & 8,13 & 8,46 & 8,69 & 8,30 & 8,40 & 8,17 \\
\hline $\mathrm{Ba}$ & 683 & 572 & 567 & 588 & 682 & 509 & 620 & 634 & 661 & 672 & 711 & 1074 \\
\hline $\mathbf{R b}$ & 61,7 & 43,3 & 49,3 & 95,2 & 46,0 & 34,5 & 56,1 & 50,1 & 58,3 & 54,8 & 50,6 & 84,4 \\
\hline Cs & 2,29 & 0,97 & 1,07 & 20,19 & 1,07 & 1,52 & 1,87 & 1,74 & 1,61 & 1,15 & 1,39 & 0,87 \\
\hline Sc & 21,48 & 27,74 & 27,60 & 27,60 & 22,26 & 25,60 & 28,41 & 27,48 & 27,84 & 28,40 & 23,52 & 15,49 \\
\hline Co & 36,6 & 38,30 & 38,40 & 40,69 & 41,00 & 39,56 & 39,00 & 37,20 & 37,86 & 40,25 & 29,90 & 32,60 \\
\hline $\mathrm{Pb}^{* * *}$ & 7,57 & 6,31 & 6,52 & 5,94 & 7,49 & & 8,91 & 9,07 & 9,48 & 8,71 & 8,65 & 10,70 \\
\hline$T h^{* * *}$ & 5,76 & 4,55 & 4,54 & 4,00 & 4,98 & & 6,00 & 6,19 & 7,10 & 5,83 & 6,18 & 9,26 \\
\hline $\mathrm{U}^{* * *}$ & 1,32 & 0,98 & 1,03 & 0,91 & 1,12 & & 1,38 & 1,41 & 1,48 & 1,39 & 1,41 & 1,84 \\
\hline $\mathbf{R b}^{* * *}$ & 57,9 & 39,5 & 42,1 & 94,1 & 47,5 & & 51,6 & 53,8 & 58,3 & 53,2 & 55,1 & 78,6 \\
\hline $\mathrm{Sr}^{* * *}$ & 736 & 504 & 516 & 836 & 979 & & 469 & 471 & 467 & 481 & 648 & 1063 \\
\hline $\mathrm{Nd}^{* * *}$ & 61,2 & 50,9 & 52,1 & 45,4 & 61,7 & & 54,6 & 56,0 & 59,6 & 55,9 & 62,8 & 68,2 \\
\hline $\mathrm{Sm}^{* * *}$ & 12,37 & 10,99 & 11,28 & 9,59 & 12,35 & & 11,44 & 11,79 & 12,23 & 11,65 & 12,99 & 11,95 \\
\hline${ }^{87} \mathrm{Sr}^{186} \mathrm{Sr}_{\mathrm{i}}$ & & & & & & & 0,70643 & & & 0,70628 & & \\
\hline${ }^{143} \mathrm{Nd} /{ }^{144} \mathrm{Ndi}_{\mathrm{i}}$ & & & & & & & 0,512255 & & & 0,512298 & & \\
\hline $200 \mathrm{~Pb} / 204 \mathrm{~Pb}_{\mathrm{i}}$ & & & & & & & 18,167 & & & 18,167 & & \\
\hline $207 \mathrm{~Pb} / 204 \mathrm{~Pb}$ & & & & & & & 15,569 & & & 15,565 & & \\
\hline $208 \mathrm{~Pb}^{204} \mathrm{~Pb}_{\mathrm{i}}$ & & & & & & & 38,286 & & & 38,268 & & \\
\hline
\end{tabular}

***= resultado obtido por espectrometria de massa com fonte de plasma induzido (ICP-MS);

Para o cálculo das razões iniciais para 130 Ma foram usados os valores de $\mathbf{R b}, \mathrm{Sr}, \mathrm{Nd}, \mathrm{Sm}, \mathrm{U}$, Th e $\mathrm{Pb}$ obtidos por meio ICP-MS. 
Tabela iii (CONT.): Análises químicas de elementos traço $(\mu \mathrm{g} / \mathrm{g})$, obtidos por ativação com nêutrons, e as razões isotópicas iniciais de $\mathrm{Sr}, \mathrm{Nd}$ e $\mathrm{Pb}$, obtidas por espectrometria de massa termoiônica, para o conjunto de amostras estudadas do Enxame Serra do Mar.

\begin{tabular}{|c|c|c|c|c|c|c|c|c|c|c|c|c|}
\hline Amostra & $\begin{array}{c}\text { RJ- } \\
7526\end{array}$ & $\begin{array}{c}\text { RJ- } \\
7544\end{array}$ & $\begin{array}{c}\text { B- } \\
1092\end{array}$ & $\begin{array}{c}\text { RJ- } \\
7542\end{array}$ & $\begin{array}{c}\text { B- } \\
1096\end{array}$ & $\begin{array}{c}\text { RJ- } \\
7543\end{array}$ & $\begin{array}{c}\text { B- } \\
1097\end{array}$ & $\begin{array}{c}\text { SSA- } \\
59\end{array}$ & $\begin{array}{c}\text { SS- } \\
39\end{array}$ & $\begin{array}{c}\text { SSA- } \\
62\end{array}$ & $\begin{array}{c}\text { SSA- } \\
56\end{array}$ & $\begin{array}{c}\text { SSG } \\
7\end{array}$ \\
\hline La & 72,7 & 89,6 & 88,40 & 81,27 & 95,97 & 97,29 & 92,5 & 85,24 & 90,59 & 86,90 & 77,5 & 81,99 \\
\hline $\mathrm{Ce}$ & 150,4 & 182,5 & 174,4 & 175,1 & 188,5 & 199,8 & 187,9 & 178,5 & 173,7 & 201,1 & 173,5 & 174,9 \\
\hline $\mathrm{Nd}$ & 74,4 & 77,2 & 75,40 & 71,25 & 78,00 & 86,50 & 86,2 & 67,57 & 68,27 & 109,67 & 77,5 & 86,11 \\
\hline Sm & 12,39 & 11,99 & 12,75 & 11,32 & 13,54 & 13,29 & 13,55 & 14,80 & 15,34 & 15,10 & 15,32 & 15,17 \\
\hline Eu & 3,33 & 3,18 & 3,22 & 3,33 & 3,68 & 3,76 & 3,27 & 4,24 & 4,70 & 5,22 & 3,79 & 3,08 \\
\hline $\mathrm{Tb}$ & 1,05 & 1,33 & 0,94 & 1,13 & 1,31 & 1,37 & 1,46 & 1,37 & 1,63 & 1,61 & 2,01 & 1,46 \\
\hline $\mathrm{Yb}$ & 2,60 & 2,82 & 2,65 & 2,05 & 3,61 & 2,52 & 2,66 & 3,62 & 3,84 & 2,99 & 4,41 & 3,42 \\
\hline Lu & 0,32 & 0,37 & 0,32 & 0,33 & 0,34 & 0,31 & 0,41 & 0,42 & 0,39 & 0,44 & 0,62 & 0,59 \\
\hline Ta & 3,41 & 3,82 & 3,70 & 3,65 & 3,90 & 4,10 & 4,12 & 3,77 & 4,12 & 3,72 & 3,65 & 3,66 \\
\hline Th & 9,72 & 12,88 & 13,00 & 12,32 & 14,63 & 14,04 & 13,33 & 11,93 & 12,43 & 13,24 & 12,72 & 12,82 \\
\hline $\mathbf{U}$ & 1,76 & 2,91 & 2,29 & 2,29 & 2,97 & 2,92 & 3,22 & 2,67 & 2,88 & 3,00 & 3,37 & 3,17 \\
\hline $\mathrm{Hf}$ & 8,50 & 10,51 & 9,56 & 9,75 & 10,44 & 11,85 & 10,67 & 11,28 & 11,65 & 12,75 & 13,60 & 13,33 \\
\hline $\mathrm{Ba}$ & 992 & 1224 & 1172 & 1176 & 1245 & 1402 & 1314 & 1186 & 1089 & 1381 & 1201 & 1211 \\
\hline $\mathbf{R b}$ & 76,5 & 110,0 & 111,8 & 105,0 & 112,8 & 124,7 & 111,0 & 111,9 & 151,3 & 124,4 & 124,6 & 113,8 \\
\hline Cs & 0,83 & 1,93 & 2,34 & 1,72 & 1,76 & 1,64 & 1,84 & 2,87 & 1,84 & 1,27 & 2,78 & 3,12 \\
\hline Sc & 15,81 & 17,00 & 16,00 & 16,60 & 15,10 & 11,30 & 13,50 & 11,34 & 11,40 & 12,10 & 11,16 & 11,00 \\
\hline Co & 31,02 & 36,00 & 31,80 & 35,20 & 28,40 & 22,40 & 25,60 & 11,70 & 12,40 & 13,30 & 7,40 & 7,00 \\
\hline $\mathrm{Pb}^{* * *}$ & 11,10 & 14,00 & & & & & 16,00 & & & 15,20 & 16,60 & \\
\hline$T h^{* * *}$ & 9,58 & 12,7 & & & & & 13,41 & & & 13,14 & 12,30 & \\
\hline $\mathbf{U}^{* * *}$ & 1,85 & 2,68 & & & & & 2,95 & & & 2,87 & 2,88 & \\
\hline $\mathbf{R b}^{* * *}$ & 80,5 & 107,5 & & & & & 116 & & & 116,6 & 122,7 & \\
\hline $\mathrm{Sr}^{* * *}$ & 1041 & 893 & & & & & 860 & & & 816 & 501 & \\
\hline $\mathrm{Nd}^{* * *}$ & 68,5 & 80,2 & & & & & 82,1 & & & 93,7 & 85,5 & \\
\hline $\mathrm{Sm}^{* * *}$ & 12,09 & 13,30 & & & & & 13,64 & & & 16,79 & 16,12 & \\
\hline${ }^{87} \mathrm{Sr} /{ }^{86} \mathrm{Sr}_{\mathbf{i}}$ & & 0,70754 & & & & & 0,70788 & & & 0,70727 & 0,70701 & \\
\hline${ }^{143} \mathrm{Nd} / 1{ }^{14} \mathrm{Ndi}_{\mathrm{i}}$ & & 0,512104 & & & & & 0,512071 & & & 0,512218 & 0,512226 & \\
\hline $206 \mathrm{~Pb}^{2} / 204 \mathrm{~Pb}_{\mathrm{i}}$ & & 17,893 & & & & & 18,026 & & & 18,097 & 18,120 & \\
\hline${ }^{207} \mathrm{~Pb}^{2} / 204 \mathrm{~Pb}_{\mathrm{i}}$ & & 15,537 & & & & & 15,563 & & & 15,558 & 15,573 & \\
\hline${ }^{208} \mathrm{~Pb}^{12044} \mathrm{~Pb}_{\mathrm{i}}$ & & 38,186 & & & & & 38,319 & & & 38,163 & 38,294 & \\
\hline
\end{tabular}

$* * *=$ resultado obtido por espectrometria de massa com fonte de plasma induzido (ICP-MS);

Para o cálculo das razões iniciais para 130 Ma foram usados os valores de $\mathrm{Rb}, \mathrm{Sr}$, Nd, Sm, U, Th e Pb obtidos por meio ICP-MS. 